\title{
Progressive freeze concentration
}

Jan-Eise Vuist

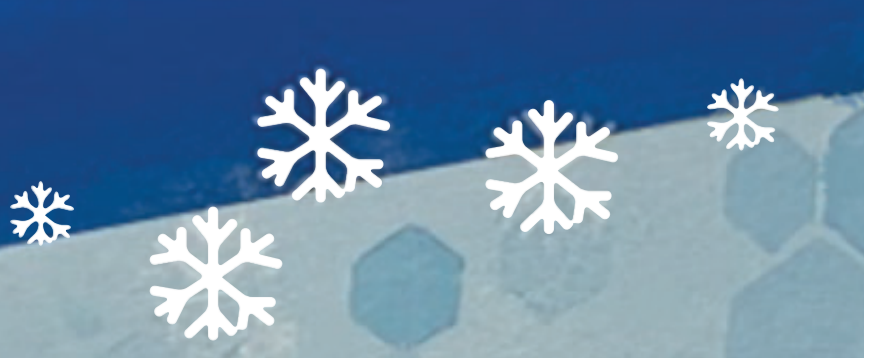

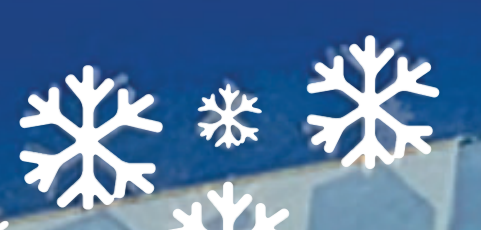
$\frac{x+2 / x}{x}$

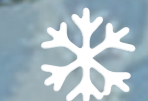
$\rightarrow 2 x$ 


\section{Propositions}

1. The main cause for inclusions in freeze concentration is concentration polarization, and not different crystal morphologies. (this thesis)

2. Progressive freeze concentration cannot be used for fractionation. (this thesis)

3. While a complex CFD-model can produce beautiful figures, more insight can be gained from a lower dimensional state-space model.

4. Writing a manuscript is like making cheese, sometimes it needs to mature on a shelf.

5. Using machine-learning, optimized for ad-revenue, for information access is not suitable for the majority of people.

6. Many personal problems can be fixed by a hug.

Propositions belonging to the thesis, entitled

Progressive freeze concentration

Johannes Eise (Jan-Eise) Vuist

Wageningen, 5 November 2021 


\title{
Progressive freeze concentration
}

\author{
Johannes Eise (Jan-Eise) Vuist
}




\section{Thesis committee}

\section{Promotors}

Dr Maarten A.I. Schutyser

Associate Professor, Laboratory of Food Process Engineering

Wageningen University \& Research

Prof. Dr Remko M. Boom

Professor of Food Process Engineering

Wageningen University \& Research

\section{Other members}

Prof. Dr K.J. Keesman, Wageningen University \& Research

Dr E. Teuling, NIZO Food Research, Ede

Dr H.J.M. Kramer, TU Delft

Dr D.R. Yntema, Wetsus, Leeuwarden 


\title{
Progressive freeze concentration
}

\author{
Johannes Eise (Jan-Eise) Vuist
}

Thesis

submitted in fulfilment of the requirements for the degree of doctor at Wageningen University

by the authority of the Rector Magnificus, Prof. Dr A.P.J. Mol, in the presence of the Thesis Committee appointed by the Academic Board to be defended in public on Friday 5 November 2021 at 4 p.m. in the Aula. 
Johannes Eise (Jan-Eise) Vuist

Progressive freeze concentration

130 pages

$\mathrm{PhD}$ thesis, Wageningen University, Wageningen, The Netherlands (2021)

With references, with summaries in English and Dutch

ISBN: 978-94-6395-914-8

DOI: $10.18174 / 550673$ 


\section{Contents}

1 Introduction 1

2 Effect of freezing rate and convection on solute inclusion 13

3 Modelling freeze concentration and concentration of proteins 29

4 Freeze concentration of protein-sucrose-salt mixtures $\quad 51$

5 Solute inclusion modelling $\quad 69$

6 General discussion $\quad 91$

$\begin{array}{ll}\text { Summary } & 111\end{array}$

$\begin{array}{ll}\text { Samenvatting } & 115\end{array}$

$\begin{array}{ll}\text { Acknowledgements } & 119\end{array}$

$\begin{array}{ll}\text { Biography } & 123\end{array}$

$\begin{array}{ll}\text { Publications } & 125\end{array}$

$\begin{array}{ll}\text { Overview of completed training activities } & 127\end{array}$ 

General introduction 


\subsection{Introduction}

Dewatering and drying are very commonly applied operations in industrial processes. It is estimated that in Dutch industry around 80 to 90 petajoule is spent on drying and dewatering (RVO 2015). This is around $8 \%$ of the total energy usage in the Dutch industry (EBN 2020). Many products from the food industry require a drying step in the process to increase the shelf-life and to reduce the volume of the product (Mujumdar 2014; Hernandez 2005). While drying is the most energy intensive part of the process that can take up to $50 \%$ of the total energy consumption required for the manufacturing of a dried food product (Ladha-Sabur et al. 2019), concentration is often used as a pre-treatment because of its higher efficiency in water removal (Baker et al. 2005; Ramírez et al. 2006). During manufacturing of food ingredients this concentration step usually increases the solids concentration from below $10 \%$ to around $40-70 \%$ solids. Most food ingredients are concentrated through evaporation. Evaporation is a fast process because the process is mainly limited by heat transfer, and operates at elevated temperatures. In a single-stage evaporator about $2.3 \mathrm{MJ}$ of heat is used to evaporate $1 \mathrm{~kg}$ of water, which is approximately equal to the latent heat of evaporation. Nowadays multi-stage evaporators in combination with thermal and/or mechanical vapour recompression use only 0.05 - 1.2 MJ per kg of water removed, depending on the number of evaporator stages (Moejes et al. 2017), albeit at the cost of significant complexity of the evaporation process. Although evaporation processes can be operated at reduced pressure and thus lower boiling point, it still operates at elevated temperatures, and not all products can withstand the increased heat load during evaporation, so alternative mild concentration methods may result in better product quality.

One of these alternative methods relies on membranes, which may be either nanofiltration or reverse osmosis membranes (Ramírez et al. 2006). The advantage of these membrane processes is that they typically are employed at room or slightly elevated temperatures, minimising thermal degradation of components in solution. Nanofiltration has the advantage that it requires less energy to operate than reverse osmosis, but it comes at the loss of small molecules, like salt, sized below $0.01 \mu \mathrm{m}$, while reverse osmosis can retain these molecules. The energy requirements are generally less than for evaporation. However, both processes are pressure-driven and are limited by osmotic pressure differences to some degree and nanofiltration is hindered by concentration polarisation. Because of the increasing osmotic pressure difference over the membrane, the maximum solids concentration that can be achieved with these membrane processes is $20 \%$ solids (Walstra et al. 1999). Membrane processes are also susceptible to fouling, which leads to large reductions in permeation rates. To avoid fouling issues, frequent cleaning steps are applied, which negatively affects the costs of such a process, and the lifetimes of the applied membranes.

Another method of concentration is to make use of freezing. When ice is formed in a solution, the ice crystals exclude other molecules from their crystal matrix. Even if some inclusions will be locked in between the ice crystals, effectively a solid is created that has a lower average concentration of solute than the solution in which they grow. When the ice is separated from the mother liquor, a concentrate can be obtained (Huige et al. 1972). Since freeze concentration makes use of cooling, instead of heating, it is suitable for liquids containing volatile or thermally sensitive components. In theory, the energy required to remove water via freeze concentration should be equal to the latent heat of fusion of water, which is approximately $0.3 \mathrm{MJ}$ per $\mathrm{kg}$ of water. This would immediately bring it in the range of op- 
timized evaporation (Moejes 2019), and potentially with less complex equipment. However, this comparison is not completely fair as the ice and concentrate still need to be separated mechanically, which requires extra energy. Besides the separation issues, the re-use of energy is more difficult in cold processes and requires the use of heat pumps.

Freeze concentration can be carried out in two different modes, direct contact systems that allows direct physical contact between the coolant and the product, and indirect systems that separate the coolant from the product using a heat exchanger (fig. 1.1). The advantage of direct contact systems is the high heat transfer rate to the product, greatly improving the efficiency of the process; however, the main disadvantage is that the coolant comes into direct contact with the product. This requires the coolant to be insoluble and non-toxic and therefore is generally not preferred in the food industry because of the risk of contamination of the product (Englezos 1994). Another approach would be to use a vacuum freezing process, however, this requires precise pressure and temperature management around the triple point, and the handling of large volumes of water vapour and requires the heat of sublimation to supplied, which is even higher than the heat of evaporation (Cheng et al. 1987). Therefore, this thesis will focus on indirect freeze concentration and specifically progressive freeze concentration. In section 1.2, an overview will be given of the available indirect freeze concentration designs. 


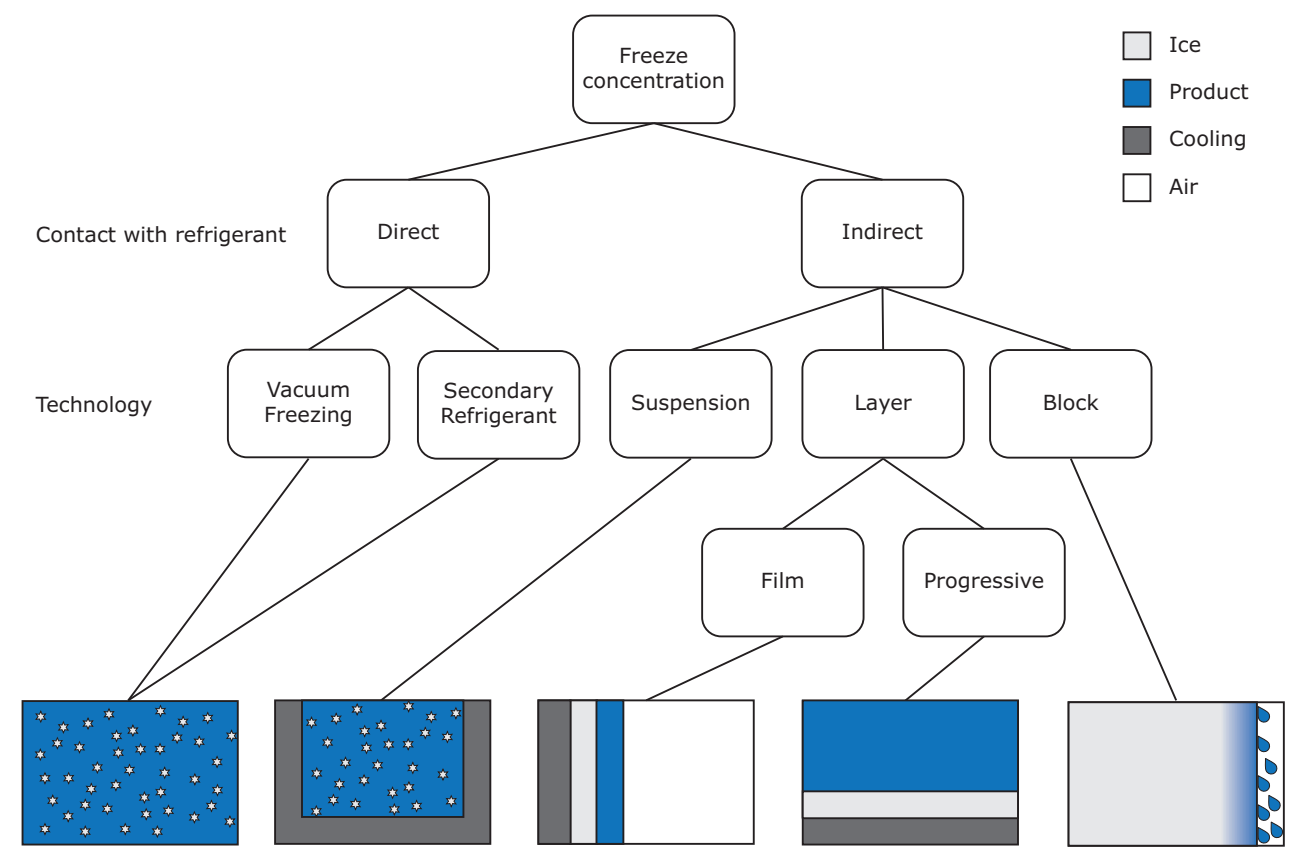

Figure 1.1: Overview of types of freeze concentration techniques with schematic representation of ice formation. The direct freeze concentration techniques will both yield ice crystals in suspension. If vacuum freezing is used the resulting water vapour has to be removed from the system. In suspension freeze concentration the ice crystals are seeded from a surface scraped heat exchanger and ripened in a cooled vessel. During film freeze concentration the liquid is flowing over a cooled surface and the ice layer is gradually built-up. Progressive freeze concentration also forms an ice layer on a cooled surface, however, the cooling surface is completely submerged and the liquid is mixed. In block freeze concentration the product is completely frozen at a slow rate and thawed making use of the freezing point depression caused by the product to achieve separation. 


\subsection{Indirect Freeze Concentration Methods}

Freeze concentration with indirect cooling can be carried out using different methods. The first is to create seed crystals in a scraped-surface heat exchanger and to let these seed crystals grow in the cooled mother liquor (Huige et al. 1972). To separate the ice from the concentrate, the slurry is fed to a counter-current wash column where the ice is melted and the crystals are washed with the melt water to remove the remaining concentrate. This is suspension freeze concentration (fig. 1.2). In this way concentrations of up to $40 \%$ solids can be achieved in a single continuous process, giving virtually no product losses. However, the method requires precise control over the crystal size to achieve efficient concentration. This method is already available on industrial scale (GEA Messo PT n.d.; Sulzer n.d.).

A second method for freeze concentration is to freeze the complete solution and then separate the concentrate by partial melting and making use of freezing point depression to achieve separation. This technique is called block freeze concentration (Petzold et al. 2015). To achieve better separation the product during this process is often frozen directionally creating a concentration gradient in the ice. After the product is completely frozen the ice block is slowly heated to just below the melting point of pure water. This allows the concentrated fraction to melt and to be separated. To enhance separation during block freeze concentration the technology can be assisted by applying a vacuum or by centrifugation of the ice block during the thaw cycle, to accelerate and improve the removal of the concentrated product (Petzold et al. 2013). High concentrations of solids of up to $70 \%$ can be achieved. Disadvantages of this method are, that the concentration is performed in multiple steps, which compromises the energy savings because the liquid has to be frozen and thawed multiple times. Until now, this method has only been applied on small, non-commercial scales.

The third method for freeze concentration is to slowly grow the ice on the surface of a heat exchanger, while the liquid is circulated over the heat exchanger. Separation of the concentrate and ice is achieved by draining the concentrate from the system and melting the ice layer. The liquid can be handled in two different ways. In film freeze concentration the liquid is recirculated in the form of a liquid film over the heat exchangers (Flesland 1995). This approach reduces the amount of liquid present in the system which can improve the concentration factor that can be achieved in a single step. The drawback of this approach is that the amount of mixing that can be applied is limited. If the flow rate is too high the liquid film will break up. This hinders the mass transfer and reduces the maximum achievable ice growth rate.

An alternative approach is progressive freeze concentration. The heat exchanger is here fully submerged in this process, and the ice layer is grown from the walls of the heat exchanger in solution (Liu et al. 1997). The liquid can then, depending on the design, be stirred or recirculated by a pump to improve the mass transfer and to lower the solute losses. In this system the liquid recirculation speed is limited by the adhesion of the ice to the surface of the heat exchangers. Care should be taken to design the system in such a way that the active area to volume ratio is as large as possible to achieve decent concentration factors. Advantages of progressive freeze concentration compared to suspension freeze concentration are that it has hardly any moving parts, that off-the-shelf equipment can be used which lowers the investment costs, and that heat integration between a concentration and melting stage can significantly reduce the energy requirements and is easy to achieve by the coupling of concentration and a 


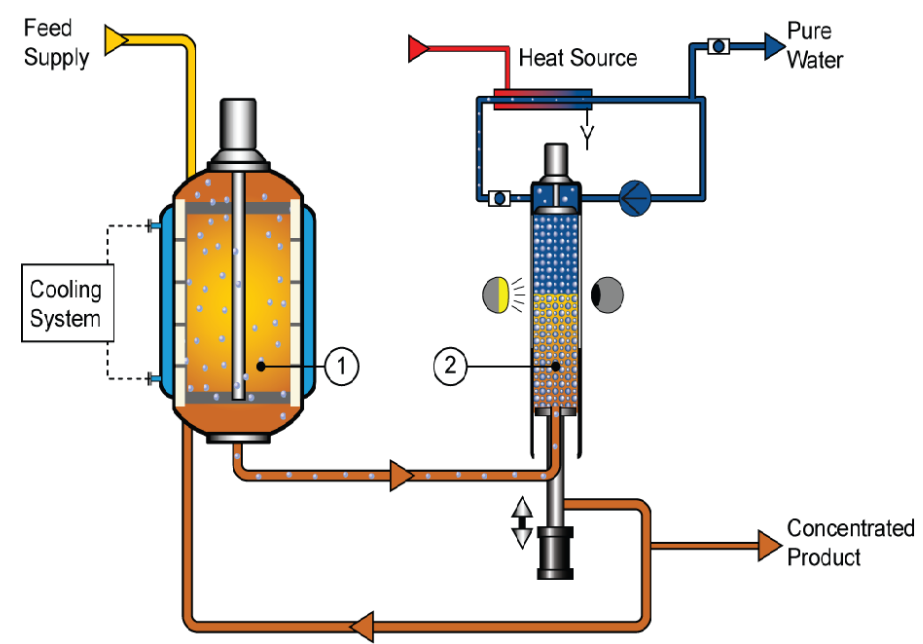

Figure 1.2: Schematic overview of suspension freeze concentration. Picture courtesy of GEA Messo PT (n.d.).

\section{Crystallizer}

Melter

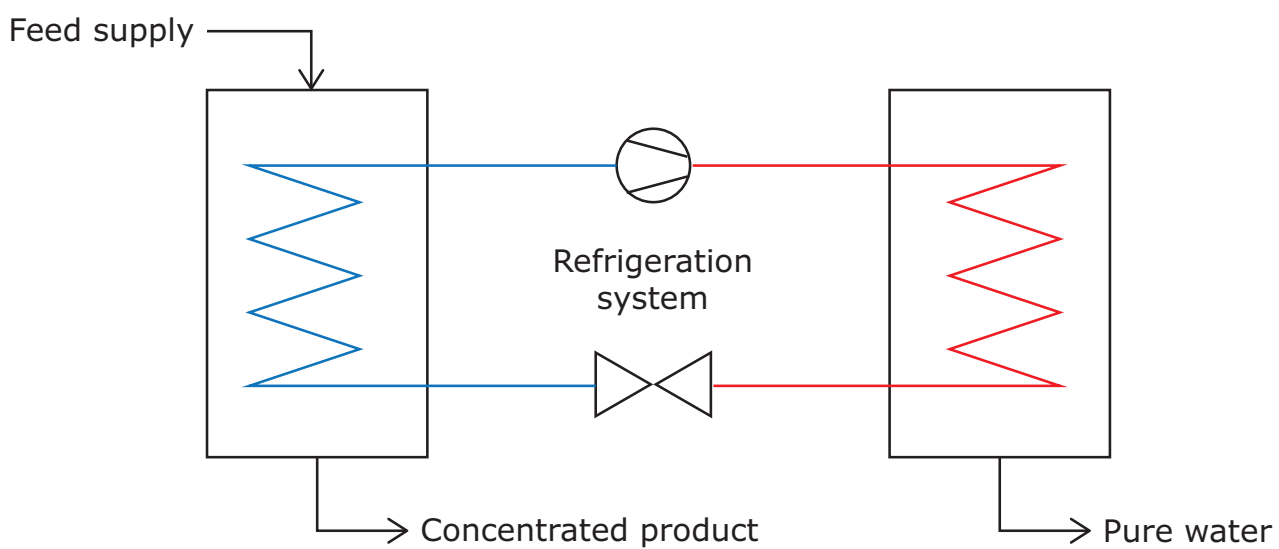

Figure 1.3: Schematic overview of progressive freeze concentration. Progressive freeze concentration operates batch-wise. In the crystallizer an ice layer is grown in solution on a heat exchanger. After removal of the concentrated product, the ice layer is melted in the melter. A crystallizer and melter can be coupled with the use of a heat pump.

thawing stage (fig. 1.3). On a larger scale there is also not much experience with progressive freeze concentration. In addition, many phenomena are not yet well understood. Therefore, this technology was selected to investigate in the study reported in this thesis. An overview of freeze concentration processes is given in table 1.1.

Even though progressive freeze concentration has potential as a well-scalable process that may deliver significant energy savings, the process is not yet well understood. Central in this, is the inclusion of the solute in the ice, which limits the concentration that can be achieved. 
Table 1.1: Overview of indirect freeze concentration designs, their application and state of technology

\begin{tabular}{|c|c|c|c|}
\hline Type & Application & Scale & References \\
\hline $\begin{array}{l}\text { Suspension } \\
\text { freeze } \\
\text { concentration }\end{array}$ & $\begin{array}{l}\text { Coffee, } \\
\text { fruit juices, } \\
\text { beer, } \\
\text { vinegar }\end{array}$ & $\begin{array}{l}\text { Industrial scale } \\
\text { Continuous up to } \\
30,000 \mathrm{~kg} \text { product per } \mathrm{h}\end{array}$ & $\begin{array}{l}\text { GEA Messo PT n.d. } \\
\text { Sulzer n.d. } \\
\text { Sánchez et al. } 2009\end{array}$ \\
\hline $\begin{array}{l}\text { Block } \\
\text { freeze } \\
\text { concentration }\end{array}$ & $\begin{array}{l}\text { Fruit juices, } \\
\text { coffee, } \\
\text { whey }\end{array}$ & $\begin{array}{l}\text { Lab scale } \\
\text { Up to } 20 \mathrm{~kg} \text { product per batch }\end{array}$ & Aider et al. 2009 \\
\hline $\begin{array}{l}\text { Film } \\
\text { freeze } \\
\text { concentration }\end{array}$ & $\begin{array}{l}\text { Sugar, } \\
\text { brine, } \\
\text { whey, } \\
\text { waste water }\end{array}$ & $\begin{array}{l}\text { Pilot scale } \\
\text { Up to } 100 \mathrm{~kg} \text { product per batch }\end{array}$ & $\begin{array}{l}\text { Flesland } 1995 \\
\text { Sánchez et al. } 2011\end{array}$ \\
\hline $\begin{array}{l}\text { Progressive } \\
\text { freeze } \\
\text { concentration }\end{array}$ & $\begin{array}{l}\text { Sugar, } \\
\text { brine, } \\
\text { coffee, } \\
\text { fruit juices, } \\
\text { vinegar }\end{array}$ & $\begin{array}{l}\text { Pilot scale } \\
\text { Up to } 100 \mathrm{~kg} \text { product per batch }\end{array}$ & $\begin{array}{l}\text { Jusoh et al. } 2009 \\
\text { Meiwa Co. Ltd } 2018\end{array}$ \\
\hline
\end{tabular}

Several studies have shown that the growth of the ice changes with freezing rate (Martel 2000; Sei et al. 2002). At low freezing rates, the ice grows regularly with a consistently progressing freeze front. In his regime, hardly any inclusions are observed; however the freezing rates are quite low (Flesland 1995). Increasing the freezing rate by applying lower temperatures in the heat exchanger, induces the freeze front to become stable: it first starts to form a distinct wave on its surface, with some locations freezing faster than others. Eventually, this results in the formation of ice needles, which are surrounded by a concentrated solution. The ice in this regime will have many inclusions, and the concentration factor can be quite low.

Currently the inclusion behaviour limits the practical applicability of the process. It is important to identify the mechanisms that give rise to these inclusions, and to quantify the heat and mass transfer rates that are connected to these regimes. In addition, the translation of these phenomena to larger scale operation is not trivial. Thus its scalability should be investigated as well. 


\subsection{Objective}

The objective of the study reported in this thesis is therefore to investigate the principles of progressive freeze concentration for concentration of solutions and its feasibility from experiments with a pilot-scale freeze concentrator. Two different sub-objectives are defined:

1. Identify the mechanisms behind the interrelation between the properties of the solutes, the applied rate of freezing and the achievable concentration factor during progressive freeze drying, and quantify these mechanisms in a model description of the process.

2. Assess the scalability of progressive freeze concentration on its concentration performance and energy consumption, by comparing lab-scale operation to pilot-scale operation.

\subsection{General Outline}

The research results reported in this thesis result from a combination of experimental and modelling work. Figure 1.4 shows a schematic outline of the thesis.

In chapter 2 freeze concentration of model solutions of sucrose and maltodextrin is evaluated in a laboratory-scale freeze concentration system. The influence of the cooling strategy and the mixing of the product on the amount of inclusion in the ice or solute loss to the ice fraction is evaluated.

Chapter 3 reports on modelling and validation tests of freeze concentration with different products, including proteins. Specifically, solutions of soy protein and whey protein were evaluated using the cooling and mixing conditions established in the previous chapter. Solute inclusion was modelled using an existing theory and this model was linked to the heat and mass balances describing the ice growth rate.

Subsequently, whey protein was selected as a model system in chapter 4 . Since most products in the food industry do not consist of only protein, mixtures of whey protein, salt, and/or sucrose were concentrated and the influence of the addition of salt and sucrose on the solute inclusion was evaluated.

With the knowledge gained in the previous chapters, a novel modelling approach for solute inclusion is proposed in chapter 5. This model aims to describe solute inclusion using the state diagram and heat and mass balances near the ice layer. This approach should enable us to estimate whether a product is a suitable candidate for progressive freeze concentration.

Chapter 6 provides a general discussion of the results obtained in this thesis, and assesses the performance of a pilot-scale progressive freeze concentrator for different solutions. The findings and implications of these results for the scale-up of progressive freeze concentration are discussed and compared to lab-scale operation. Optimizations for the operation of the freeze concentrator are proposed. Finally, we conclude with an outlook on how progressive freeze concentration could be implemented for industrial-scale concentration. 


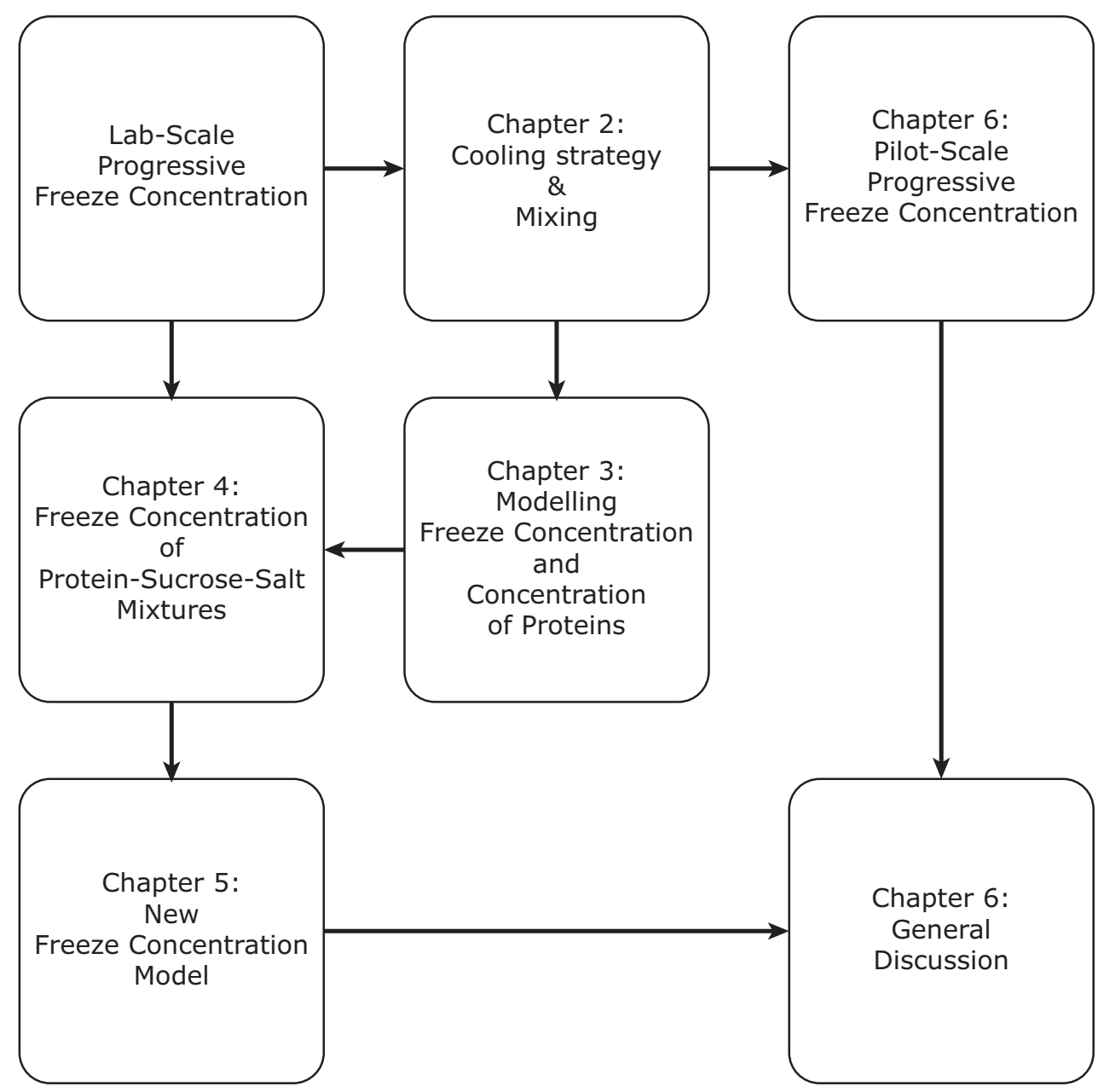

Figure 1.4: Schematic outline of this thesis. 


\section{References}

Aider, Mohammed, Damien De Halleux, and Inna Melnikova (Mar. 2009). "Skim Milk Whey Cryoconcentration and Impact on the Composition of the Concentrated and Ice Fractions". In: Food and Bioprocess Technology 2 (1), pp. 80-88. ISSN: 1935-5130. DOI: 10.1007/s11947-007-0023-0 (cit. on p. 7).

Baker, C. G. J. and K. A. McKenzie (Feb. 2005). "Energy Consumption of Industrial Spray Dryers". In: Drying Technology 23 (1-2), pp. 365-386. ISSN: 0737-3937. DOI: 10.1081/DRT-200047665 (cit. on p. 2).

Cheng, C. Y., W. C. Cheng, and M. D. Yang (Dec. 1987). "The vacuum freezing multiple phase transformation process". In: Desalination 67 (C), pp. 139-153. ISSN: 0011-9164. DOI: 10.1016/00119164 (87) 90239-6 (cit. on p. 3).

EBN (2020). Energieverbruik in Nederland in 2019. URL: https : //www . energieinnederland.nl/ feiten-en-cijfers/uitgebreid/2019/energieverbruik (cit. on p. 2).

Englezos, P. (Jan. 1994). “The Freeze Concentration Process and its Applications”. In: Developments in Chemical Engineering and Mineral Processing 2 (1), pp. 3-15. ISSN: 0969-1855. DOI: 10.1002/ apj. 5500020102 (cit. on p. 3).

Flesland, Ola (Jan. 1995). "Freeze concentration by layer crystallization". In: Drying Technology 13.8-9 (8-9), pp. 1713-1739. ISSN: 1532-2300. DOI: 10.1080/07373939508917048 (cit. on pp. 5, 7).

GEA Messo PT (n.d.). IceCon®. URL: https : // www . gea . com/nl/products / evaporators crystallizers/icecon. jsp (cit. on pp. 5-7).

Hernandez, Ernesto (2005). "Concentration of liquid foods". In: pp. 447-459 (cit. on p. 2).

Huige, N. J. J. and H. A. C. Thijssen (1972). "Production of large crystals by continuous ripening in a stirrer tank". In: Journal of Crystal Growth 13-14 (C), pp. 483-487. ISSN: 0022-0248. DOI: 10 . 1016/0022-0248 (72) 90285-0 (cit. on pp. 2, 5).

Jusoh, M., R. M. Yunus, and M. A. Abu Hassan (Dec. 2009). "Performance investigation on a new design for Progressive Freeze Concentration system". In: Journal of Applied Sciences 9.17 (17), pp. 3171-3175. ISSN: 1812-5654. DOI: 10.3923/jas. 2009.3171.3175 (cit. on p. 7).

Ladha-Sabur, Alia, Serafim Bakalis, Peter J. Fryer, and Estefania Lopez-Quiroga (Apr. 2019). "Mapping energy consumption in food manufacturing”. In: Trends in Food Science and Technology 86, pp. 270-280. ISSN: 0924-2244. DOI: 10.1016/j.tifs.2019.02.034 (cit. on p. 2).

Liu, Ling, Osato Miywaki, and Kozo Nakamura (1997). "Progressive Freeze-Concentration of Model Liquid Food." In: Food Science and Technology International, Tokyo 3.4 (4), pp. 348-352. ISSN: 1341-7592. DOI: 10.3136/fsti9596t9798.3.348 (cit. on p. 5).

Martel, C. James (2000). "Influence of Dissolved Solids on the Mechanism of Freeze-Thaw Conditioning”. In: Water Research 34.2 (2), pp. 657-662. DOI: 10.1016/S0043-1354 (99) 00163-3 (cit. on p. 7).

Meiwa Co. Ltd (2018). Progressive-Freezing-Concentration Machine. URL: https : / / www . meiwaind.co.jp/en/products/product-06/ (visited on 01/07/2021) (cit. on p. 7).

Moejes, S. N. (2019). "Redesign of the Milk Powder Production Chain: Assessment of Innovative Technologies". English. WU thesis 7361 Includes bibliographical references. - With summary in English. $\mathrm{PhD}$ thesis. Wageningen University. ISBN: 9789463950831 . DOI: 10.18174/498246 (cit. on p. 3).

Moejes, S. N. and A. J. B. van Boxtel (2017). "Energy saving potential of emerging technologies in milk powder production". English. In: Trends in Food Science and Technology 60, pp. 31-42. ISSN: 0924-2244. DOI: $10.1016 / j$.tifs . 2016.10.023 (cit. on p. 2).

Mujumdar, Arun S. (July 2014). Handbook of Industrial Drying. 4th ed. Boca Raton: Taylor \& Francis, pp. 1-1348. ISBN: 1574446681. DOI: 10.1080/07373938808916399 (cit. on p. 2).

Petzold, G. and J. M. Aguilera (Oct. 2013). "Centrifugal freeze concentration". In: Innovative Food Science and Emerging Technologies 20, pp. 253-258. ISSN: 1466-8564. DOI: 10.1016/J . IFSET . 2013.05.010 (cit. on p. 5). 
Petzold, Guillermo, Jorge Moreno, Paz Lastra, Katerin Rojas, and Patricio Orellana (Aug. 2015). "Block freeze concentration assisted by centrifugation applied to blueberry and pineapple juices". In: Innovative Food Science \& Emerging Technologies 30, pp. 192-197. ISSN: 1466-8564. DOI: 10.1016/ j.ifset. 2015.03 .007 (cit. on p. 5).

Ramírez, C. A., M. Patel, and K. Blok (2006). "From Fluid Milk to Milk Powder: Energy Use and Energy Efficiency in the European Dairy Industry”. In: Energy 31 (12), pp. 1984-2004. ISSN: 0360-5442. DOI: $10.1016 / j$. energy . 2005.10.014 (cit. on p. 2).

RVO (2015). Best Practice Droogprocessen, p. 18. URL: https : //www.rvo.nl/sites/default/ files /2015/10/Best \%20practise\%20Droogprocessen $\% 20$ oktober $\% 202015$. pdf (cit. on p. 2).

Sánchez, J., E. Hernández, J. M. Auleda, and M. Raventós (Feb. 2011). "Review: Freeze Concentration Technology Applied to Dairy Products". In: Food Science and Technology International 17.1 (1), pp. 5-13. ISSN: 1082-0132. DOI: 10.1177/1082013210382479 (cit. on p. 7).

Sánchez, J., Y. Ruiz, J. M. Auleda, E. Hernández, and M. Raventós (Aug. 2009). "Review. Freeze concentration in the fruit juices industry". In: Food Science and Technology International 15.4 (4), pp. 303-315. ISSN: 1082-0132. DOI: 10.1177/1082013209344267 (cit. on p. 7).

Sei, Tadanori, Takehiko Gonda, and Yoshiyasu Arima (Apr. 2002). "Growth Rate and Morphology of Ice Crystals Growing in a Solution of Trehalose and Water". In: Journal of Crystal Growth 240 (1-2), pp. 218-229. ISSN: 0022-0248. DOI: 10.1016/S0022-0248(02)00875-8 (cit. on p. 7).

Sulzer (n.d.). Freeze Concentration I Sulzer. URL: https : / / www . sulzer . com / en / shared / products/freeze-concentration (cit. on pp. 5, 7).

Walstra, P., T. J. Geurts, A. Noomen, A. Jellema, and M. A. J. S. van Boekel (1999). Dairy Technology: Principles of Milk. Properties and Processes. Marcel Dekker. ISBN: 9780824702281 (cit. on p. 2). 



\section{Effect of freezing rate and convection on solute inclusion}

This chapter has been published as:

Vuist, J. E., Boom, R. M., \& Schutyser, M. A. I. (2021).

Solute inclusion and freezing rate during progressive freeze concentration of sucrose and maltodextrin solutions.

Drying Technology, 39:10, 1285-1293,

https://doi.org/10.1080/07373937.2020.1742151 


\begin{abstract}
Progressive freeze concentration is an alternative method to concentrate aqueous industrial streams compared to evaporation or membrane separation. In this research sucrose and maltodextrin solutions were concentrated in a stirred progressive freeze concentrator. The solute inclusion in the formed ice was studied using varying stirring speeds, initial concentrations and freezing plate temperatures. Under constant freezing plate temperature, a lower limit was found for the solute inclusions with increasing stirrer speeds. To improve the freeze concentration process, a decreasing temperature ramp was applied to the freezing plate. This yielded 2 to 3 times less solute inclusions in the ice, while maintaining similar ice yields.
\end{abstract}

\title{
Nomenclature
}

\begin{tabular}{lll}
\hline Symbol & Description & Unit \\
\hline$\alpha$ & Slope of cooling curve & ${ }^{\circ} \mathrm{C} \mathrm{min}^{-1}$ \\
$\beta$ & Coefficient of parabolic cooling curve & ${ }^{\circ} \mathrm{C} \mathrm{s}^{-2}$ \\
$\mu$ & Dynamic viscosity & $\mathrm{Pa} \mathrm{s}$ \\
$\rho$ & Liquid density & $\mathrm{kg} \mathrm{m} \mathrm{m}^{-3}$ \\
$C_{L}$ & Concentration of solute in feed solution & $\%(\mathrm{w} / \mathrm{w})$ \\
$C_{S}$ & Concentration of solute in ice & $\%(\mathrm{w} / \mathrm{w})$ \\
$D$ & Diameter of stirrer & $\mathrm{m}$ \\
$K$ & Average solute inclusion & - \\
$N$ & Rotational speed & $\mathrm{rad} \mathrm{s}$ \\
$\mathrm{N}_{\mathrm{Re}}$ & Reynolds number & - \\
$t$ & Experimental time & $\mathrm{s}$ \\
\hline
\end{tabular}




\subsection{Introduction}

Concentration of aqueous food streams is a routine operation in the food industry to prepare for (spray) drying, to increase shelf-life and to reduce transportation volumes. Multiple techniques are available, based on evaporation or freeze concentration. While thermal evaporation is the most common industrial technique and is readily applicable to many streams, such as dairy or sugar, it has drawbacks for streams containing heat-sensitive components (Sánchez et al. 2009). Components such as proteins and flavors either become damaged through the heat-treatment or may co-evaporate with the water from the product stream, resulting in a loss of product quality. During freeze concentration, these components are only exposed to low temperatures and therefore suffer minimal thermal damage. It is therefore considered a mild concentration technique (Moreno et al. 2015; Petzold et al. 2009).

During freeze concentration water is frozen as ice crystals, which excludes the solute molecules, when the degree of supercooling is not too high (Lewis et al. 2015). Supercooling is the process of lowering the temperature below the freezing point while the ice crystals are not yet formed due to absence of nucleation (Okawa et al. 2009). Sudden nucleation then leads to the formation of small crystals, which will enclose much of the solutes between the ice crystals. When the freezing surface is at low temperature, the ice crystals tend to grow in dendritic shape. Between the dendrites concentrated solution may be trapped, which decreases the overall separation between ice and solution (Miyawaki et al. 2005; Nakagawa et al. 2009; Zode et al. 2020). At lower rates of freezing, the crystals will be larger, the solute will have time to diffuse into the solution, and the entrapment of solutes is much lower (Myerson et al. 2019).

Freeze concentration can be performed in three main ways: suspension freeze concentration, block freeze concentration and progressive freeze concentration. These have been extensively reviewed by various authors for applications in fruit juices, coffee extracts, dairy and desalination (Sánchez et al. 2009; Sánchez et al. 2011; Kadi et al. 2017; Kalista et al. 2018). During suspension freeze concentration, the ice growth and the degree of supercooling are maintained by continuously seeding the suspension with fresh crystals. The ice crystals are then washed and melted in a continuous washing filter (Huige et al. 1972). This technique is commercially available and has applications in the fruit juice and beer industry (Sánchez et al. 2009; Deshpande et al. 1984). Advantage of this form of freeze concentration is the ease of creating pure ice by the high surface area of the crystals (Lewis et al. 2015). Drawback of the technology is the need for a continuous wash filter, which requires precise operation to melt the ice to remove it from solution(Sánchez et al. 2009). During block freeze concentration the product is nearly completely directionally frozen and selectively thawed to retrieve the concentrate (Moreno et al. 2014; Petzold et al. 2015). The advantage of this method is the simple equipment although there should be a precise control of the freezing rate to achieve good separation (Petzold et al. 2015). During progressive freeze concentration the ice crystal(s) are grown on the wall of a heat exchanger and the ice layer is removed after the concentration process. Leaving the ice on the wall eliminates the need for a washing filter, which reduces the complexity of the system. A drawback of progressive freeze concentration is however that it is a batch operation. After growth of the ice layer the concentrate is removed and the ice is melted and removed from the system. Subsequently, the system is filled with a next batch. By operating at least two freeze concentration units in a parallel mode, they may be heat integrated by using a heat pump. This approach reduces the total energy usage of the 
process and thus increases the economic feasibility of the progressive freeze concentration process (Rane et al. 2005).

Many researchers studying progressive freeze concentration have focused on the inclusion of solute in the ice. Parameters that determine solute inclusion are especially the initial solution concentration, the cooling temperature and the agitation or flow rate (Miyawaki et al. 2005; Liu et al. 1997; Jusoh et al. 2009; Miyawaki et al. 2016). Recent research has investigated these parameters applying freeze concentration to various food products, such as for example apple juice, dairy and coffee extract (Ding et al. 2019; Sequera et al. 2019; Moussaoui et al. 2018; Bona Muñoz et al. 2018; Correa et al. 2018). A common problem is that with increased product concentration, the viscosity of most concentrates will increase. This increase in viscosity will hinder mass transfer of solutes from the boundary layer to the bulk and therefore enhance solute inclusion. The cooling temperature determines the ice growth rate and therefore has large influence on solute inclusion. In most work the temperature was kept constant. The most commonly studied solutes are sugars or salts (Huige et al. 1972; Jusoh et al. 2009; Flesland 1995; Miyawaki et al. 1998).

Due to the ice growth and solute exclusion by the ice, concentration polarization occurs at the boundary (Miyawaki et al. 2005; Chen et al. 2000; Moreno et al. 2014). The concentration polarization leads to increased concentration close to the ice layer. The concentration difference between the layer close to the ice and the bulk will lead to diffusion of solutes back into the concentrate. With forced convection the transport of solute molecules can be enhanced and the diffusive boundary layer is minimized in thickness. Forced convection can thus contribute to less solute inclusion in the ice. In this study a small stirred tank was used for progressive freeze concentration, in which the ice was grown on a heat exchanger plate at the bottom of the tank. The influence of convection was studied by varying stirrer rate in the tank. This system may be effectively scaled to a progressive freeze concentration system using for example heat exchanger plates on which ice is grown and in which hydrodynamics are varied with variable flow rates. Sucrose and maltodextrin were selected as model solute components in this study. Sucrose was selected as it is a major constituent of fruit juices (Sánchez et al. 2009). Maltodextrin was selected as a larger molecule which has a lower diffusion coefficient in water (Perdana et al. 2014; Sano et al. 1993).

The objective of this study is to investigate the relationship between inclusion behavior of solutes and hydrodynamic conditions near the growing ice layer during progressive freeze concentration. Previous studies have often used progressive freeze concentration systems, which are optimized for studying solute partitioning behavior at the ice water interface (Miyawaki et al. 1998). In this study we chose a different set-up which can apply more realistic cooling and hydrodynamic conditions, when scaling up to a plate heat exchanger for ice growth. This is especially relevant for scaling-up the progressive freeze concentration process. 


\subsection{Material and methods}

\section{Experimental set-up}

The film freeze concentration experiments were conducted in a small-scale test apparatus (Genceli et al. 2007). The test apparatus was constructed from an acrylic cylinder with $90 \mathrm{~mm}$ internal diameter (fig. 2.1). The bottom of the cylinder was a stainless-steel chamber that was flushed with cooling fluid. The vessel was equipped with a pitched two-bladed stirrer. To monitor the temperature during the experiments, thermocouples were placed in the vessel at 1,2 , and $5 \mathrm{~mm}$ from the bottom surface, plus one thermocouple at $10 \mathrm{~mm}$ below the liquid surface and two thermocouples in the in- and outgoing liquid flow. All thermocouples (type $\mathrm{T}$ ) were connected to 24-bit data logger (National Instruments, cDAQ-9214, $\pm 0.01{ }^{\circ} \mathrm{C}$ relative accuracy, USA).

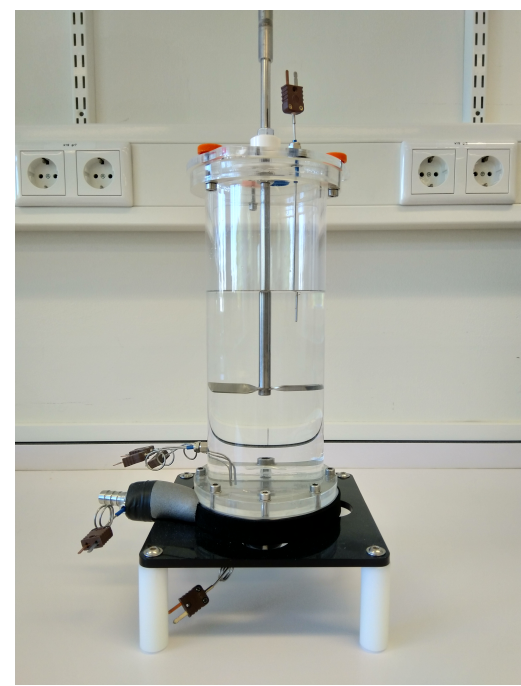

(a)

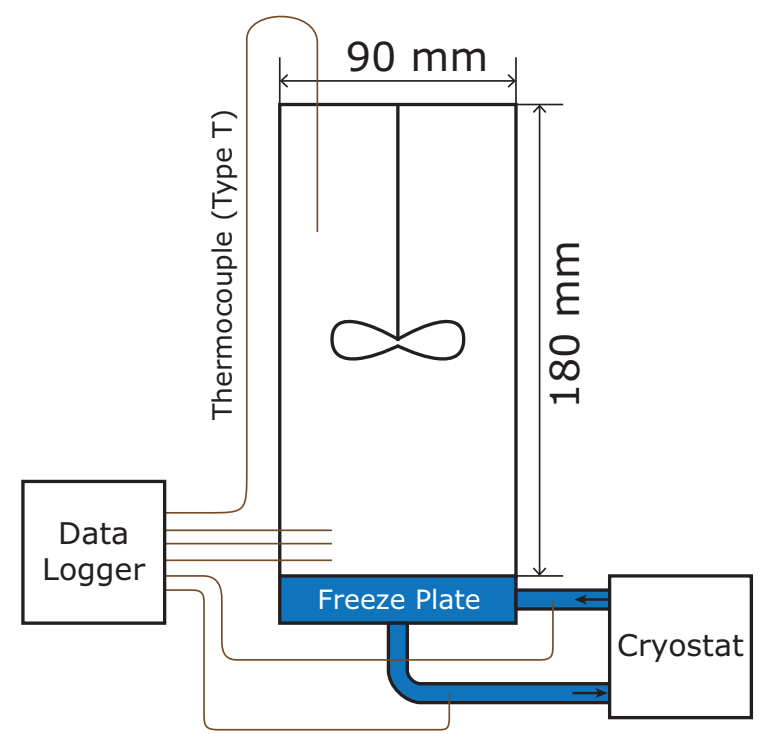

(b)

Figure 2.1: Small-scale stirred tank with cooling plate and ice growth at the bottom for progressive freeze concentration, (a) Picture of set-up, (b) Schematic representation with dimensions.

\section{Materials}

Sucrose and maltodextrin solutions with various concentrations were used as feed solutions. Sucrose $(342.30 \mathrm{~g} / \mathrm{mol}$ ) was obtained from Sigma-Aldrich (BioXtra, $>99.5 \%$ ) and maltodextrin DE12 ( $\approx 3423.0 \mathrm{~g} / \mathrm{mol}$ ) from Roquette Freres (Glucidex 12). The feed solutions were pre-cooled to $4{ }^{\circ} \mathrm{C}$ before use. To determine the sucrose concentration in the sample, we used a refractometer (Anton Paar, Abbemat 500, Germany). To determine the maltodextrin concentration, we heated the pre-weighed solutions overnight in an oven at $105{ }^{\circ} \mathrm{C}$ and weighed them afterwards. The solutions were reused for a maximum of 5 days and separate solutions were used for experiments on the same day. 
Table 2.1: Measured freezing point using DSC

\begin{tabular}{ccc}
\hline & \multicolumn{2}{c}{ Measured freezing point $\left[{ }^{\circ} \mathrm{C}\right]$} \\
\cline { 2 - 3 } Concentration $[\%(\mathrm{w} / \mathrm{w})]$ & Sucrose & Maltodextrin \\
\hline 6 & -0.3 & 0.0 \\
18 & -1.9 & - \\
36 & -4.5 & - \\
\hline
\end{tabular}

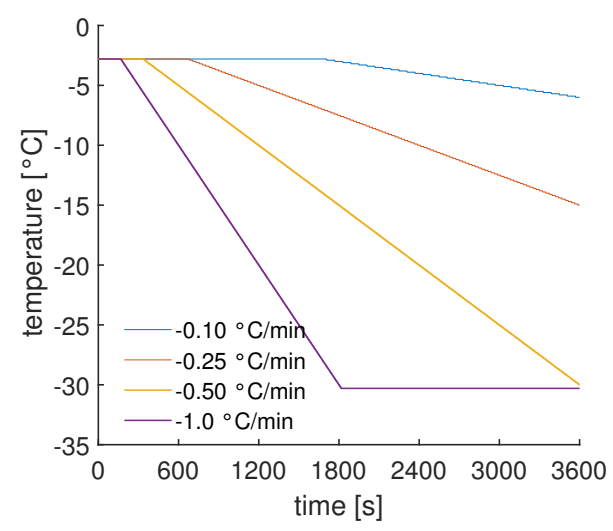

(a)

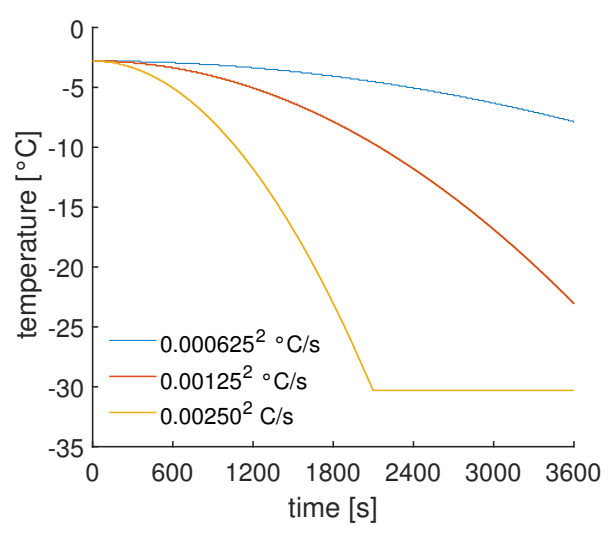

(b)

Figure 2.2: Applied temperature profiles for the decreasing cold wall temperature experiments in this study. (a) Linear and (b) Parabolic

\section{Freeze concentration experiments}

The first set of freeze concentration experiments were conducted with constant cold wall temperatures, ranging from $5{ }^{\circ} \mathrm{C}, 7.5{ }^{\circ} \mathrm{C}$, and $10{ }^{\circ} \mathrm{C}$ below the freezing point of the solution. The freezing points were determined using differential scanning calorimetry (TA instruments DSC250, USA, $20 \mu \mathrm{g}$ sample, $10{ }^{\circ} \mathrm{C} / \mathrm{min}$ cooling rate, $1{ }^{\circ} \mathrm{C} / \mathrm{min}$ heating rate from $-30{ }^{\circ} \mathrm{C}$ to $10^{\circ} \mathrm{C}$ ). The determined freezing points can be found in table 2.1 .

The stirrer speeds were varied between 50, 150, 300, and $500 \mathrm{rpm}$. Sucrose solutions of 6, 18 , and $36 \%(\mathrm{w} / \mathrm{w})$ and a $6 \%(\mathrm{w} / \mathrm{w})$ maltodextrin DE12 were concentrated for 30 minutes. A second set of freeze concentration experiments were carried out with a decreasing cold wall temperature (fig. 2.2) to mediate the high initial ice growth rate when using a constant cold wall temperature. We chose a linear decreasing (eq. (2.1)) and a quadratically decreasing (eq. (2.2)) cold wall temperature. All profiles start at $-2.8{ }^{\circ} \mathrm{C}$, which is $2.5^{\circ} \mathrm{C}$ below the freezing point of the $6 \%(\mathrm{w} / \mathrm{w})$ sucrose solution used.

$$
\begin{aligned}
& T=\min \left(-\alpha t,-2.8^{\circ} \mathrm{C}\right) \\
& T=-\beta t^{2}-2.8^{\circ} \mathrm{C}
\end{aligned}
$$


Where $\alpha$ is the slope of the cooling profile in ${ }^{\circ} \mathrm{C} / \mathrm{min}$ and where $\beta$ is the coefficient for the parabolic equation in ${ }^{\circ} \mathrm{C} / \mathrm{s}^{2}$. These experiments ran for 60 minutes at a stirrer speed of 500 rpm, with a $6 \%(\mathrm{w} / \mathrm{w})$ sucrose solution.

At the start of the freeze concentration experiments, a droplet $(100 \mathrm{~L})$ of pure water was deposited on the freeze plate, which forms a seed crystal preventing high initial super cooling. If initial super cooling is not prevented, sudden, very fast initial ice growth may lead to excessive inclusions at the start of the process (Miyawaki et al. 2005) or may lead to ice crystals forming in suspension rather than on the freeze plate. When the droplet was completely frozen, the feed solution was introduced via a filling port at the top of the cylinder. To prevent air inclusion the stirring was only started after the solution had submerged the stirrer blades. At the end of the experiment the liquid was removed by pouring it from the cylinder and the ice was melted. Both fractions were weighted, and the sucrose content was determined with a refractometer (Anton Paar Abbemat 500, Germany). The dry matter content of the maltodextrin solution was determined drying the samples, in pre-weighed pans overnight in an oven at $105{ }^{\circ} \mathrm{C}$. All experiments were carried out in duplicate.

\section{Data analysis}

To compare the intensity of the convective flow in a stirred vessel for the different concentrations and solutes, the impeller Reynolds number is computed:

$$
\mathrm{N}_{\mathrm{Re}}=\frac{\rho N D^{2}}{\mu}
$$

The average solute inclusion can be expressed with the ratio of the solute concentration in ice and the solute concentration in the original solution:

$$
K=\frac{C_{S}}{C_{L}}
$$

\subsection{Results and Discussion}

\section{Ice formation}

The ice yield of progressive freeze concentration was compared for different stirrer rates and cold wall temperatures (fig. 2.3a). The yield showed little dependence on the stirrer rate. Only at $50 \mathrm{rpm}$ we did observe a minor increase in ice yield, but higher stirrer speed yielded always similar amounts of ice. At the lowest agitation rates, the heat transfer from the bulk of the solution towards the ice is slow and will therefore result in faster ice growth. However, the heat transfer in general is relatively fast compared to the mass transfer of the solute and is not limiting at somewhat better agitation (Gunathilake et al. 2013).

A clear dependence was found on the cold wall temperature. Lower temperatures yielded more ice because the driving force for heat transfer is higher. The ice yield was found to decrease somewhat with increased solute concentration due to the increased freezing point depression at higher sucrose concentrations (fig. 2.3b), especially when considering that the 


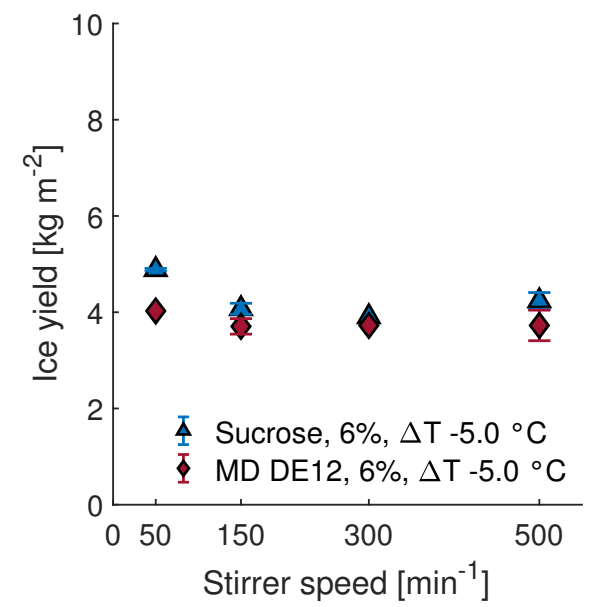

(a)

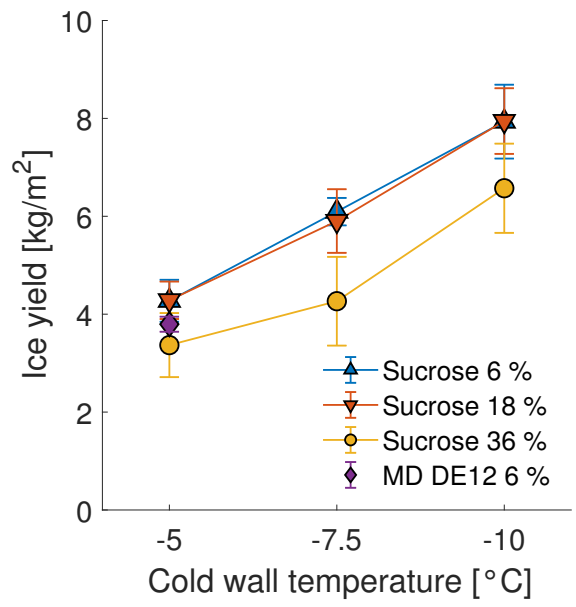

(b)

Figure 2.3: Effect of applied freeze plate temperature and solute concentration on the ice formation after 30 minutes of freeze concentration. (a) Ice yield for sucrose $6 \%(\mathrm{w} / \mathrm{w})$ and maltodextrin DE12 $6 \%(\mathrm{w} / \mathrm{w})$ vs. stirrer speed. (b) Ice yield for sucrose and maltodextrin DE12 solution averaged over the stirrer speeds. The error bars indicate the standard deviation.

concentration of solute at the ice-solution interface is much larger than in the bulk, due to the concentration polarization (Sman 2016). The maltodextrin solutions show a lower ice yield than the $6 \%(\mathrm{w} / \mathrm{w})$ sucrose solution. This is caused by the higher viscosity of the solution compared to the $6 \%(\mathrm{w} / \mathrm{w})$ sucrose. A higher viscosity hinders the ice formation (Budiaman et al. 1987). In fact, viscosity may also be an additional explanation for the decrease in ice yield with increasing concentration of sucrose.

\section{Sucrose and maltodextrin inclusion in ice}

The degree of solute inclusion in ice depends on the hydrodynamics close to the ice layer. In fig. 2.4a the average solute inclusion (eq. (2.4)) is plotted versus the Reynolds numbers (eq. (2.3)) for different solute concentrations. The solute inclusion decreased at increasing Reynolds numbers for all different solutions and cold wall temperatures. As expected, the $18 \%(\mathrm{w} / \mathrm{w})$ and $36 \%(\mathrm{w} / \mathrm{w})$ sucrose solutions showed more inclusion than the $6 \%(\mathrm{w} / \mathrm{w})$ sucrose solutions (fig. 2.4a). This is most probably caused by the strong increase in concentration at the ice-liquid boundary leading to more favorable circumstances for solute inclusion, plus the increased viscosity of these solutions in the concentration polarization layer, contributing to a thicker boundary layer.

An increase of the stirrer speed increases the shear above the ice surface, which improves the transport of the solute away from the ice-liquid boundary and therefore reduces the diffusion limitation in the boundary layer during freeze concentration (Bird et al. 2002). We observe that the dependence on the Reynolds number or stirrer speed becomes stronger for lower concentrations (fig. 2.4a). This can be explained because at increasing concentrations 


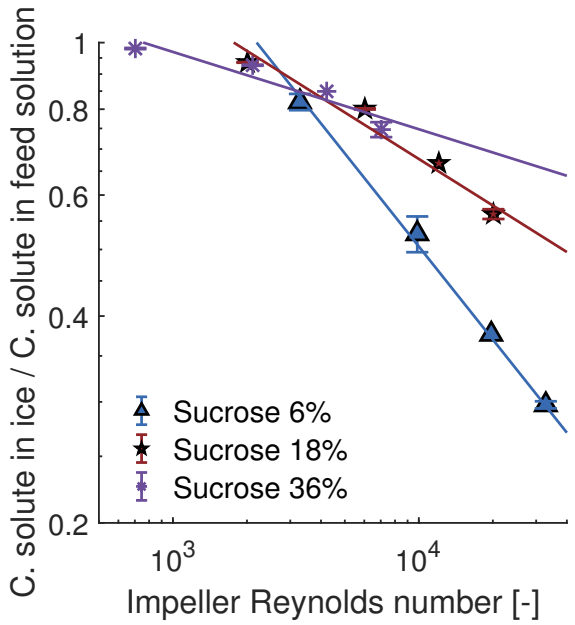

(a)

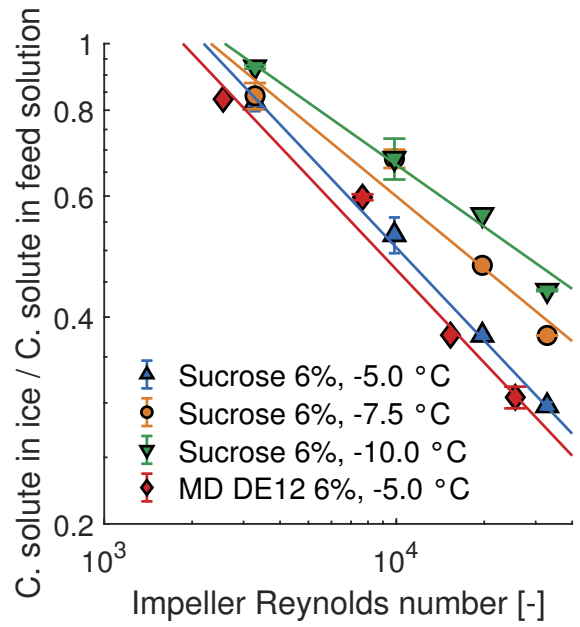

(b)

Figure 2.4: Effect of impeller Reynolds number on the effective solute inclusion after 30 minutes. (a) The effect of increasing sucrose concentration at $-5.0^{\circ} \mathrm{C}$ below the freeze point of the solution. (b) The effect of decreasing freeze plate temperature. The error bars indicate standard deviation.

viscosity increases rapidly, which again hinders mass transfer and promotes inclusion. For freezing rates, we also observe a dependence on Reynolds number, where solute inclusion increases with faster freezing rates (fig. 2.4b). This can be explained as the ice growth rate increases with increasing freezing rate, while the stirring rate remains the same. This is in line what has been found by Liu et al. (1997) and Jusoh et al. (2009).

Perhaps surprisingly, the freezing of maltodextrin solutions is quite comparable to those with $6 \%$ (w/w) sucrose (fig. 2.4b). Maltodextrins, being larger molecules, diffuse more slowly and give rise to higher viscosities, but give less freezing point depression due to the larger molecular weight. These effects may cancel out each other at least partially.

\section{Decreasing cold wall temperature}

With a constant cold wall temperature, freezing initially proceeds much faster and then slows down. The decrease in ice growth is due to the increasing thickness of the ice layer, which reduced the heat transfer from the ice growth front to the cooling plate. The higher initial ice growth rate leads more inclusion during the initial period compared to a later stage. To avoid this initial strong inclusion, we adjusted the cold wall temperature such that the temperature difference with the ice growth front starts relatively small and then gradually increases during the process leading to more constant ice growth rates.

The used temperature profiles can be found in fig. 2.2. Initially a certain degree of supercooling is necessary to ensure nucleation and have the freezing process started. The ice yield was comparable for the cooling programs with $-5{ }^{\circ} \mathrm{C}$ constant temperature (average ice growth rate $=1.30 \times 10^{-3} \mathrm{~mm} / \mathrm{s}$ ), $-0.1{ }^{\circ} \mathrm{C} / \mathrm{min}$ linear profile (average ice growth 


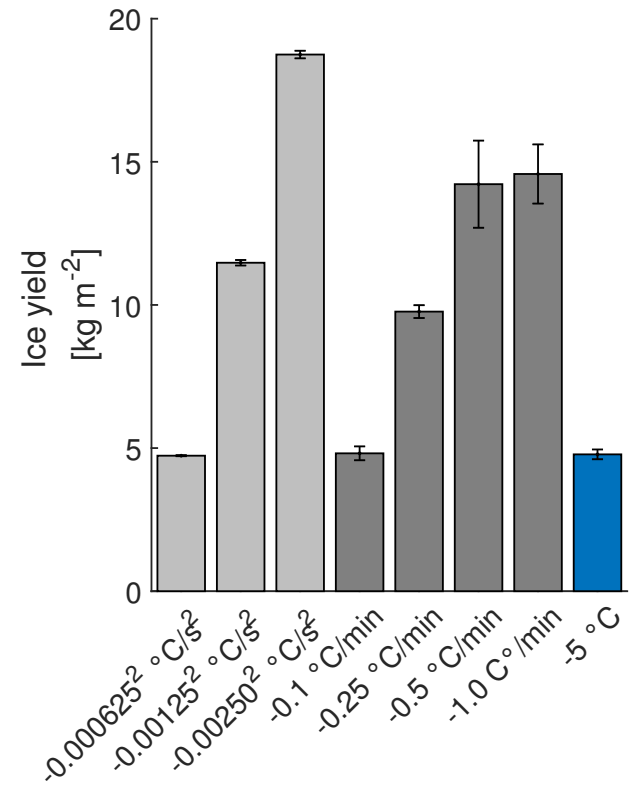

(a)

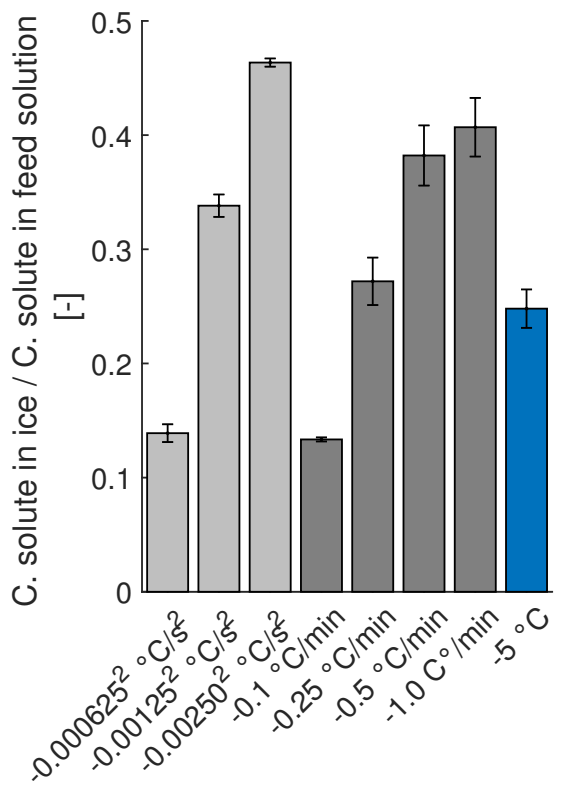

(b)

Figure 2.5: Freeze concentration ice yield (a) and solute inclusion (b) after 60 minutes for the temperature profiles in fig. 2.2. The light gray bars indicate linear decreasing temperature profiles, the dark gray bars indicate parabolic temperature profiles, the blue bar indicates constant temperature profile.

rate $\left.=1.31 \times 10^{-3} \mathrm{~mm} / \mathrm{s}\right)$ and $\left(6.25 \times 10^{-4}\right)^{2}{ }^{\circ} \mathrm{C} / \mathrm{s}^{2}$ quadratic profile (average ice growth rate $=1.29 \times 10^{-3} \mathrm{~mm} / \mathrm{s}$ ), and was larger with steeper decrease of the applied temperature profiles (fig. 2.5a). The larger ice yield is achieved by a larger heat removal from the system. The slopes of $-1.0{ }^{\circ} \mathrm{C} / \mathrm{min}$ (average ice growth rate $=3.96 \times 10^{-3} \mathrm{~mm} / \mathrm{s}$ ) and $\left(2.50 \times 10^{-3}\right)^{2}{ }^{\circ} \mathrm{C} / \mathrm{s}^{2}$ (average ice growth rate $=5.10 \times 10^{-3} \mathrm{~mm} / \mathrm{s}$ ) were limited by the minimum temperature of the cryostat $\left(-30^{\circ} \mathrm{C}\right)$, thus giving a lower ice yield, than what would be expected if the profile would continue below this temperature. The sucrose inclusion, for the $-0.1{ }^{\circ} \mathrm{C} / \mathrm{min}$ and $\left(6.25 \times 10^{-4}\right)^{2}{ }^{\circ} \mathrm{C} / \mathrm{s}^{2}$, could be reduced by approximately a factor two when compared to the constant temperature operation (fig. 2.5b), while having the same ice yield. The other profiles include more sucrose but also yield more ice. The higher ice yield in these cases will lead to a higher concentration in the remaining solution, but the overall separation is worse. These experiments show that for successful operation of progressive freeze concentration, good control of the ice growth rate is necessary for optimal separation and concentration. Modeling of the ice growth rate and the inclusion behavior of the solute could assist in optimizing the ideal temperature profile for the cold wall temperature, increasing the ice yield and lowering the solute inclusion.

\section{Yield versus purity}

The aim of a concentration method is to concentrate a solution as much as possible, while minimizing the losses of the solute. When comparing solute losses, we observe a distinct 


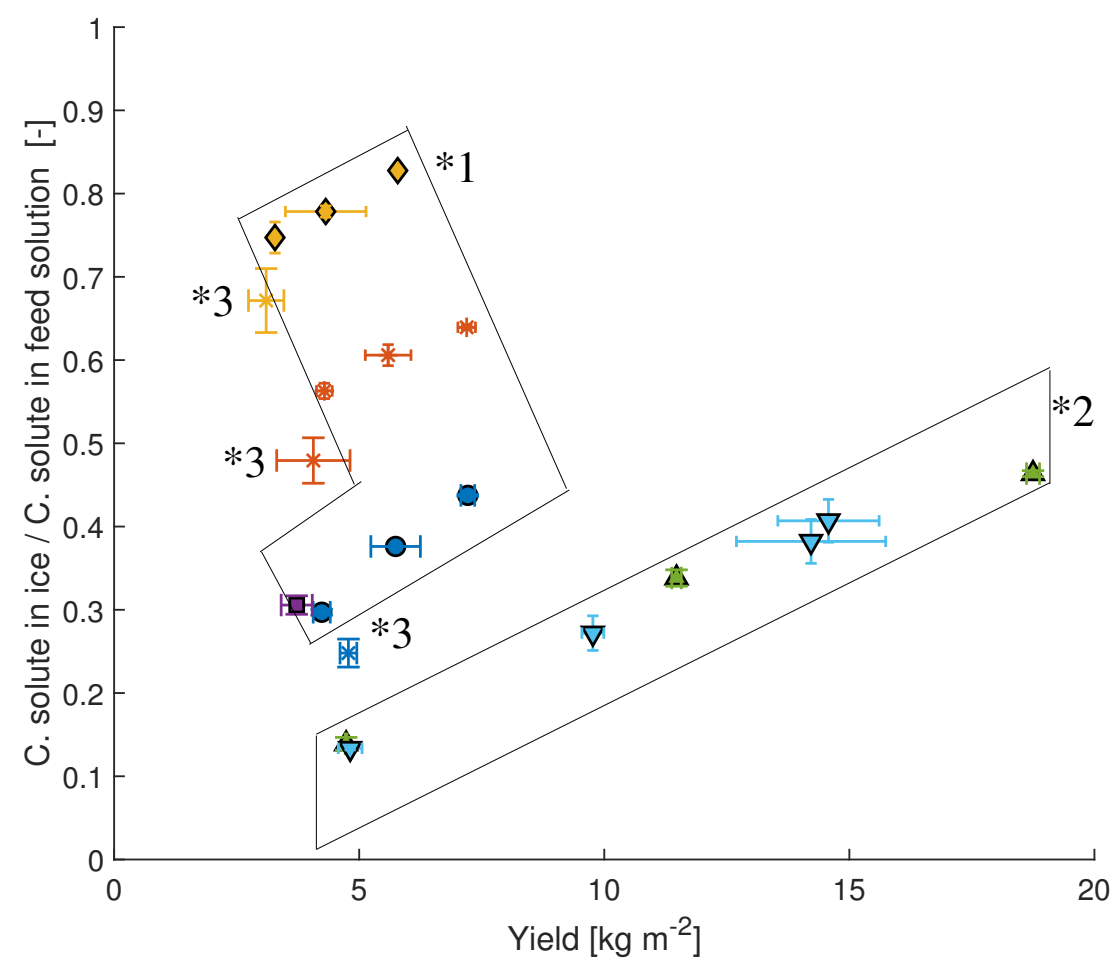

- Sucrose $6 \%, 1 / 2 \mathrm{~h}$

- MD DE12 6\%, $1 / 2 \mathrm{~h}$

x Sucrose $6 \% \mathrm{~T}=-5^{\circ} \mathrm{C}, 1 \mathrm{~h}$

- Sucrose 18\%, $1 / 2 \mathrm{~h}$

$\Delta$ Sucrose $6 \% \mathrm{~T}=-(\beta \mathrm{t})^{2}, 1 \mathrm{~h}$

Sucrose $18 \% \mathrm{~T}=-5^{\circ} \mathrm{C}, 1 \mathrm{~h}$

$\diamond$ Sucrose $36 \%, 1 / 2 \mathrm{~h}$

$\nabla$ Sucrose $6 \% \mathrm{~T}=-(\alpha \mathrm{t}), 1 \mathrm{~h}$

Sucrose $36 \% \mathrm{~T}=-5^{\circ} \mathrm{C}, 1 \mathrm{~h}$

Figure 2.6: Yield versus impurities in the ice for different operating conditions. Group 1 represents operation at constant temperature for 30 minutes. Group 2 represents operation with variable cold wall temperature. Group 3 represents operation at constant temperature for 60 minutes.

grouping of the freeze concentration processes employing a constant temperature, which have a lower yield and significant inclusions (fig. 2.6, group 1). In this group, the level of inclusion increases with increasing solute concentration. A lower cold wall temperature increases the ice yield but reduces the purity, mostly due to high initial inclusion during the fast initial freezing. This is evident in the observation that extending the freezing time from 30 to 60 minutes gives a less than proportional increase of the ice yield, but lower overall solution inclusion (fig. 2.6, group 3). This shows that the slowing of the freezing process reduces the solute conclusions over time.

Therefore, experiments were carried out with varying ramps (fig. 2.2). It could be observed that indeed a cold wall temperature profile that decreases in time gives significantly 
lower solute inclusion (fig. 2.6, group 2), mostly because of the reduced initial degree of supercooling near the cold wall, while the lower temperatures at later stages, increase the ice yield. The rate of progression in cooling, must be balanced with the rate of mass transfer of the solute from the freezing plane towards the solution bulk. A ramp that is too steep will result in more inclusion, caused by the ice growth rate and the drag by the water flux becoming higher than the diffusion rate of the solute away from the ice boundary, causing it to accumulate in the boundary layer (Miyawaki et al. 1998; Bayindirli et al. 1993). Too much concentration polarization may even lead to phase changes and precipitation of the solute, which again will favor solute inclusion (Young et al. 1949). These relative inclusions get higher with increasing feed concentration. This is supported by Miyawaki et al. (1998), who conclude that the ice growth rate should be low enough to prevent strong concentration polarization in the boundary layer. For this, the velocity of the ice front should be balanced with the diffusion in the boundary layer and the transport in the bulk of the liquid.

The yields reported show the amount of ice formed for the given duration of the experiment. When comparing the ice yield from the experiments with constant temperature at $-5^{\circ} \mathrm{C}$ for $1 / 2 \mathrm{~h}$ and $1 \mathrm{~h}$, then one can observe that the yield is similar or increases a little bit for the lowest sucrose concentration. This shows that the majority of the ice is formed at the beginning of the process and the minor increase in ice yield in time shows that the system is near its steady state in terms of heat transfer. It is interesting to note that the sucrose inclusions decrease during the second half hour, which may be explained by diffusion of sucrose from the concentrated domains in the ice layer into the bulk liquid.

\subsection{Conclusion}

The inclusion behavior of sucrose and maltodextrin during progressive freeze concentration was closely coupled to agitation rate and ice growth rate in the stirred tank set-up. Agitation should be large to reduce concentration polarization in the boundary layer and thus minimize undesired solute inclusion. Operating at a constant cold wall temperature led initially to high solute inclusions due to the high ice growth rate at the start of the process. To improve this, we investigated application of variable cooling profiles with a linear or progressive decrease of temperature over time. This approach was found promising to increase the ice yield while at the same time reducing solute inclusion. Ideally, the ice growth rate is thus controlled at a constant value to minimize solute inclusions, while still having a significant ice yield. This would allow better scaling of the results to larger scale progressive freeze concentrators. The more accurate control of ice growth rate the availability of predictive models that describe ice growth and solute inclusion over time is indispensable. 


\section{References}

Bayindirli, Levent, Mustafa Özilgen, and Suat Ungan (1993). "Mathematical analysis of freeze concentration of apple juice”. In: Journal of Food Engineering 19 (1), pp. 95-107. ISSN: 0260-8774. DOI: 10.1016/0260-8774 (93) 90063-P (cit. on p. 24).

Bird, R. Byron, Warren E. Stewart, and Edwin N. Lightfoot (2002). Transport Phenomena. Monograph $<$ br/ $><$ br/>Oorspr. uitg. : 1960. Wiley, p. 895. ISBN: 0521433630. DOI: 10 . $1051 /$ jp4 : 20020462 (cit. on p. 20).

Bona Muñoz, Isabella de, Ariadna Rubio, Mónica Blanco, Mercè Raventós, Eduard Hernández, and Elane Schwinden Prudêncio (Oct. 2018). "Progressive freeze concentration of skimmed milk in an agitated vessel: Effect of the coolant temperature and stirring rate on process performance". In: Food Science and Technology International 25 (2), pp. 150-159. ISSN: 1082-0132. DOI: 10.1177/ 1082013218803263 (cit. on p. 16).

Budiaman, E. R. and O. Fennema (1987). "Linear Rate of Water Crystallization as Influenced by Viscosity of Hydrocolloid Suspensions”. In: Journal of Dairy Science 70 (3), pp. 547-554. ISSN: 00220302. DOI: $10.3168 /$ jds . S0022-0302 (87)80039-5 (cit. on p. 20).

Chen, Ping and Xiao Dong Chen (Apr. 2000). "A generalized correlation of solute inclusion in ice formed from aqueous solutions and food liquids on sub-cooled surface". In: Canadian Journal of Chemical Engineering 78.2 (2), pp. 312-319. ISSN: 0008-4034. DOI: 10.1002/cjce.5450780205 (cit. on p. 16).

Correa, Lady J., Ruth Y. Ruiz, and Fabian L. Moreno (Feb. 2018). "Effect of falling-film freeze concentration on bioactive compounds in aqueous coffee extract". In: Journal of Food Process Engineering 41 (1). ISSN: 1745-4530. DOI: 10.1111/jfpe. 12606 (cit. on p. 16).

Deshpande, S. S., Munir Cheryan, Shridhar K. Sathe, and D. K. Salunkhe (Jan. 1984). "Freeze concentration of fruit juices". In: C R C Critical Reviews in Food Science and Nutrition 20.3 (3), pp. $173-$ 248. ISSN: 0099-0248. DOI: 10.1080/10408398409527389 (cit. on p. 15).

Ding, Zhongxiang, Frank G. F. Qin, Jiaojiao Yuan, Simin Huang, Runhua Jiang, and Youyuan Shao (Sept. 2019). "Concentration of apple juice with an intelligent freeze concentrator". In: Journal of Food Engineering 256, pp. 61-72. ISSN: 0260-8774. DOI: 10.1016/j · jfoodeng . 2019.03.018 (cit. on p. 16).

Flesland, Ola (Jan. 1995). "Freeze concentration by layer crystallization”. In: Drying Technology 13.8-9 (8-9), pp. 1713-1739. ISSN: 1532-2300. DOI: 10.1080/07373939508917048 (cit. on p. 16).

Genceli, F. Elif, Martin Lutz, Anthony L. Spek, and Geert Jan Witkamp (Dec. 2007). "Crystallization and characterization of a new magnesium sulfate hydrate MgSO4 11H2O". In: Crystal Growth and Design 7 (12), pp. 2460-2466. ISSN: 1528-7483. DOI: 10.1021/cg060794e (cit. on p. 17).

Gunathilake, Mihiri, Kiyomi Shimmura, and Osato Miyawaki (2013). "Analysis of solute distribution in ice formed in progressive freeze-concentration". In: Food Science and Technology Research 19.3 (3), pp. 369-374. ISSN: 1344-6606. DOI: 10.3136/fstr.19.369 (cit. on p. 19).

Huige, N. J. J. and H. A. C. Thijssen (1972). "Production of large crystals by continuous ripening in a stirrer tank". In: Journal of Crystal Growth 13-14 (C), pp. 483-487. ISSN: 0022-0248. DOI: 10. 1016/0022-0248 (72)90285-0 (cit. on pp. 15, 16).

Jusoh, M., R. M. Yunus, and M. A. Abu Hassan (Dec. 2009). "Performance investigation on a new design for Progressive Freeze Concentration system". In: Journal of Applied Sciences 9.17 (17), pp. 3171-3175. ISSN: 1812-5654. DOI: 10.3923/jas . 2009.3171.3175 (cit. on pp. 16, 21).

Kadi, Khadije El and Isam Janajreh (2017). "Desalination by Freeze Crystallization: An Overview". In: Int. J. of Thermal \& Environmental Engineering 15.2 (2), pp. 103-110. DOI: 10.5383/i jtee. 15. 02.004 (cit. on p. 15).

Kalista, Brenda, Hyein Shin, Jaeweon Cho, and Am Jang (Dec. 2018). "Current development and future prospect review of freeze desalination". In: Desalination 447, pp. 167-181. ISSN: 0011-9164. DOI: 10.1016/j.desal.2018.09.009 (cit. on p. 15).

Lewis, Alison Emslie, Marcelo Martins Seckler, Herman Kramer, and Gerda Van Rosmalen (Jan. 2015). Industrial crystallization: Fundamentals and applications. Cambridge University Press, pp. 1-323. ISBN: 9781107280427. DOI: 10.1017/CB09781107280427 (cit. on p. 15). 
Liu, Ling, Osato Miywaki, and Kozo Nakamura (1997). "Progressive Freeze-Concentration of Model Liquid Food.” In: Food Science and Technology International, Tokyo 3.4 (4), pp. 348-352. ISSN: 1341-7592. DOI: 10.3136/fsti9596t9798.3.348 (cit. on pp. 16, 21).

Miyawaki, Osato, Ling Liu, and Kozo Nakamura (Sept. 1998). "Effective partition constant of solute between ice and liquid phases in progressive freeze-concentration". In: Journal of Food Science 63.5 (5), pp. 756-758. ISSN: 0022-1147. DOI: 10.1111/j.1365-2621.1998.tb17893.x (cit. on pp. 16, 24).

Miyawaki, Osato, Ling Liu, Yoshito Shirai, Shigeru Sakashita, and Kazuo Kagitani (July 2005). "Tubular ice system for scale-up of progressive freeze-concentration”. In: Journal of Food Engineering 69.1 (1), pp. 107-113. ISSN: 0260-8774. DOI: $10.1016 / \mathrm{j} \cdot \mathrm{j}$ foodeng . 2004.07 .016 (cit. on pp. 15, 16, 19).

Miyawaki, Osato et al. (Feb. 2016). "Progressive freeze-concentration of apple juice and its application to produce a new type apple wine". In: Journal of Food Engineering 171, pp. 153-158. ISSN: 02608774. DOI: $10.1016 / \mathrm{j}$. jfoodeng. 2015.10.022 (cit. on p. 16).

Moreno, F. L., M. X. Quintanilla-Carvajal, L. I. Sotelo, C. Osorio, M. Raventós, E. Hernández, and Y. Ruiz (May 2015). "Volatile compounds, sensory quality and ice morphology in falling-film and block freeze concentration of coffee extract". In: Journal of Food Engineering 166, pp. 64-71. ISSN: 0260-8774. DOI: 10.1016/j . jfoodeng. 2015.05.018 (cit. on p. 15).

Moreno, F. L., M. Raventós, E. Hernández, and Y. Ruiz (2014). "Block freeze-concentration of coffee extract: Effect of freezing and thawing stages on solute recovery and bioactive compounds". In: Journal of Food Engineering 120.1 (1), pp. 158-166. ISSN: 0260-8774. DOI: 10 . 1016 / j . jfoodeng. 2013.07.034 (cit. on pp. 15, 16).

Moussaoui, Chaimae, Mónica Blanco, Isabella de Bona Muñoz, Mercè Raventós, and Eduard Hernández (Aug. 2018). "An approach to the optimization of the progressive freeze concentration of sucrose solutions in an agitated vessel". In: Separation Science and Technology 33.1 (1), pp. 1-11. ISSN: 0149-6395. DOI: 10.1080/01496395.2018.1508231 (cit. on p. 16).

Myerson, Allan S., Deniz Erdemir, and Alfred Y. Lee (June 2019). Handbook of industrial crystallization. English. Third edit. Cambridge ; Cambridge University Press, pp. 1-528. ISBN: 9781139026949 DOI: $10.1017 / 9781139026949$ (cit. on p. 15).

Nakagawa, Kyuya, Shohei Maebashi, and Koji Maeda (Oct. 2009). "Concentration of aqueous dye solution by freezing and thawing”. In: Canadian Journal of Chemical Engineering 87 (5), pp. 779-787. ISSN: 0008-4034. DOI: 10.1002/cjce. 20213 (cit. on p. 15).

Okawa, Seiji, Tetsuya Ito, and Akio Saito (Mar. 2009). "Effect of crystal orientation on freeze concentration of solutions". In: International Journal of Refrigeration 32 (2), pp. 246-252. ISSN: 0140-7007. DOI: $10.1016 /$ j.ijrefrig. 2008.06.001 (cit. on p. 15).

Perdana, Jimmy, Ruud G. M. Van Der Sman, Martijn B. Fox, Remko M. Boom, and Maarten A. I. Schutyser (2014). "Measuring and modelling of diffusivities in carbohydrate-rich matrices during thin film drying". In: Journal of Food Engineering 122 (1), pp. 38-47. ISSN: 0260-8774. DOI: 10. 1016/j · jfoodeng. 2013.08.033 (cit. on p. 16).

Petzold, G. and J. M. Aguilera (2009). "Ice morphology: Fundamentals and technological applications in foods". In: Food Biophysics 4 (4), pp. 378-396. ISSN: 1557-1858. DOI: 10.1007/s11483-0099136-5 (cit. on p. 15).

Petzold, Guillermo, Jorge Moreno, Paz Lastra, Katerin Rojas, and Patricio Orellana (Aug. 2015). "Block freeze concentration assisted by centrifugation applied to blueberry and pineapple juices". In: Innovative Food Science \& Emerging Technologies 30, pp. 192-197. ISSN: 1466-8564. DOI: 10.1016/ j.ifset.2015.03.007 (cit. on p. 15).

Rane, Milind V. and Siddharth K. Jabade (Oct. 2005). "Freeze concentration of sugarcane juice in a jaggery making process". In: Applied Thermal Engineering 25.14-15 (14-15), pp. 2122-2137. ISSN: 1359-4311. DOI: 10.1016/j . applthermaleng. 2005.01.014 (cit. on p. 16).

Sánchez, J., E. Hernández, J. M. Auleda, and M. Raventós (Feb. 2011). "Review: Freeze Concentration Technology Applied to Dairy Products”. In: Food Science and Technology International 17.1 (1), pp. 5-13. ISSN: 1082-0132. DOI: 10.1177/1082013210382479 (cit. on p. 15). 
Sánchez, J., Y. Ruiz, J. M. Auleda, E. Hernández, and M. Raventós (Aug. 2009). "Review. Freeze concentration in the fruit juices industry". In: Food Science and Technology International 15.4 (4), pp. 303-315. ISSN: 1082-0132. DOI: 10.1177/1082013209344267 (cit. on pp. 15, 16).

Sano, Yuji and Shuichi Yamamoto (1993). "Mutual Diffusion Coefficient of Aqueous Sugar Solutions". In: Journal of Chemical Engineering of Japan 26 (6), pp. 633-636. ISSN: 0021-9592. DOI: 10 . 1252/jcej. 26.633 (cit. on p. 16).

Sequera, S. C., Y. Ruiz, F. L. Moreno, M. X. Quintanilla-Carvajal, and F. Salcedo (Feb. 2019). "Rheological evaluation of gelation during thermal treatments in block freeze concentration of coffee extract". In: Journal of Food Engineering 242, pp. 76-83. ISSN: 0260-8774. DOI: 10 . 1016/ j . jfoodeng. 2018.07.030 (cit. on p. 16).

Sman, R. G. M. van der (Apr. 2016). "Phase field simulations of ice crystal growth in sugar solutions". In: International Journal of Heat and Mass Transfer 95, pp. 153-161. ISSN: 0017-9310. DOI: 10 . 1016/j.ijheatmasstransfer.2015.11.089 (cit. on p. 20).

Young, Frank E. and Francis T. Jones (1949). "Sucrose hydrates: The sucrose-water phase diagram". In: Journal of Physical and Colloid Chemistry 53 (9), pp. 1334-1350. ISSN: 0022-3654. DOI: 10. 1021/j150474a004 (cit. on p. 24).

Zode, Sandeep S., Samarth D. Thakore, and Arvind K. Bansal (Oct. 2020). "Effect of process parameters on phase behavior and particle size of aspirin during freeze concentration". In: Drying Technology 38 (14), pp. 1891-1903. ISSN: 1532-2300. DOI: 10 . 1080/07373937 . 2019 . 1686010 (cit. on p. 15). 



\section{Modelling freeze concentration and concentration of proteins}

This chapter has been published as:

Vuist, J. E., Linssen, R., Boom, R. M., \& Schutyser, M. A. I. (2021).

Modelling ice growth and inclusion behaviour of sucrose and proteins during progressive freeze concentration.

Journal of Food Engineering, 303, [110592].

https://doi.org/10.1016/j.jfoodeng.2021.110592 


\begin{abstract}
This study focused on modelling ice growth and solute inclusion behaviour during progressive freeze concentration of sucrose, soy protein, and whey protein. Experiments were conducted in a small stirred tank set-up and ice growth was modelled using mass and heat balances. Solute inclusion was estimated using an intrinsic distribution coefficient. For sucrose solutions, the intrinsic distribution coefficient is proposed dependent on the initial and critical concentrations, where the last is related to the fast increase in viscosity and decrease in diffusivity when the solution approaches glass transition. Predictions were found in agreement with experimental data, except when dendritic ice growth was observed. Solutions of whey and soy proteins behaved differently due to their large difference in solubility. These proteins also showed different inclusion behaviour compared to sucrose, due to lower freezing point depression and lower concentrations far away from glass transition.
\end{abstract}




\section{Nomenclature}

\begin{tabular}{|c|c|c|}
\hline Symbol & Description & Unit \\
\hline$\overline{\Delta H_{f u s}}$ & Heat of fusion & $\mathrm{kJ} \mathrm{kg}^{-1}$ \\
\hline$\delta$ & Thickness of the boundary layer & $\mathrm{m}$ \\
\hline$\mu$ & Dynamic viscosity & $\mathrm{Pa} \mathrm{s}$ \\
\hline$\rho_{\text {ice }}$ & Density of ice & $\mathrm{kg} \mathrm{m} \mathrm{m}^{-3}$ \\
\hline $\mathrm{R}$ & Universal gas constant & $\mathrm{J} \mathrm{K}^{-1} \mathrm{~mol}^{-1}$ \\
\hline$A_{f p}$ & Area cooling plate & $\mathrm{m}^{2}$ \\
\hline$C_{\text {critical }}$ & Critical concentration for freeze concentration & $\mathrm{kg} \mathrm{kg}^{-1}$ \\
\hline$C_{i}$ & Concentration of solute at the ice boundary & $\mathrm{kg} \mathrm{kg}^{-1}$ \\
\hline$C_{l}$ & Concentration of solute in solution & $\mathrm{kg} \mathrm{kg}^{-1}$ \\
\hline$C_{s}$ & Concentration of solute in ice & $\mathrm{kg} \mathrm{kg}^{-1}$ \\
\hline$D$ & Diffusion coefficient & $\mathrm{m}^{2} \mathrm{~s}^{-1}$ \\
\hline$d$ & Diameter freeze cell & $\mathrm{m}$ \\
\hline$h$ & Heat transfer coefficient (liquid boundary layer) & $\mathrm{W} \mathrm{m} \mathrm{m}^{-1} \mathrm{~K}^{-1}$ \\
\hline$h_{o v, i}$ & Heat transfer coefficient (overall, ice + heat exchanger) & $\mathrm{W} \mathrm{m}^{-1} \mathrm{~K}^{-1}$ \\
\hline$K$ & Average distribution coefficient & - \\
\hline$k$ & Mass transfer coefficient & $\mathrm{m} \mathrm{s}^{-1}$ \\
\hline$K_{0}$ & Intrinsic distribution coefficient & - \\
\hline$L$ & Specific length & $\mathrm{m}$ \\
\hline$L_{\text {ice }}$ & Thickness of ice & $\mathrm{m}$ \\
\hline$L_{w}$ & Thickness of the wall & $\mathrm{m}$ \\
\hline$M_{\text {ice }}$ & Mass of ice & $\mathrm{kg}$ \\
\hline$N$ & Stirring rate & $\mathrm{s}^{-1}$ \\
\hline $\mathrm{N}_{\mathrm{Re}}$ & Reynold's number & - \\
\hline $\mathrm{N}_{\mathrm{Sc}}$ & Schmidt's number & - \\
\hline $\mathrm{N}_{\mathrm{Sh}}$ & Sherwood's number & - \\
\hline$q$ & Specific heat flow & $\mathrm{W} \mathrm{m}^{-2}$ \\
\hline$q_{f p}$ & Heat transfer from the bulk fluid & $W m^{-2}$ \\
\hline$q_{\text {ice }}$ & Heat transfer through ice layer & $\mathrm{W} \mathrm{m}^{-2}$ \\
\hline$t$ & Time & $\mathrm{s}$ \\
\hline$T_{\text {coolant }}$ & Temperature of the coolant & ${ }^{\circ} \mathrm{C}$ \\
\hline$T_{f p}$ & Temperature of the freezing point & ${ }^{\circ} \mathrm{C}$ \\
\hline$T_{f p, 0}$ & Temperature of the freezing point of pure water & ${ }^{\circ} \mathrm{C}$ \\
\hline$T_{g}$ & Glass transition temperature & ${ }^{\circ} \mathrm{C}$ \\
\hline$T_{l}^{s}$ & Temperature of the liquid & ${ }^{\circ} \mathrm{C}$ \\
\hline$T_{m}$ & Melting temperature & ${ }^{\circ} \mathrm{C}$ \\
\hline$v_{i c e}$ & Velocity of the boundary & $\mathrm{m} \mathrm{s}^{-1}$ \\
\hline$x$ & Distance from boundary layer & $\mathrm{m}$ \\
\hline$x_{s}$ & Mole fraction of solute & - \\
\hline
\end{tabular}





\subsection{Introduction}

Freeze concentration is the process to concentrate aqueous streams by the removal of water as ice crystals after cooling the stream to its freezing point. The main advantage of freeze concentration over concentration by evaporation is that heat sensitive components are not affected at the low temperatures in the process (Berk 2009; Sánchez et al. 2011; Auleda et al. 2011). There are three different approaches to carry out freeze concentration, i.e. suspension freeze concentration, block freeze concentration and progressive freeze concentration. In suspension freeze concentration the ice crystals are grown in suspension and are removed through a continuous wash filter This process is already available on an industrial scale (Sánchez et al. 2011; Kadi et al. 2017). In block freeze concentration the solution is completely frozen and then selectivily thawed to remove the concentrate (Moreno et al. 2014; Petzold et al. 2015). In progressive freeze concentration the ice is grown as a layer on a heat exchanger surface. This process is till now mostly investigated at lab scale and some at pilot scale, although some small scale industrial units with a maximum capacity of around 501 exist and a larger scale unit (100 1) is under development. (Rane et al. 2005; Miyawaki et al. 2005; Meiwa Co. Ltd 2018). To scale this technology ultimately to an industrially relevant scale and apply it to relevant product streams, more insight is required in the dynamics of the process, which requires both experimental and modelling work.

Progressive freeze concentration involves partial freezing of the fluid on the surface of a heat exchanger(Halde 1980; Liu et al. 1997). Forced convection reduces concentration polarization close to the ice surface and thus lowers the amount of solute inclusions into the ice (Vuist et al. 2020). Progressive freeze concentration is operated as a batch process. When the ice layer has a specified maximum thickness and thus the solution has reached the desired concentration, the operation is ended by draining the system. Subsequently the ice is melted to collect the water from the concentrate. If a higher concentration factor is desired, a second progressive freeze concentration step may be applied to the concentrate.

The process of progressive freeze concentration has been studied for various equipment designs. Generally, for minimum solute inclusion in the ice layer, high agitation and low freezing rates are required. Flesland (1995) used an open system with the liquid flowing over a cooling plate and observed that concentration of sucrose solutions could be realised albeit the desired recovery was only achieved at low ice growth rates and by applying a multi-step freeze concentration process (Flesland 1995; Ratkje et al. 1995). Liu et al. (1997) used a cylinder submerged in a cooled ethanol bath to concentrate glucose solutions. Later, this system was scaled up to a closed tubular device (Miyawaki et al. 2005). In this device, coffee, tomato juice, and sucrose were concentrated, which demonstrated the potential of progressive freeze concentration to relevant streams in food industry. Raventós et al. (2007) used a setup based on a falling film and Ojeda et al. (2017) used a setup consisting of a stirred tank with cooled walls. They applied freeze concentration to sucrose solutions and concluded that the eutectic point was the limiting factor for freeze concentration. However, sucrose solutions are known for their supersaturation and show no eutectic concentration behaviour (Sman 2016; Sman 2017).

To allow scaling of film freeze concentration towards industrial scale, modelling can be used to design larger-scale freeze concentration processes and to estimate the efficiency and economics at this scale. In several previous studies models were developed for the film freeze 
concentration process. Ratkje et al. (1995) assumed the growth rate of ice to be constant and derived that inclusions may be prevented when the ice growth rate is below a maximum threshold determined by the temperature difference between the ice front and the cooling surface and the diffusion rate of the solute (Scholz 1993; Scholz et al. 1993; Flesland 1995; Ratkje et al. 1995). Auleda et al. (2011) proposed a modelling approach for a falling film freeze concentrator based on the work of P. Chen et al. (2000), who employed a semi-empirical correlation based on freezing point depression, ice growth rate and the liquid velocity. They expanded upon this work to determine the maximum allowable freezing rate and to account for different geometries of the cooling systems (X. D. Chen et al. 2015). Miyawaki et al. (1998) proposed an intrinsic distribution coefficient $\left(K_{0}\right)$ to predict solute inclusion during progressive freeze concentration. This intrinsic distribution coefficient is the ratio between the solute concentration in the ice and the solute concentration in the solution at the boundary, when the boundary moves infinitesimally slowly (eq. (3.1)).

$$
K_{0}=\frac{C_{s}}{C_{i}}
$$

The intrinsic distribution coefficient $K_{0}$ is in fact an empirical parameter that can be obtained from freeze concentration experiments with a specific solute. Gunathilake et al. (2013) observed that $K_{0}$ is concentration dependent. Gu et al. (2006) related the intrinsic distribution coefficient to the osmotic pressure, which in it self is directly related to the water activity of the solution. This worked well for calculating the coefficient for single component system containing salt, however for glucose and dextran mixtures they found that the viscosity had a large influence on the intrinsic distribution coefficient. P. Chen et al. (2000) related the distribution coefficient to the freezing point depression via a semi-empirical relationship and found the correlation to fit well for falling film freeze concentration and suspension freeze concentration.

The aim of this work is to develop a coupled heat and mass transfer model to describe the freeze concentration process including solute inclusion. Specifically, we investigate the relation of the intrinsic distribution coefficient $\left(K_{0}\right)$ to the phase behaviour of the solute and the solvent to predict solute inclusion. We hypothesise that $K_{0}$ is related to the ratio of the concentration of the solution and a critical concentration related to the glass transition. We compare freeze concentration experiments and model predictions for protein and sugar solutions. Measurements were done at lab scale in which the ice growth rate and solute inclusion were both analysed.

\subsection{Theory}

\section{Ice growth}

The average ice growth rate on the cooling plate follows from the energy balance over the ice boundary (eq. (3.2)) Rane et al. (2005).

$$
\begin{aligned}
\frac{\mathrm{d} M_{i c e}}{\mathrm{~d} t} & =\frac{\left(q_{i c e}-q_{f p}\right) A_{f p}}{\Delta H_{f u s}} \\
q_{i c e} & =h\left(T_{l}-T_{f p}\right) \\
q_{f p} & =h_{o v, i}\left(T_{f p}-T_{\text {coolant }}\right)
\end{aligned}
$$


We assume that the ice growth is proportional to the excess of heat removed via the ice layer (eq. (3.4)) minus the heat transported towards the ice boundary from the fluid bulk (eq. (3.3)). If we assume that the ice is growing uniformly, the ice growth rate can be derived via the ice density (eq. (3.5)). The heat of fusion, $\Delta H_{f u s}$, was assumed to be equal to that of water $(333.5 \mathrm{~kJ} / \mathrm{kg})$.

$$
v_{\text {ice }}=\frac{\mathrm{d} L_{\text {ice }}}{\mathrm{d} t}=\frac{q_{\text {ice }}-q_{f p}}{\Delta H_{\text {fus }} \rho_{\text {ice }}}
$$

\section{Solute Inclusion}

The concentration effect in film freeze concentration is caused by exclusion of the solute from the ice. However the exclusion of the solute is not perfect and this leads to solute inclusion. This can be expressed as an average distribution coefficient, $K$ (eq. (3.6)). The average distribution coefficient can be measured after a freeze concentration experiment by analysing the composition of the fluid $\left(C_{l}\right)$ and the ice phase $\left(C_{s}\right)$, respectively (fig. 3.1). Due to concentration polarisation the average distribution coefficient is not equal to the intrinsic distribution coefficient (eq. (3.1)) (Burton et al. 1953a).

$$
\begin{aligned}
K & =\frac{C_{s}(t)}{C_{l}} \\
K_{0} & =\frac{C_{s}}{C_{i}}
\end{aligned}
$$

The concentration polarisation above the ice surface can be described with a mass balance over the hydrodynamic boundary layer (eq. (3.8)).

$$
-D \frac{\mathrm{d} C}{\mathrm{~d} x}+v_{i c e} C=v_{i c e} C_{S}
$$

The frame of reference for this mass balance is the ice surface which is defined to be at $x=0$. Ice growth leads to a flux of water with speed $v_{i c e}$ into the ice. $C_{S}$ is the concentration of solute in the ice, $C$ is the concentration in the boundary layer, and $D$ is the diffusion coefficient of the solute in the solvent. The boundary conditions for this equation are $C=C_{i}$ at $x=0$ (the concentration in the liquid phase) and $C=C_{l}$ at $x=-\delta$ where $\delta$ is the boundary layer thickness. When these boundary conditions are used eq. (3.8) can be integrated to obtain eq. (3.9).

$$
\frac{C_{i}-C_{s}}{C_{l}-C_{s}}=\exp \left(\frac{v_{i c e} \delta}{D}\right)
$$

When combining eq. (3.9) with the definition for the intrinsic distribution coefficient and replacing $D / \delta$ by the mass transfer coefficient $k$, a practical expression is obtained for the concentration of the solute at the ice boundary (eq. (3.10)).

$$
C_{s}=\frac{\exp \left(\frac{v_{\text {ice }}}{k}\right) C_{l}}{\exp \left(\frac{v_{\text {ice }}}{k}\right)+\frac{1}{K_{0}}-1}
$$




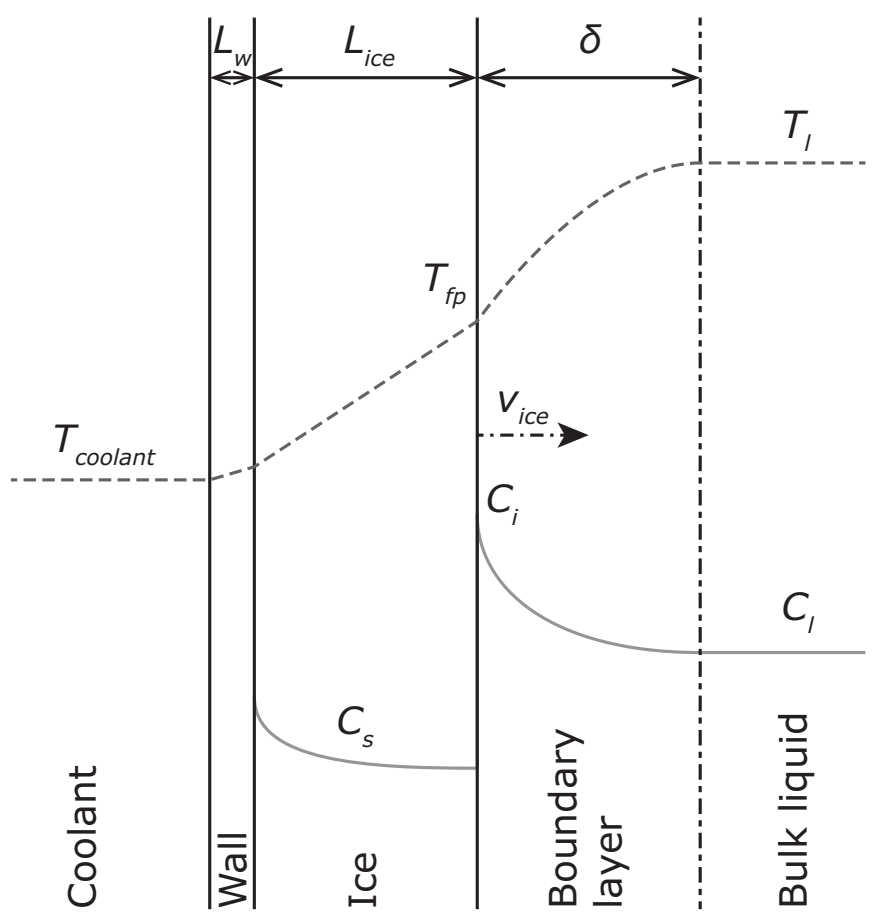

Figure 3.1: Schematic drawing of the temperature and concentration profiles near the cold wall. For visualization the system is rotated with $90^{\circ}$.

\section{Intrinsic distribution coefficient}

The intrinsic distribution coefficient, $K_{0}$, is proposed by Burton et al. (1953a) as the ratio of the concentration of solute in the ice, $C_{s}$ and that in the liquid at the interface, $C_{i}$. This ratio converges to a constant value when the temperature of the ice approaches the freezing temperature (Burton et al. 1953b; Burton et al. 1953a). Gunathilake et al. (2013) showed that for sucrose systems the intrinsic distribution coefficient depends on the solution concentration $\left(C_{l}\right)$. Gu et al. (2006) observed this dependence also for different salts and glucose and related the intrinsic distribution coefficient to the osmotic pressure, although they could not explain the behaviour of glucose at $20 \%$.

$$
\begin{aligned}
K_{0} & =\frac{C_{l}}{C_{\text {critical }}} \\
C_{\text {critical }} & =f\left(T_{m}, T_{g}^{\prime}\right)
\end{aligned}
$$

As small carbohydrates like sucrose tend to be supersaturated at low temperatures, rather than allow crystallization of the carbohydrate, we cannot use a eutectic point, which normally should lead to the maximum degree of freeze concentration. We therefore propose that the value of $K_{0}$ (eq. (3.11)) is, for small carbohydrates, dependent on the ratio between the solute concentration in the liquid and the concentration determined by a margin above where the apparent glass temperature $\left(T_{g}^{\prime}\right)$ meet the solidus line $\left(T_{m}\right)$, this is deemed the critical concen- 


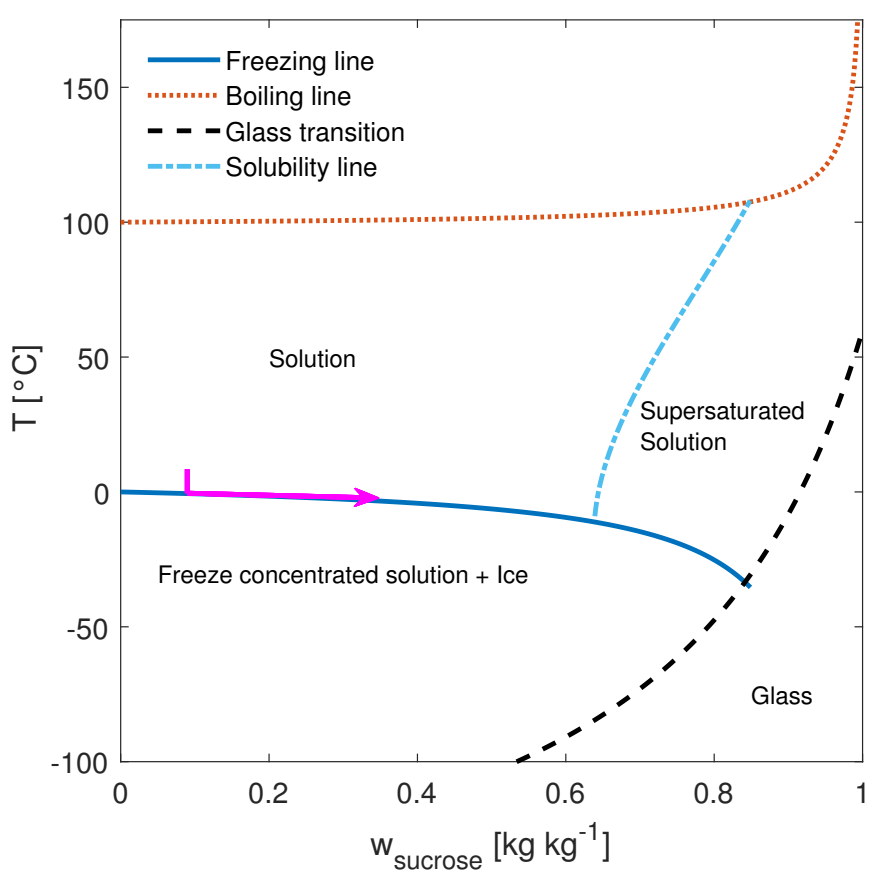

Figure 3.2: State diagram of sucrose after Y. H. Roos (2010) and Sman (2017). The purple arrow indicates the trajectory of the solution during progressive freeze concentration.

tration (eq. (3.12)) (Sman et al. 2019; Y. Roos et al. 1991a; Y. Roos et al. 1991b). For sucrose this value was determined to be $0.62 \mathrm{~kg} / \mathrm{kg}$.

The ultimate end point for freeze concentration would be the point where the freezing line would cross the line of the glass temperature fig. 3.2. At this point a maximally freeze concentrated system would be obtained (Y. Roos et al. 1991a; Y. Roos et al. 1991b). In the glassy state a domain of pure ice and small glassy domains of the maximally freeze concentrated sugar solution would co-exist. Since the diffusion coefficient at the glass temperature is effectively zero, this would imply that the ice would have the exact same composition as the solution, as the solutes cannot diffuse away from the freezing frontier anymore. However, before reaching the glass transition temperature, we have to consider the rapidly increasing viscosity when approaching this solidification point (Williams et al. 1955). This increase in viscosity for sucrose solutions becomes relevant when the solution is super-saturated, especially when working at low temperatures during freeze concentration (Kauzmann 1948). It leads to significant reduction of the mass transfer rate in the boundary layer and as a result the solute concentration gradient in the boundary layer will increase. Due to the higher concentrations, the inclusion rate increases and a less effective separation is achieved. In this case the intrinsic partition coefficient (eq. (3.11)) can be considered to give an indication of the remaining capacity for a carbohydrate system to be concentrated. 

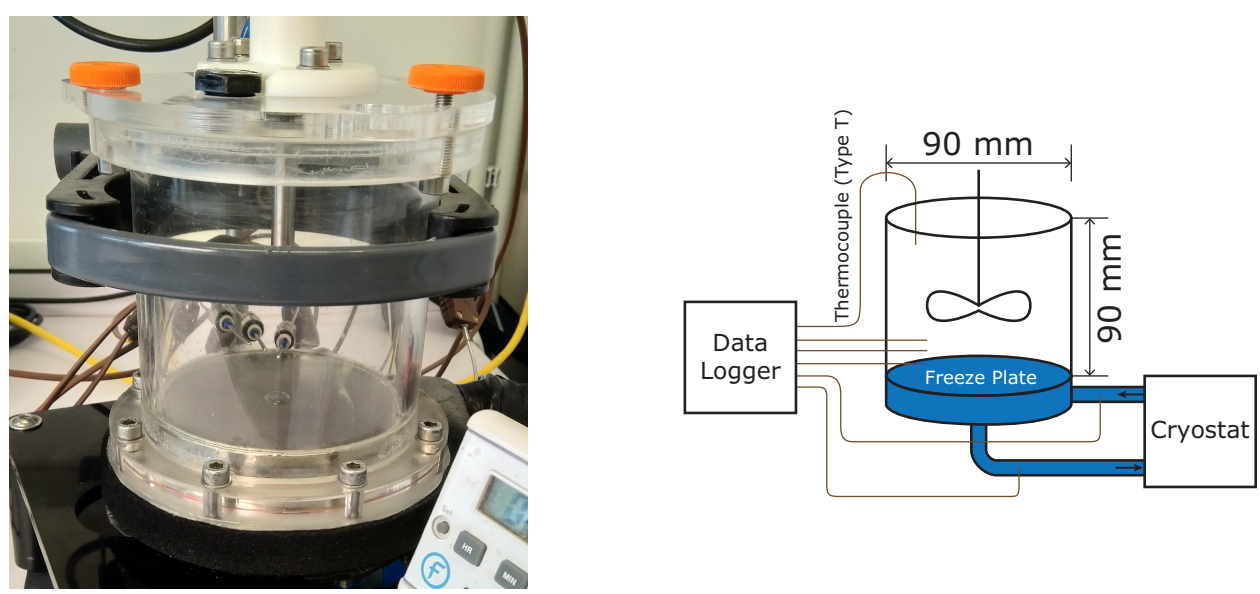

Figure 3.3: Picture (left) and schematic representation (right) of the small-scale setup

\subsection{Material and methods}

\section{Description of the progressive freeze concentrator}

A schematic drawing of the lab scale film freeze concentrator, used in this paper, is shown in fig. 3.3. A similar set-up has been used in previous work (Vuist et al. 2020), compared to this system the volume has been reduced by reducing the height of the cylinder to $90 \mathrm{~mm}$. The system consists of a vessel that contains the solution that needs to be concentrated, separated with a metal plate from a chamber that contains circulating fluid, temperature-controlled by an external cryostat. The experiments are started by first freezing a droplet $(0.1 \mathrm{ml})$ of distilled water to prevent supercooling of the liquid and to avoid spontaneous bulk crystallization of a supercooled liquid. As soon as the droplet is frozen, the precooled liquid feed is added through a funnel. After the vessel has been filled completely, stirring is started. After the experiment the concentrated liquid is drained from the tank and the ice layer is wiped dry with a paper tissue. Subsequently the ice layer is melted. Samples were taken from the liquid at $t=0$ and at $t=$ end, plus a sample was taken from the molten ice. The samples were stored frozen until analysis. For the concentration experiments four different cooling programmes were used: two constant temperature programmes at $5{ }^{\circ} \mathrm{C}$ or $10^{\circ} \mathrm{C}$ below the freezing point of the solution for 1 hour, only applied to the soy protein concentrate, and two decreasing temperature programmes starting $2.5^{\circ} \mathrm{C}$ below the freezing point and then decreasing by $0.1{ }^{\circ} \mathrm{C} /$ minute or $0.5{ }^{\circ} \mathrm{C} /$ minute for 1 hour applied to all solutions. The freezing points of the solutions have been calculated using the Clausius-Clapeyron equation (eq. (3.13)).

$$
\ln \left(1-x_{s}\right)=\frac{\Delta H_{f u s}}{\mathrm{R}}\left(\frac{1}{T_{f p, 0}}-\frac{1}{T_{f p}}\right)
$$

\section{Materials}

Solutions of sucrose, soy protein concentrate (SPC) and whey protein isolate (WPI) solutions were used as feed solutions. Sucrose was obtained from Sigma-Aldrich (USA, BioXtra, purity $>99.5 \%$ ), SPC was obtained from Vitablend (The Netherlands, Unico HS IP, minimum $70 \%$ protein), and WPI was obtained from Davisco (Switzerland, BiPro®, purity $>97.0 \%$ ). 
Sodium phosphate dibasic and sodium phosphate monobasic were obtained from SigmaAldrich (USA, at least analytical grade). All solutions were prepared with ultrapure water from a Milli-Q system (Millipore Corporation, United States).

\section{Methods}

\section{Solution preparation}

Sucrose and WPI solutions were prepared by dissolving sucrose and WPI in ultrapure water. The solutions were stirred at room temperature until everything was dissolved. The SPC solution was prepared by dissolving the SPC overnight at $4{ }^{\circ} \mathrm{C}$ while stirring was applied. The next day the solution was centrifuged for 30 minutes at $16,000 \times \mathrm{G}$ and $4{ }^{\circ} \mathrm{C}$ to remove any residual insoluble particles. The supernatant was then collected to be used as the solution in concentration experiments. The solutions were stored at $0{ }^{\circ} \mathrm{C}$ in an ice bath until usage the next day.

\section{Ice growth measurement}

The ice growth during the freeze concentration of the proteins was monitored by time-lapse pictures taken during the experiment. These pictures were analysed using image analysis software (ImageJ, USA) to determine the ice growth rate (fig. 3.4). The width of the front bolt $(8.38 \mathrm{~mm})$ in the picture is used as a reference for sizing. With this reference, the ratio of pixels per mm was calculated and thus the ice thickness could be quantified.

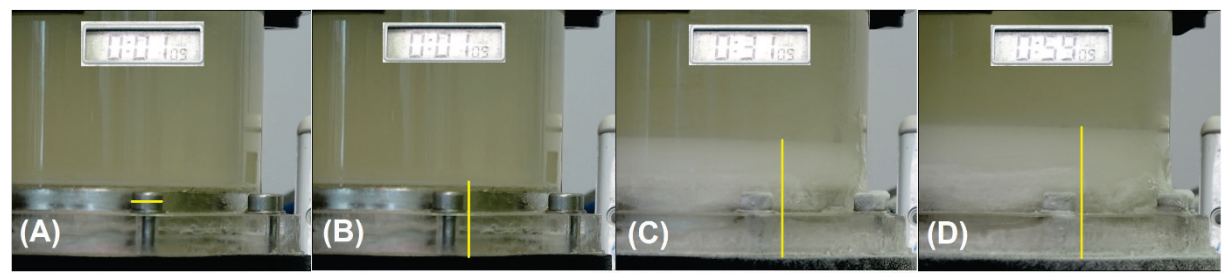

Figure 3.4: Method to measure ice growth; $(A)$ width of the bolt, $(B)$ thickness after 1 min, (C) thickness after $31 \mathrm{~min}$, (D) thickness after $59 \mathrm{~min}$.

\section{Sucrose content}

The sucrose content of the sucrose solution was determined using a refractometer (Anton Paar, Abbemat 500, Germany)

\section{Protein content analysis}

For both the SPC and WPI samples the dry weight was determined. For this, the samples were placed in pre-weighed cups and dried overnight at $105{ }^{\circ} \mathrm{C}$. The SPC samples were further analysed using the Dumas method. Approximately $10 \mathrm{mg}$ of dry sample was weighed in an aluminium cup and then closed. The nitrogen content was measured (ThermoFisher, FlashEA 1112 series $\mathrm{N}$ Analyser, USA) and multiplied with a conversion factor 6.25 to convert the nitrogen content to protein mass. The WPI samples were analysed using HPSEC (Thermo Ultimate 3000 HPLC, ThermoFisher Scientific, USA) on two columns in series (TSKGel G3000SWXL and G2000SWXL, both $5 \mu \mathrm{m} 300 \times 7.8 \mathrm{~mm}$ ) at $30{ }^{\circ} \mathrm{C}$, using UV-Vis detection at $214 \mathrm{~nm}$. The sample size was $10 \mu \mathrm{l}$. The feed samples were diluted 10 times with water, the 
ice fraction samples were used undiluted. The eluent was $30 \%$ Acetonitrile in Milli-Q water with $0.1 \%$ Trifluoracetic acid. The flow rate of the eluent was $1.5 \mathrm{ml}$ per minute.

\section{Equation solving}

The differential equations were solved using a variable order Runge-Kutta method (ode45, Mathworks MATLAB R2019b, USA) (Dormand et al. 1980; Shampine et al. 1997).

\section{Determination of intrinsic partition coefficient}

To determine the intrinsic partition coefficient $K_{0}$, we express the partition coefficient as function of the intrinsic partition coefficient, the ice growth rate and mass transfer coefficient by rearranging eq. (3.10) and using the definition of $K$ (eq. (3.6)) to obtain eq. (3.18). This equation can again be rewritten into eq. (3.19) giving a linear relation between $\ln (1 / K-1)$ and $v_{\text {ice }} / k$ (Pradistsuwana et al. 2003). The mass transfer coefficient, $k$ was determined from the Sherwood relation for stirred tanks (eqs. (3.14) to (3.17)).

$$
\begin{aligned}
\mathrm{N}_{\mathrm{Sh}} & =\frac{k}{D / L} \\
\mathrm{~N}_{\mathrm{Sh}} & =0.36 \mathrm{~N}_{\mathrm{Re}}{ }^{\frac{2}{3}} \mathrm{~N}_{\mathrm{Sc}}{ }^{\frac{1}{3}} \\
\mathrm{~N}_{\mathrm{Re}} & =\frac{\rho N d^{2}}{\mu} \\
\mathrm{N}_{\mathrm{Sc}} & =\frac{\mu}{D \rho} \\
K & =\frac{K_{0}}{K_{0}+\left(1-K_{0}\right) \exp \left(-\frac{v_{\text {ice }}}{k}\right)} \\
\ln \left(\frac{1}{K}-1\right) & =\ln \left(\frac{1}{K_{0}}-1\right)-\frac{v_{\text {ice }}}{k}
\end{aligned}
$$

By fitting this linear equation to experimental data obtained at different ice growth rates and/or stirrer rates we can obtain the intrinsic partition coefficient by extrapolating $v_{\text {ice }} / k \rightarrow 0$ (fig. 3.5). 


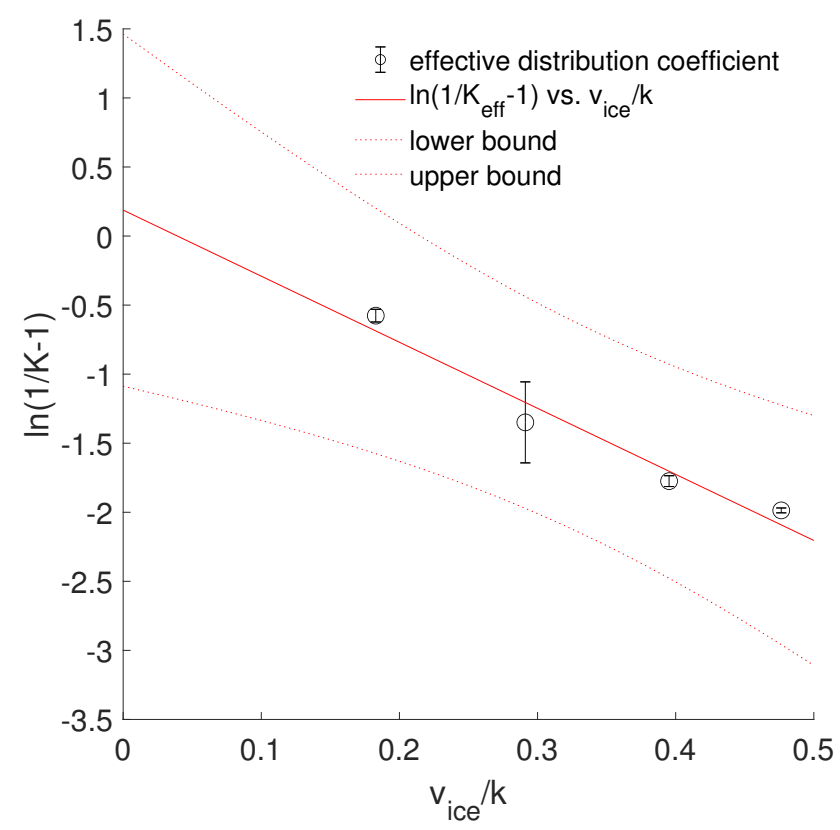

Figure 3.5: Result of linear regression on inclusion data obtained for Soy Protein Concentrate

\subsection{Results and discussion}

\section{Modelling ice growth rate as function of time}

We first measured ice thicknesses as a function of time for different conditions and compared those to the predictions by the energy balance (eq. (3.5))(fig. 3.6). Figure 3.6a shows the ice thickness increase for a $4 \%(\mathrm{w} / \mathrm{w})$ soy protein concentrate solution with a constant plate temperature of $-10{ }^{\circ} \mathrm{C}$ and a stirring rate of $300 \mathrm{rpm}$. There is a slight overestimation of the ice growth in the initial phase, but at larger times the agreement is quite good. This slight overestimation of the initial ice growth may be explained by our use of a fixed density in the model, which is critical for calculating the ice thickness (eq. (3.5)). In the initial phase the growth rate is very high, leading to more inclusions leading to a significantly larger ice volume compared to the ice volume in the model. Figure 3.6b shows the ice growth for the same solution stirred at $700 \mathrm{rpm}$. At this high stirring rate the ice growth is consistently overestimated for the entire process. We expect this is due to the increased heat loss via the side walls of the tank leading to a slowdown of the ice growth in practice. This effect is more pronounced for the $-5{ }^{\circ} \mathrm{C}$ cooling temperature, because at this temperature relatively more cooling capacity is used for compensating the heat influx from the environment than for ice growth.

In fig. 3.6c the ice growth ice is shown using a linear decreasing temperature of the freezing plate with a $4 \%(\mathrm{w} / \mathrm{w})$ SPC solution. The ice thickness increases approximately in linearly, except for an initial lag, which can be observed for the $-0.1{ }^{\circ} \mathrm{C} /$ minute cooling profile. This lag may be caused by two effects that are not taken into account into the model. First, the 


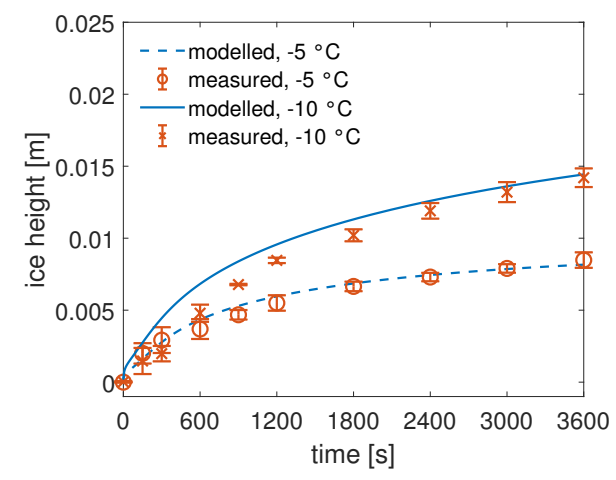

(a) $4 \%(\mathrm{w} / \mathrm{w}) \mathrm{SPC}, 300 \mathrm{rpm}$

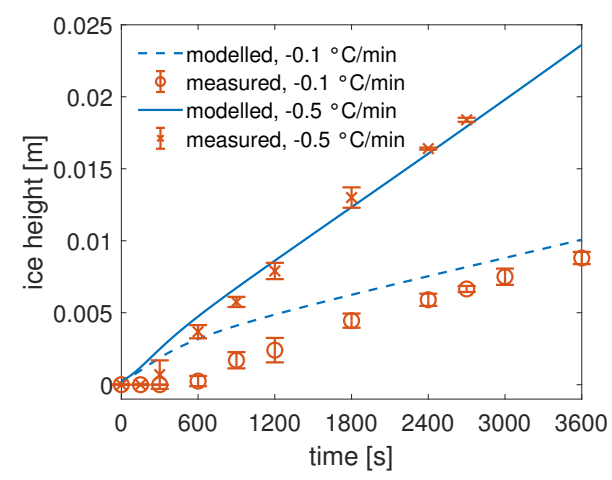

(c) $4 \%(\mathrm{w} / \mathrm{w})$ SPC, $300 \mathrm{rpm}$

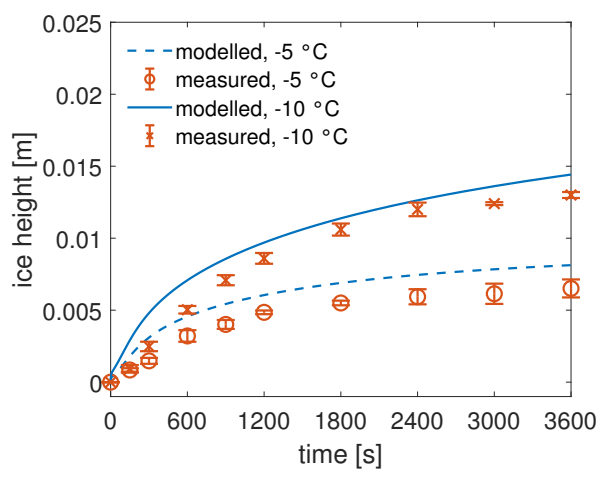

(b) $4 \%(\mathrm{w} / \mathrm{w})$ SPC, $700 \mathrm{rpm}$

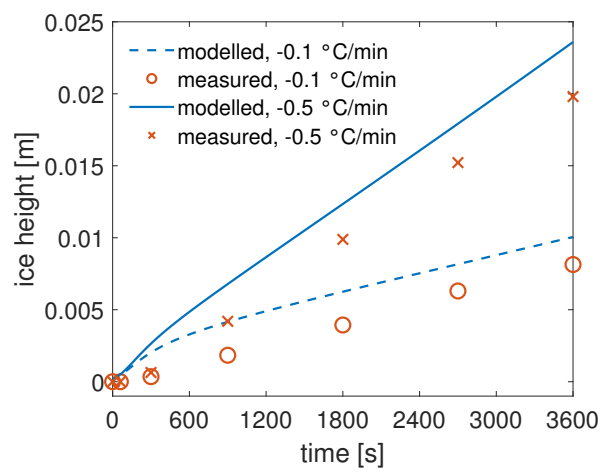

(d) $4 \%(\mathrm{w} / \mathrm{w}) \mathrm{WPI}, 500 \mathrm{rpm}$

Figure 3.6: Modelled and measured ice growth for SPC and WPI at different cooling profiles and different stirring rates for 1 hour.

gradual cooling of the walls of the cylinder and the heat influx from the environment have not been taken into account, and these effect are relatively large for a small temperature difference between the liquid and the coolant, relative to the heat removed for ice growth. A second aspect is the crystallisation kinetics (Myerson et al. 2019). At $-0.5^{\circ} \mathrm{C} /$ minute the lag is not noticable, as the faster decrease in temperature dominates.

In fig. 3.6d, freeze concentration with the same temperature ramps is shown for a $4 \%(\mathrm{w} / \mathrm{w})$ WPI solution. One may compare with fig. 3.6c for a 4\% SPC solution. The calculated values for ice height are almost similar. This is expected as both solutions have similar density, viscosity and heat conductivity. However a systematic overestimation is observed for the Whey Protein Isolate solution. This overestimation is probably caused by the ice being purer, as we will show below, and thus the ice has a lower volume than the ice during freeze concentration with SPC since there are less inclusions. For all solutions concentrated the ice growth rate was around $1 \mu \mathrm{m} / \mathrm{s}$ for $0.1{ }^{\circ} \mathrm{C} /$ minute cooling and $5 \mu \mathrm{m} / \mathrm{s}$ for $0.5^{\circ} \mathrm{C} /$ minute. These values are inline with the values reported in literature (Miyawaki et al. 2005; Gunathilake et al. 2013; Moreno et al. 2014).

The calculated and measured ice masses after one hour of freeze concentration are compared in fig. 3.7. For the constant cold wall temperature conditions the calculated values 


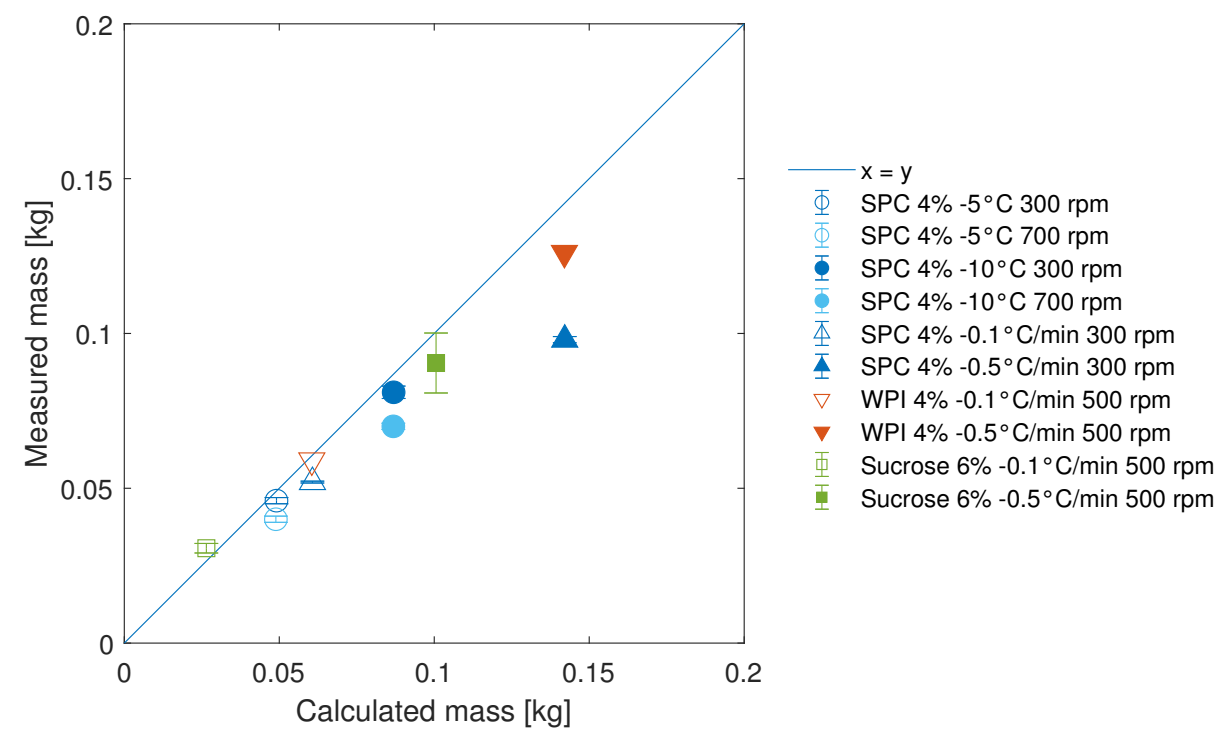

Figure 3.7: Parity plot between the calculated ice mass and measured ice mass after 1 hour of freeze concentration.

are relatively close to the parity line. The calculated values for the $0.1{ }^{\circ} \mathrm{C} /$ minute decreasing ramp show a similar trend for both SPC and WPI, slightly overestimating the ice mass formed. The calculated values for $0.5{ }^{\circ} \mathrm{C} /$ minute WPI show a slightly larger overestimation than for the $0.1{ }^{\circ} \mathrm{C} /$ minute decrease and SPC shows an even larger overestimation. This is probably caused by more solute inclusions. The inclusions of pockets of highly concentrated solution reduce the conductivity (Kestin et al. 1984; Bonales et al. 2017). While the larger volume and thus thickness of the ice layer also reduces the conductance. Both effects slow the ice growth more than predicted by our model that does not include these effects.

\section{Solute inclusion}

Solute inclusion has been modelled according to eq. (3.10) and is presented in fig. 3.8 as the average solute distribution, together with the measured solute inclusion. The solute inclusion with a cooling ramp of $0.5^{\circ} \mathrm{C}$ per minute is underestimated for all the solutes. The increased concentration polarisation at a higher ice growth rate causes more inclusion than would be expected from the concentration in the bulk. This increased concentration polarisation may again lead to a more supercooling and thus formation of dendritic ice crystals, which leads to increased solute inclusion (Myerson et al. 2019). The formation of dendritic ice crystals is obviously not taken into account in the current model. The obtained measured inclusions for sucrose are found similar to those reported by Miyawaki et al. (2005). Since the whey protein used in our experiments contains almost no lactose and salts we have found hardly any inclusion of protein in our experiments at low ice growth rates. Sánchez et al. (2011) reported distribution coefficients range from 0.25 to 0.45 depending on the solids concentration.

For the sucrose solutions concentrated with a cooling ramp of $0.1^{\circ} \mathrm{C}$ per minute, the solute inclusion for the $6 \%(\mathrm{w} / \mathrm{w})$ sucrose solution is overestimated while for the other solutions 


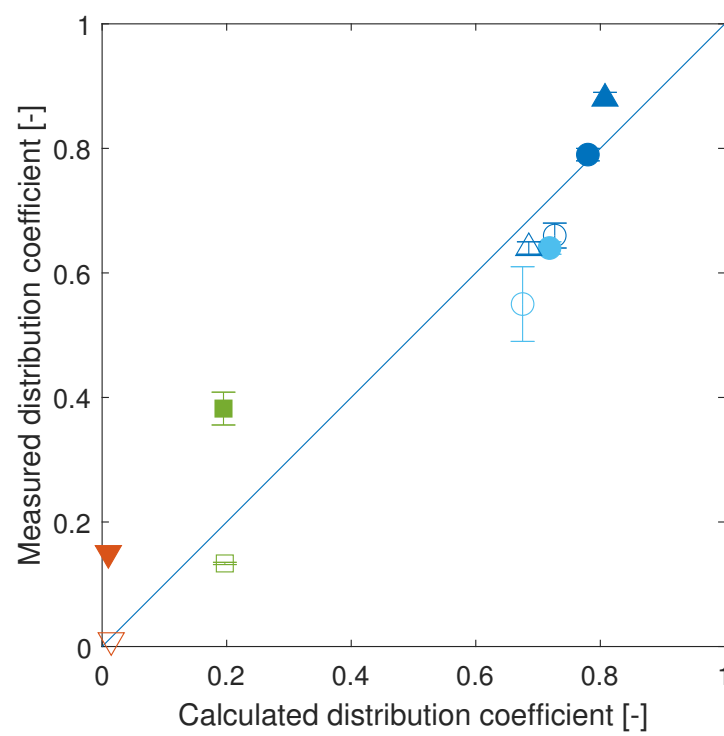

$\mathrm{x}=\mathrm{y}$

SPC $4 \%-5^{\circ} \mathrm{C} 300 \mathrm{rpm}$

SPC $4 \%-5^{\circ} \mathrm{C} 700 \mathrm{rpm}$

SPC $4 \%-10^{\circ} \mathrm{C} 300 \mathrm{rpm}$

SPC $4 \%-10^{\circ} \mathrm{C} 700 \mathrm{rpm}$

SPC $4 \%-0.1^{\circ} \mathrm{C} / \mathrm{min} 300 \mathrm{rpm}$

SPC $4 \%-0.5^{\circ} \mathrm{C} / \mathrm{min} 300 \mathrm{rpm}$

WPI $4 \%-0.1^{\circ} \mathrm{C} / \mathrm{min} 500 \mathrm{rpm}$

WPI $4 \%-0.5^{\circ} \mathrm{C} / \mathrm{min} 500 \mathrm{rpm}$

Sucrose $6 \%-0.1^{\circ} \mathrm{C} / \mathrm{min} 500 \mathrm{rpm}$

Sucrose $6 \%-0.5^{\circ} \mathrm{C} / \mathrm{min} 500 \mathrm{rpm}$

Figure 3.8: Parity plot between calculated distribution coefficients and measured distribution coefficients after 1 hour of freeze concentration.

the solute inclusion is underestimated (fig. 3.8). This is caused by a larger supercooling at these concentrations. Even though the cooling profile was adjusted for each solution to yield the same $\Delta T$ considering the freezing point depression, the initial temperature could not be adjusted. This causes an initial delay in ice growth and therefore the cooling profile already had progressed to a lower temperature (fig. 3.6). This leads to more supercooling near the cold wall resulting in the formation of ice dendrites.

A large difference in inclusion can be noticed between soy protein and whey protein solutions (fig. 3.8). Soy protein leads to much inclusion while whey protein gives very low to almost no inclusion. The main difference between the two solutions is the solubility of the proteins (Shen 1976; Elgedaily et al. 1982). Whey protein isolate contains highly soluble globular proteins (Sánchez et al. 2011). In contrast, SPC consists for a large part of insoluble particles. Compared to soluble proteins, the diffusion rate of particles is negligible, and therefore these particles will be included in the ice. For SPC, this is almost $80 \%$ of all proteins. WPI is so well soluble, and can diffuse from the ice freezing front into the bulk solution.

\section{Outlook to future application of the model and optimization of the process}

Even though there are some deviations from the experiments, the model is sufficiently accurate for exploring untested conditions and for optimising the process. One case of interest would be to optimise the process to reach a certain ice layer thickness, instead of comparing cooling strategies with a fixed end time. This would involve the comparison of the inclusion behaviour between the different cooling rates, towards the same amount of ice generated. fig. 3.9 shows the results for a WPI solution at an initial solid content of $4 \%(\mathrm{w} / \mathrm{w})$ and for sucrose solutions at 6,18 , and $36 \%(\mathrm{w} / \mathrm{w})$ solid content. Most remarkable is that the level of inclusions is almost 


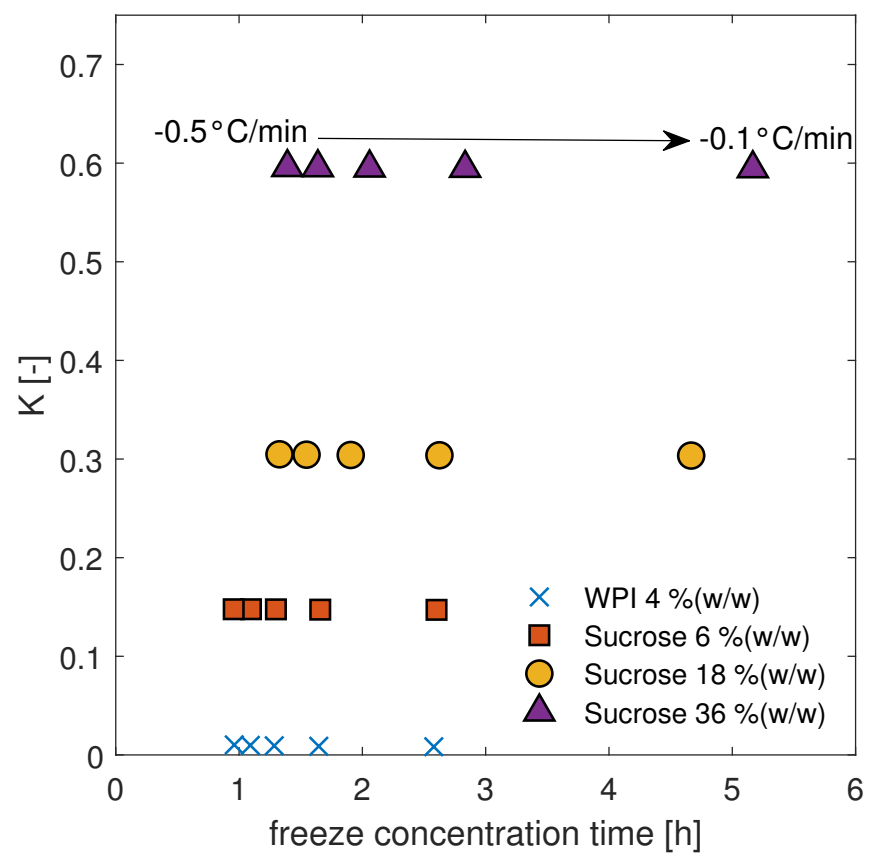

Figure 3.9: Simulation results of freeze concentration for varying cooling rates ending at a fixed ice layer thickness $(2.25 \mathrm{~cm})$. The effective distribution coefficient as function of time to freeze concentrate till the set ice thickness.

constant between the lowest cooling rate $\left(-0.1^{\circ} \mathrm{C}\right.$ per minute) and the highest cooling rate ($0.5^{\circ} \mathrm{C}$ per minute). This indicates that while there is a higher inclusion rate at higher cooling rates, the averaged level of inclusions per $\mathrm{kg}$ of formed ice is nearly constant, while the ice growth rates are $\approx 1 \mu \mathrm{m} / \mathrm{s}$ and $5 \mu \mathrm{m} / \mathrm{s}$ respectively. This means that only the mass transfer near the ice boundary is of influence on the efficiency of progressive freeze concentration (Liu et al. 1997; Vuist et al. 2020). Within the range of the ice growth rate, the distribution coefficient is only weakly dependent on the ice growth rate. The value of $\mathrm{K}$ varies from 0.2903 to 0.2935 for a range of ice growth rates between 0 and $10 \mu \mathrm{m} / \mathrm{s}$.

The model can be used to evaluate the evolution of ice yield and solute inclusion in time for different process conditions. In fig. 3.10 the simulation results for $18 \%(\mathrm{w} / \mathrm{w})$ sucrose are presented. As expected there is a steep initial ice growth followed by a constant freezing rate fig. 3.10a. This initial growth is reflected in the effective partition coefficient (fig. 3.10b), which starts at a high value; then levels off and then continues to decrease slowly due to the increasing concentration in the bulk fluid (fig. 3.10c), which increases faster than the increase in concentration in the ice (fig. 3.10d).

An optimum in solute inclusion is shown in fig. $3.10 \mathrm{~d}$ after around $10 \%$ of the end time. This could be chosen as an end point for the process when optimizing for the lowest possible level of solute inclusion. The minimum effective distribution coefficient is lower at lower ice 


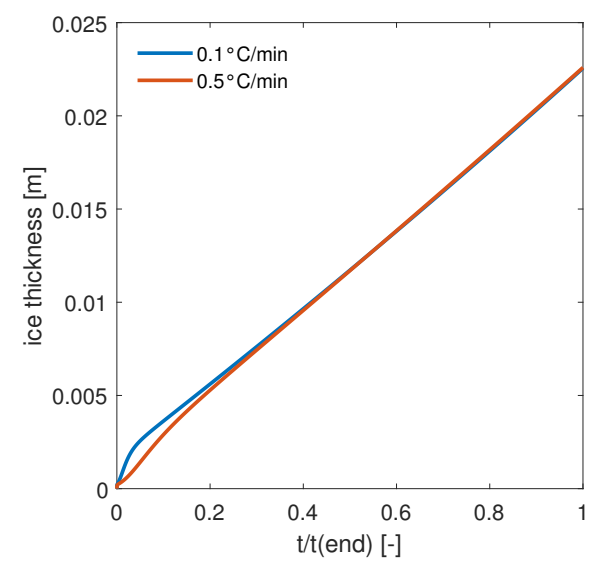

(a) Ice thickness

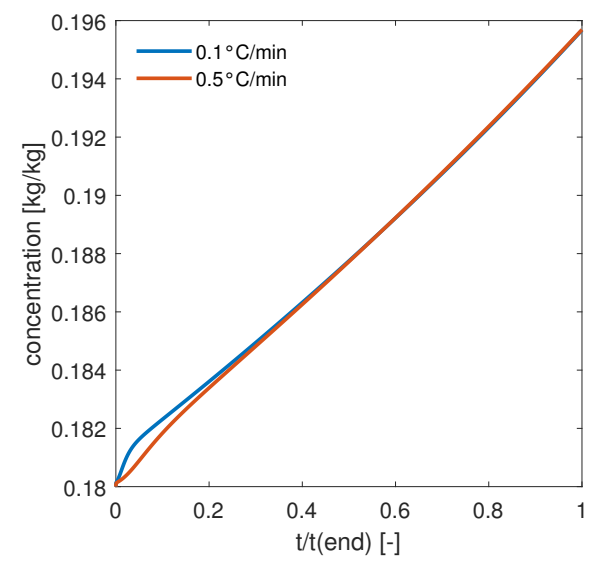

(c) Concentration in solution

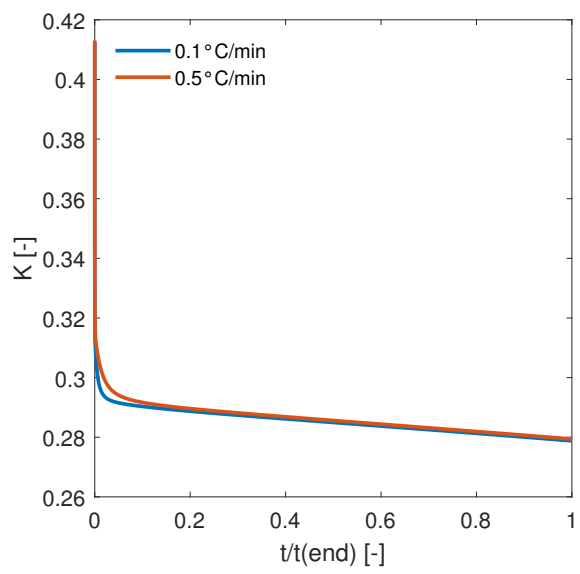

(b) Effective distribution coefficient

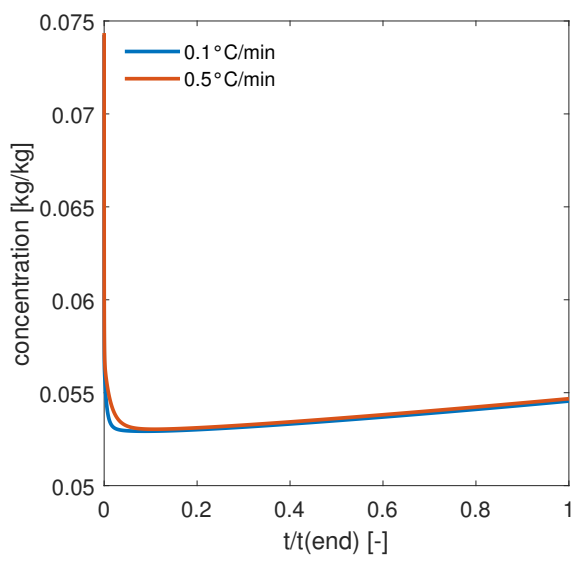

(d) Concentration in ice

Figure 3.10: Concentration of $18 \%(w / w)$ sucrose at two cooling rates, calculated. 
growth rates and could be lowered even further, for example by improving the mass transfer rate. However, in practice, the end point can be chosen to be later to allow for a thicker ice layer since the increase of concentration in the ice, and therefore the solute loss, is not steep after this point. This thicker ice layer would allow for a more productive unit. These results also show that the cooling surface to volume ratio should be as high as possible to achieve a high concentration factor in a single step.

\subsection{Conclusion}

Progressive freeze concentration was studied using a lab-scale progressive freeze concentrator. A model based on an energy and mass balance was created, using an effective distribution coefficient for solute inclusion. The intrinsic distribution coefficient for sucrose solutions depends on the initial sucrose concentration and on the critical (saturation) concentration, which is probably related to the fast increase in viscosity and reduction in diffusivity when a sucrose solution gets closer to the glass transition. Solutions of proteins behave differently, since their freezing line is flatter, and their solutions in the concentration polarization layer do not come near their glass transition line. Whey protein isolate, which is well soluble, gives very low inclusions; but soy protein isolate, which mostly consists of small insoluble protein particles gives very large levels of inclusions, up to $80 \%$. The freezing rate has little influence on the achieved effective distribution coefficient, when evaluated at similar amounts of ice produced. The model did indicate a minimum in the level of inclusions, which may be used in the design of the process towards optimal concentration. 


\section{References}

Auleda, J. M., M. Raventós, and E. Hernández (Nov. 2011). "Calculation method for designing a multiplate freeze-concentrator for concentration of fruit juices". In: Journal of Food Engineering 107.1, pp. 27-35. ISSN: 0260-8774. DOI: 10.1016/J . JFOODENG . 2011.06.006 (cit. on pp. 33, 34).

Berk, Zeki (2009). "Freeze drying (lyophilization) and freeze concentration". In: Food Process Engineering and Technology. Elsevier, pp. 929-945. ISBN: 9780123736604. DOI: 10 . 1016/B978-012-415923-5.00023-X (cit. on p. 33).

Bonales, L. J., A. C. Rodriguez, and P. D. Sanz (Dec. 2017). "Thermal conductivity of ice prepared under different conditions". In: International Journal of Food Properties 20.sup1, pp. 610-619. ISSN: 1094-2912. DOI: 10.1080/10942912.2017.1306551 (cit. on p. 43).

Burton, J. A., E. D. Kolb, W. P. Slichter, and J. D. Struthers (Nov. 1953a). "Distribution of Solute in Crystals Grown from the Melt. Part II. Experimental". In: The Journal of Chemical Physics 21.11, pp. 1991-1996. ISSN: 0021-9606. DOI: 10.1063/1.1698729 (cit. on pp. 35, 36).

- (Nov. 1953b). "Distribution of Solute in Crystals Grown from the Melt. Part II. Experimental". In: The Journal of Chemical Physics 21.11, pp. 1991-1996. ISSN: 0021-9606. DOI: 10 . 1063/1 . 1698729 (cit. on p. 36).

Chen, Ping and Xiao Dong Chen (Apr. 2000). "A generalized correlation of solute inclusion in ice formed from aqueous solutions and food liquids on sub-cooled surface". In: Canadian Journal of Chemical Engineering 78.2 (2), pp. 312-319. ISSN: 0008-4034. DOI: 10.1002/cjce.5450780205 (cit. on p. 34).

Chen, Xiao Dong, Winston Duo Wu, and Ping Chen (Apr. 2015). "An analytical relationship of concentrationdependent interfacial solute distribution coefficient for aqueous layer freeze concentration". In: AIChE Journal 61.4, pp. 1334-1344. ISSN: 0001-1541. DOI: 10.1002/aic. 14722 (cit. on p. 34).

Dormand, J. R. and P. J. Prince (Mar. 1980). "A family of embedded Runge-Kutta formulae”. In: Journal of Computational and Applied Mathematics 6.1, pp. 19-26. ISSN: 0377-0427. DOI: 10.1016/0771050X (80) 90013-3 (cit. on p. 40).

Elgedaily, A., A. M. Campbell, and M. P. Penfield (May 1982). "Solubility and Water Absorption of Systems Containing Soy Protein Isolates, Salt and Sugar". In: Journal of Food Science 47.3, pp. 806809. ISSN: 0022-1147. DOI: 10.1111/j.1365-2621.1982.tb12719.x (cit. on p. 44).

Flesland, Ola (1995). "Freeze concentration by layer crystallization". In: Drying Technology 13.8-9, pp. 1713-1739. ISSN: 0737-3937. DOI: 10.1080/07373939508917048 (cit. on pp. 33, 34).

Gu, X., T. Suzuki, and Osato Miyawaki (May 2006). "Limiting Partition Coefficient in Progressive Freeze-concentration". In: Journal of Food Science 70.9, E546-E551. ISSN: 0022-1147. DOI: 10. 1111/j.1365-2621.2005. tb08317.x (cit. on pp. 34, 36).

Gunathilake, Mihiri, Kiyomi Shimmura, and Osato Miyawaki (2013). "Analysis of solute distribution in ice formed in progressive freeze-concentration". In: Food Science and Technology Research 19.3, pp. 369-374. ISSN: 1344-6606. DOI: 10.3136/fstr. 19.369 (cit. on pp. 34, 36, 42).

Halde, Rolf (Jan. 1980). "Concentration of impurities by progressive freezing”. In: Water Research 14.6, pp. 575-580. ISSN: 0043-1354. DOI: 10.1016/0043-1354 (80) 90115-3 (cit. on p. 33).

Kadi, Khadije El and Isam Janajreh (2017). "Desalination by Freeze Crystallization: An Overview". In: Int. J. of Thermal \& Environmental Engineering 15.2 (2), pp. 103-110. DOI: 10.5383/i jtee. 15. 02.004 (cit. on p. 33).

Kauzmann, Walter. (Oct. 1948). "The Nature of the Glassy State and the Behavior of Liquids at Low Temperatures." In: Chemical Reviews 43.2, pp. 219-256. ISSN: 0009-2665. DOI: 10. 1021/cr60135a002 (cit. on p. 37).

Kestin, J., J. V. Sengers, B. Kamgar-Parsi, and J. M. H. Levelt Sengers (Jan. 1984). "Thermophysical Properties of Fluid H2O”. In: Journal of Physical and Chemical Reference Data 13.1, pp. 175-183. ISSN: 0047-2689. DOI: 10.1063/1.555707 (cit. on p. 43).

Liu, Ling, Osato Miywaki, and Kozo Nakamura (1997). "Progressive Freeze-Concentration of Model Liquid Food." In: Food Science and Technology International, Tokyo 3.4 (4), pp. 348-352. ISSN: 1341-7592. DOI: 10.3136/fsti9596t9798.3.348 (cit. on pp. 33, 45). 
Meiwa Co. Ltd (Jan. 2018). Meiwa Co., Ltd. URL: https ://www.meiwa-ind.co.jp/en/products/ product-06/ (cit. on p. 33).

Miyawaki, Osato, Ling Liu, and Kozo Nakamura (Sept. 1998). "Effective partition constant of solute between ice and liquid phases in progressive freeze-concentration". In: Journal of Food Science 63.5 (5), pp. 756-758. ISSN: 0022-1147. DOI: 10.1111/j.1365-2621.1998.tb17893.x (cit. on p. 34).

Miyawaki, Osato, Ling Liu, Yoshito Shirai, Shigeru Sakashita, and Kazuo Kagitani (July 2005). "Tubular ice system for scale-up of progressive freeze-concentration”. In: Journal of Food Engineering 69.1 (1), pp. 107-113. ISSN: 0260-8774. DOI: $10.1016 / \mathrm{j} \cdot \mathrm{j}$ foodeng . 2004.07 .016 (cit. on pp. 33, 42, 43).

Moreno, F. L., M. Raventós, E. Hernández, and Y. Ruiz (Jan. 2014). "Block freeze-concentration of coffee extract: Effect of freezing and thawing stages on solute recovery and bioactive compounds". In: Journal of Food Engineering 120, pp. 158-166. ISSN: 0260-8774. DOI: 10.1016/J . JFOODENG . 2013.07.034 (cit. on pp. 33, 42).

Myerson, Allan S., Deniz Erdemir, and Alfred Y. T. A. T. T. Lee (2019). "Handbook of Industrial Crystallization". English. In: Handbook of Industrial Crystallization. Third edit. Cambridge ; Cambridge University Press. Chap. 9, pp. 266-289. ISBN: 9781139026949 1139026941. DOI: 10.1017/ 9781139026949 (cit. on pp. 42, 43).

Ojeda, A., F. L. Moreno, R. Y. Ruiz, M. Blanco, M. Raventós, and E. Hernández (Aug. 2017). "Effect of Process Parameters on the Progressive Freeze Concentration of Sucrose Solutions". In: Chemical Engineering Communications 204.8, pp. 951-956. ISSN: 0098-6445. DOI: 10 . 1080/00986445. 2017.1328413 (cit. on p. 33).

Petzold, Guillermo, Jorge Moreno, Paz Lastra, Katerin Rojas, and Patricio Orellana (Aug. 2015). "Block freeze concentration assisted by centrifugation applied to blueberry and pineapple juices". In: Innovative Food Science \& Emerging Technologies 30, pp. 192-197. ISSN: 1466-8564. DOI: 10.1016/ J.IFSET . 2015.03.007 (cit. on p. 33).

Pradistsuwana, Chidphong, Prapasri Theprugsa, and Osato Miyawaki (2003). "Measurement of Limiting Partition Coefficient in Progressive Freeze-Concentration”. In: Food Science and Technology Research 9.2, pp. 190-192. ISSN: 1344-6606. DOI: 10.3136/fstr.9.190 (cit. on p. 40).

Rane, Milind V. and Siddharth K. Jabade (Oct. 2005). "Freeze concentration of sugarcane juice in a jaggery making process”. In: Applied Thermal Engineering 25.14-15 (14-15), pp. 2122-2137. ISSN: 1359-4311. DOI: 10.1016/j . applthermaleng. 2005.01.014 (cit. on pp. 33, 34).

Ratkje, Signe Kjelstrup and Ola Flesland (1995). "Modelling the freeze concentration process by irreversible thermodynamics". In: Journal of Food Engineering 25.4, pp. 553-568. ISSN: 0260-8774. DOI: 10.1016/0260-8774 (94)00034-7 (cit. on pp. 33, 34).

Raventós, M., E. Hernández, J. Auleda, and A. Ibarz (Mar. 2007). "Concentration of aqueous sugar solutions in a multi-plate cryoconcentrator". In: Journal of Food Engineering 79.2, pp. 577-585. ISSN: 0260-8774. DOI: 10.1016/j · jfoodeng. 2006.02.017 (cit. on p. 33).

Roos, Yrjö and Marcus Karel (June 1991a). "Amorphous state and delayed ice formation in sucrose solutions". In: International Journal of Food Science \& Technology 26.6, pp. 553-566. ISSN: 09505423. DOI: $10.1111 /$ j.1365-2621.1991.tb02001.x (cit. on p. 37).

- (Jan. 1991b). "Phase Transitions of Amorphous Sucrose and Frozen Sucrose Solutions". In: Journal of Food Science 56.1, pp. 266-267. ISSN: 0022-1147. DOI: 10 . 1111/ j . 1365-2621 . 1991. tb08029.x (cit. on p. 37).

Roos, Yrjö H. (Apr. 2010). "Glass Transition Temperature and Its Relevance in Food Processing”. In: Annual Review of Food Science and Technology 1.1, pp. 469-496. ISSN: 1941-1413. DOI: 10.1146/ annurev. food.102308.124139 (cit. on p. 37).

Sánchez, J., E. Hernández, J. M. Auleda, and M. Raventós (Feb. 2011). "Review: Freeze Concentration Technology Applied to Dairy Products". In: Food Science and Technology International 17.1 (1), pp. 5-13. ISSN: 1082-0132. DOI: 10.1177/1082013210382479 (cit. on pp. 33, 43, 44).

Scholz, R., K. Wangnick, and J. Ulrich (Aug. 1993). "On the distribution and movement of impurities in crystalline layers in melt crystallization processes". In: Journal of Physics D: Applied Physics 26.8B, B156-B161. ISSN: 0022-3727. DOI: 10.1088/0022-3727/26/8B/025 (cit. on p. 34). 
Scholz, Reinhard (1993). "Die Schichtkristallisation als thermisches Trennverfahren". German. PhD thesis. Dusseldorf: Universitat Bremen (cit. on p. 34).

Shampine, Lawrence F. and Mark W. Reichelt (Jan. 1997). “The MATLAB ODE Suite”. In: SIAM Journal on Scientific Computing 18.1, pp. 1-22. ISSN: 1064-8275. DOI: 10.1137/S1064827594276424 (cit. on p. 40).

Shen, Jerome L. (July 1976). "Solubility profile, intrinsic viscosity, and optical rotation studies of acid precipitated soy protein and of commercial soy isolate". In: Journal of Agricultural and Food Chemistry 24.4, pp. 784-788. ISSN: 0021-8561. DOI: 10.1021/jf60206a044 (cit. on p. 44).

Sman, R. G. M. van der (Apr. 2016). "Phase field simulations of ice crystal growth in sugar solutions". In: International Journal of Heat and Mass Transfer 95, pp. 153-161. ISSN: 0017-9310. DOI: 10. 1016/j.ijheatmasstransfer . 2015.11.089 (cit. on p. 33).

- (2017). "Predicting the solubility of mixtures of sugars and their replacers using the Flory-Huggins theory”. In: Food \& Function 8.1, pp. 360-371. ISSN: 2042-6496. DOI: 10 . 1039/ C6F001497F (cit. on pp. 33, 37).

Sman, R. G. M. van der and Lisa J. Mauer (2019). "Starch gelatinization temperature in sugar and polyol solutions explained by hydrogen bond density". In: Food Hydrocolloids 94, pp. 371-380. ISSN: 0268-005X. DOI: 10.1016/j . foodhyd.2019.03.034 (cit. on p. 37).

Vuist, Jan Eise, Remko M. Boom, and Maarten A. I. Schutyser (Mar. 2020). "Solute inclusion and freezing rate during progressive freeze concentration of sucrose and maltodextrin solutions". In: Drying Technology, pp. 1-9. ISSN: 0737-3937. DOI: 10.1080/07373937.2020.1742151 (cit. on pp. 33, 38, 45).

Williams, Malcolm L., Robert F. Landel, and John D. Ferry (July 1955). “The Temperature Dependence of Relaxation Mechanisms in Amorphous Polymers and Other Glass-forming Liquids". In: Journal of the American Chemical Society 77.14, pp. 3701-3707. ISSN: 0002-7863. DOI: 10 . 1021 / ja01619a008 (cit. on p. 37). 


\section{Freeze concentration of protein-sucrose-salt mixtures}

This chapter has been accepted for publication as:

Vuist, J. E., Boom, R. M., \& Schutyser, M. A. I. (2021).

Progressive freeze concentration of protein-sucrose-salt mixtures. Innovative Food Science and Emerging Technologies. 


\begin{abstract}
Progressive freeze concentration of whey protein solutions is evaluated. Since solutions in industry are more complex, the effect of the addition of sodium chloride and sucrose on the inclusion behaviour is studied as well. Using a progressive freeze concentrator solutions of whey protein and mixtures of whey protein and/or sucrose and/or sodium chloride were freeze concentrated. At an initial concentration of $4 \%(\mathrm{w} / \mathrm{w})$, whey proteins were not included in the ice fraction. At higher concentrations the inclusions are caused by the increase in viscosity in the boundary layer, impeding mass transfer. The addition of sucrose caused a similar effect. Presence of sodium chloride causes inclusions through the occurrence of a zone where the solution is locally super-cooled and leads to the formation of dendritic ice which encapsulates pockets of solution in the ice layer. Mixtures of both sucrose and sodium chloride gave no additive effect on solute inclusion but just a concurrent effect.
\end{abstract}

Nomenclature

\begin{tabular}{lll}
\hline Symbol & Description & Unit \\
\hline$C_{b}$ & Initial concentration & $\%(\mathrm{w} / \mathrm{w})$ \\
$C_{i}$ & Concentration in ice fraction & $\%(\mathrm{w} / \mathrm{w})$ \\
$C_{l}$ & Concentration in concentrate & $\%(\mathrm{w} / \mathrm{w})$ \\
$C F$ & Concentration factor & - \\
$K$ & Distribution coefficient & - \\
\hline
\end{tabular}




\subsection{Introduction}

Protein recovery in the food industry from side streams that may contain plant or dairy proteins, has gained increasing interest as it not only can prevent pollution, but can also yield a high value protein product (Waglay et al. 2014). During recovery these proteins need to be concentrated and dried. For concentration, typically processing steps such as evaporation under reduced pressure, or reversed osmosis are applied. Even evaporation at reduced pressure imposes a significant thermal load to the proteins and thus negatively affects the properties of the proteins. Reversed osmosis is a milder concentration method, but is limited in the concentration factor it can achieve, due to the rapid increase in the osmotic pressure at higher concentrations. Therefore, in this study we investigate freeze concentration as a method to concentrate protein aqueous streams. A major advantage of freeze concentration is the very low temperature during processing, which retains the quality of the proteins by for example retarding undesired proteolysis and browning (Janson et al. 1974; Deshpande et al. 1984; Voudouris et al. 2017). Freeze concentration is performed by selective growth of ice crystals in suspension or in an ice layer. The latter approach, often referred to as progressive freeze concentration, is less known than suspension freeze concentration, but requires less complicated and thus more economic equipment (Sánchez et al. 2011b). After an ice layer is grown the concentrated solution is drained from the system, and the ice is melted and drained in its turn. The cycle can then be repeated.

In literature, only few scientific studies on progressive freeze concentration have been reported. The solutions evaluated ranged from pure solutions comprising only bovine serum albumin (Janson et al. 1974; Singh et al. 2006) to more realistic streams, such as dairy streams (Dickey et al. 1995; Sánchez et al. 2011a; Sánchez et al. 2011b; Belen et al. 2018; Bona Muñoz et al. 2019) and tofu process streams (Belén et al. 2012; Belén et al. 2013). Janson et al. (1974) assessed progressive freeze concentration for dilute $((<0.2 \%(\mathrm{w} / \mathrm{v}))$ serum albumin solutions with varying concentrations of salt. They concluded that freeze concentration is suitable for concentration of dilute protein solutions and showed that the native protein activity was preserved. However, they also observed that at higher protein or salt concentrations the protein yield was reduced due to increased protein inclusion in the ice. Sánchez et al. (2011a) evaluated falling film freeze concentration of whey on pilot scale and observed that the loss of dry matter increased at higher concentrations. Unfortunately, they did not analyse whether specific proteins of the whey were lost more than other proteins present in the whey. Belen et al. (2018) noticed during freeze concentration that lowering the salt concentration in whey improved the separation efficiency. We therefore hypothesize that the inclusion of protein in the ice is influenced by the change in freezing point due to the low-molecular weight components that accumulate in the concentration polarization layer. We think that the difference between salts and sucrose is created by the very high viscosity of the high concentrations of sucrose in this polarization layer in combination with the low temperatures, giving rise to high viscosities and concurrent low diffusivities of the protein in this polarization layer.

Most industrially relevant streams that may be subjected to freeze concentration are mixtures of different solutes. Specifically, most protein solution contain salts and carbohydrates, which may affect the inclusion of the proteins. To mimic such industrially relevant solutions, we investigate the influence of sodium chloride and sucrose as model components on the progressive freeze concentration of whey protein isolate. Whey protein was chosen as model protein as it is well-soluble and readily available in high purity. The freeze concentra- 
tion experiments were performed on lab scale in a stirred vessel with a cooling plate at the bottom, using optimal freeze concentration conditions based on our earlier work (Vuist et al. 2020). For different combinations of whey protein isolate, sodium chloride and/or sucrose, we determined the solute inclusion in the ice and the liquid solute concentration to establish the effective overall distribution coefficient. A systematic set of experiments allowed us to distinguish between the effect of various sucrose and sodium chloride concentrations and combinations thereof on the performance of the freeze concentration. We employed a range of sucrose and sodium chloride concentrations that seem realistic for future application and can be expected to affect the charge of the proteins and viscosity of the solution and therefore protein functionality (Ghanimah et al. 2018). To test the hypotheses for more concentrated whey protein solutions, an additional set of experiments was conducted at a higher initial concentration of whey protein isolate.

\subsection{Materials and methods}

\section{Materials and solution preparation}

Whey protein isolate ( $>99 \%$ protein, $<0.5 \%$ fat and lactose, BiPro ${ }^{\mathrm{TM}}$ ) was purchased from Davisco (Switzerland). Sucrose and sodium chloride were obtained from Sigma-Aldrich (Germany) and were of analytical grade ( $>99.5 \%$ pure). Solutions with whey protein isolate were prepared at $4,6,8,10$, and $12 \%(\mathrm{w} / \mathrm{w})$ dry matter. Whey protein isolate and sucrose mixtures were prepared at $4 \%(\mathrm{w} / \mathrm{w})$ whey protein isolate and $0.5,1$, or $4 \%(\mathrm{w} / \mathrm{w})$ sucrose and a set at $8 \%(\mathrm{w} / \mathrm{w})$ whey protein isolate and 1 or $4 \%(\mathrm{w} / \mathrm{w})$ sucrose was prepared. Whey protein isolate and sodium chloride mixtures were prepared with $4 \%(\mathrm{w} / \mathrm{w})$ whey protein and $0.5,1$, or $4 \%(\mathrm{w} / \mathrm{w})$ sodium chloride. $8 \%(\mathrm{w} / \mathrm{w})$ whey protein isolate solution were prepared with 1 or $4 \%(\mathrm{w} / \mathrm{w}) \mathrm{NaCl}$. All mixtures are summarized in table 4.1 . The solutions were prepared by dissolving the sucrose and/or the sodium chloride, subsequently, adding the whey protien isolate. The solution was stirred until all material was dissolved. The solutions were stored overnight in an ice bath $\left(0{ }^{\circ} \mathrm{C}\right)$ to ensure complete hydration. All solutions were prepared with demineralized water. 
Table 4.1: Overview of the prepared whey protein - sucrose - salt mixtures.

\begin{tabular}{|c|c|c|}
\hline $\begin{array}{c}\text { WPI } \\
{[\%(w / w)]}\end{array}$ & $\begin{array}{c}\mathrm{NaCl} \\
{[\%(\mathrm{w} / \mathrm{w})}\end{array}$ & $\begin{array}{l}\text { Sucrose } \\
{[\%(\mathrm{w} / \mathrm{w})]}\end{array}$ \\
\hline 4 & - & - \\
\hline 4 & 0.5 & - \\
\hline 4 & - & 0.5 \\
\hline 4 & 1 & - \\
\hline 4 & - & 1 \\
\hline 4 & 1 & 1 \\
\hline 4 & 4 & - \\
\hline 4 & - & 4 \\
\hline 4 & 4 & 1 \\
\hline 4 & 1 & 4 \\
\hline 4 & 4 & 4 \\
\hline 6 & - & - \\
\hline 8 & - & - \\
\hline 8 & 1 & - \\
\hline 8 & - & 1 \\
\hline 8 & 1 & 1 \\
\hline 8 & 4 & - \\
\hline 8 & - & 4 \\
\hline 8 & 4 & 1 \\
\hline 8 & 1 & 4 \\
\hline 8 & 4 & 4 \\
\hline 10 & - & - \\
\hline 12 & - & - \\
\hline
\end{tabular}

\section{Freezing point measurements}

The freezing points of the solutions were determined using differential scanning calorimetry (DSC). Samples (10-20 $\mu \mathrm{g})$ were inserted in a closed pan and introduced in the calorimeter (DSC250, TA Instruments, USA). An empty pan was used as a reference. The sample was then equilibrated to $-30{ }^{\circ} \mathrm{C}$ and kept there for 1 minute to ensure full crystallisation of the sample. Then a heating ramp of $0.5{ }^{\circ} \mathrm{C} /$ minute was started until $20^{\circ} \mathrm{C}$. After this the cycle was repeated but then with a heating ramp of $0.1{ }^{\circ} \mathrm{C} /$ minute. The obtained DSC thermograms were analysed for the endothermic peak, using the software interfaced with the DSC. The peak temperatures from the ramp of $0.1^{\circ} \mathrm{C} /$ minute was used as the melting temperature.

\section{Progressive freeze concentration}

The progressive freeze concentration experiments were carried out in a stirred vessel, shown in fig. 4.1, as described in our earlier work (Vuist et al. 2020). To prevent super-cooling of the to be concentrated solution, a droplet of $100 \mu \mathrm{L}$ demineralized water was deposited and frozen on the pre-cooled surface before each experiment, to supply a sead for the freezing process. The temperature of the cryostat was then adjusted to $2.5^{\circ} \mathrm{C}$ below the freezing point of the feed solution. After a five-minute waiting time approximately $500 \mathrm{~mL}$ feed solution was 

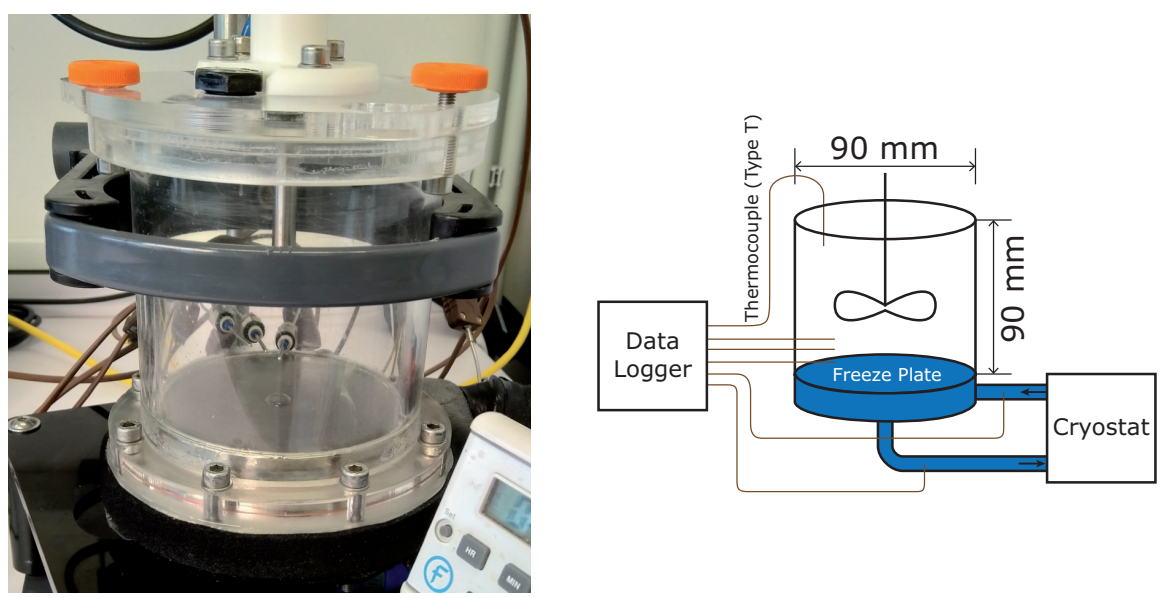

Figure 4.1: Picture (left) and schematic overview (right) of the used freeze concentrator.

introduced to the system and the cooling programme was initiated. The cooling programme used for all experiments started at $2.5^{\circ} \mathrm{C}$ below the freezing point and then decreased at a rate of $0.1{ }^{\circ} \mathrm{C}$ per minute. This cooling programme was established in our previous work and was found to give to a minimum of solute inclusions for sucrose and maltodextrin solutions in the same vessel (Vuist et al. 2020). The stirrer was operated at $500 \mathrm{rpm}$, as this speed minimizes both foam formation and solute inclusion. After 1 hour the concentrated solution was removed from the system by pouring and the ice was cleaned with a tissue paper to remove adhering liquid. The ice was then melted. The concentrated solution, melted ice, and the initial feed solution were weighed and sampled for further analyses. The average concentrations in the ice and in the bulk were determined at the end of each experiment. The degree of inclusion of the whey protein is evaluated by calculating the effective distribution coefficient, $K$ (eq. (4.1)), where $C_{i}$ is the average included dry matter concentration in the ice and $C_{l}$, is the concentration in the concentrated solution after 1 hour of freeze concentration. The concentration factor (eq. (4.2)) is calculated for the composition analysis. $C_{b}$ is the initial concentration.

$$
\begin{aligned}
K & =C_{i} / C_{l} \\
C F & =C_{l} / C_{b}
\end{aligned}
$$

The dry matter content was determined for each sample by pouring a small amount in a pre-weighed aluminium cup and weighing. Subsequently, the samples were dried overnight in an oven at $105{ }^{\circ} \mathrm{C}$. Afterwards the cups were weighed again, which then allowed us to calculate the dry matter content.

\section{Composition analysis}

In order to analyse the concentrations of protein and sucrose in the feed, concentrate and ice, high-performance size exclusion chromatography (HPSEC) was used. HPSEC for protein analysis was performed using a Thermo Ultimate 3000 HPLC (ThermoFisher Scientific, 
USA) equipped with two columns TSKGel G3000SWXL ( $5 \mu \mathrm{m} 300 \times 7.8 \mathrm{~mm})$ and G2000SWXL $(5 \mu \mathrm{m} 300 \times 7.8 \mathrm{~mm})$, one after the other. The temperature of the column oven was 30 ${ }^{\circ} \mathrm{C}$. The absorbance was measured with a UV-VIS detector at $214 \mathrm{~nm}$. Amounts of $10 \mu \mathrm{L}$ were injected. The eluent was $30 \%$ Acetonitrile in Milli-Q water with $0.1 \%$ Trifluoracetic acid. The flow rate of the eluent was $1.5 \mathrm{~mL} / \mathrm{min}$. HPSEC for sucrose analysis was performed using Thermo Ultimate 3000 HPLC (ThermoFisher Scientific, USA) equipped with the column Shodex KS-802 (300x8mm). The temperature of the column oven was $50{ }^{\circ} \mathrm{C}$. The refractive index detector Shodex RI-501 (Shodex, USA) was used to measure the amount of sucrose present in the sample. Amounts of $10 \mu \mathrm{L}$ were injected. The eluent was Milli-Q water used with a flow rate of $1 \mathrm{~mL} / \mathrm{min}$.

To analyse the amount of salt in the different fractions, a conductivity meter (MettlerToledo, the Netherlands) was used. A calibration curve was made by preparing salt solutions of $0.2 \%, 1 \%, 2 \%, 5 \%$ and $10 \%(\mathrm{w} / \mathrm{w}) \mathrm{NaCl}$ in Milli-Q water. A linear calibration line was obtained. The formula for this linear relation was used to translate the measured conductivity into the salt content in the fractions. This all was done at room temperature (Mettler-Toledo, the Netherlands).

\section{Experimental set-up}

The freeze concentration experiments with whey protein solutions were performed as independent duplicates. Thanks to the good reproducibility of this first set of experiments, single experiments of each of the mixtures with the sucrose and sodium chloride mixtures were considered sufficient to examine the effect of the additions of sucrose and $\mathrm{NaCl}$. For the determination of the dry matter content, two samples from each fraction were analysed. The full composition analysis was only performed for the mixtures containing $4 \%(\mathrm{w} / \mathrm{w})$ protein.

\subsection{Results and discussion}

Initial freeze concentration experiments with pure whey protein solutions were carried out and characterised on solute inclusion behaviour. Subsequently, the effect of the addition of sucrose and sodium chloride on solute whey protein inclusion and their combined effect were studied.

\section{Freezing point measurements}

From the exothermic peak the freezing points of the different prepared solutions were calculated (fig. 4.2). For the solutions with only whey protein isolate the results are in line with expectations. At $4 \%(\mathrm{w} / \mathrm{w})$ WPI there is a small deviation and a temperature above $0{ }^{\circ} \mathrm{C}$ is reported, for the other WPI solutions the peak is found to be around $0{ }^{\circ} \mathrm{C}$. The deviation from the expected melting temperature for these samples is most probably caused by undesired freeze concentration during the freezing of the sample in the DSC. When this is the case, the shape of the peak becomes distorted and the measured melting trajectory can be widened leading to a deviating peak temperature. During our freeze concentration experiments we assumed that the freezing point depression for pure WPI solutions was negligible. This is reasonable since the melting point depression based on the molecular weight of the protein is expected to be negligible. 


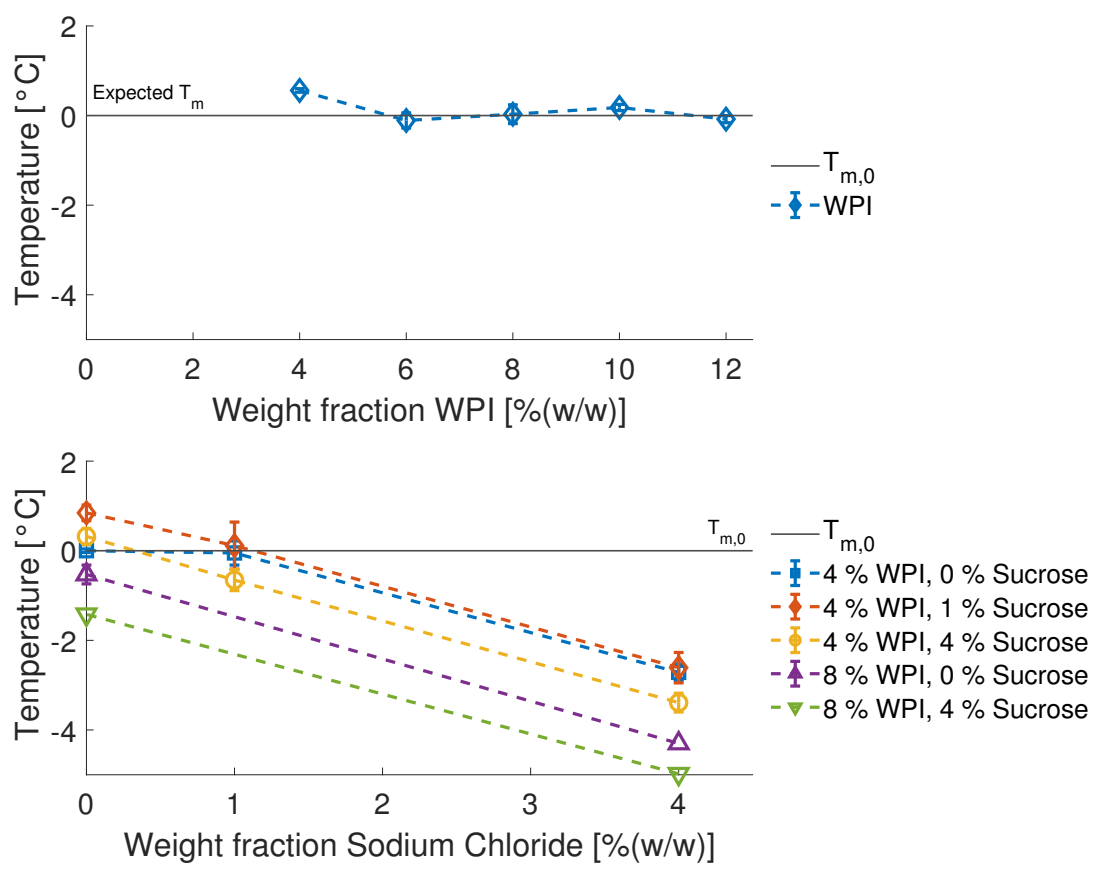

Figure 4.2: Measured freezing points for the pure whey protein solutions (top) and the mixtures (bottom). The error bars indicate the standard deviation $(n=2)$. The dashed lines are drawn to guide the eye.

For the freezing points of the whey protein-sodium chloride-sucrose mixtures we observe an upwards shift in the expected melting temperatures. This upward shift is caused by the occurence of a melting range due to the solution being a mixture and not a pure compound. Since we are observing a melting peak where the sample is not completely in equilibrium with the heating element, the peak can be shifted above the melting temperature of pure water. The observed trends do match the expectations and, therefore, this shift has no further consequences for our conclusions. The addition of sodium chloride causes a large freezing point depression while the effect for sucrose is much smaller. This is in line with Blagden's law for freezing point depression (Barrow 1961).

\section{Freeze concentration of whey protein solutions}

Pure whey protein solutions of different concentrations were freeze concentrated in the stirred vessel using fixed operating conditions, i.e. stirrer speed and cooling profile were kept the same. By camera observation we observed that the ice growth rate was similar for all solutions: approximately $50 \mathrm{~g}$ of ice was formed during each experiment (data not shown). During progressive freeze concentration a diffusive boundary layer is formed on top of the growing ice layer due to the exclusion of solutes at the interface with the ice. A concentration polarization layer thus develops in this boundary layer (Myerson et al. 2019). Since the ice growth rate can be considered constant, the only difference between the inclusion rates of the solutes is their ability to diffuse out of the boundary layer and the thickness of this boundary layer 


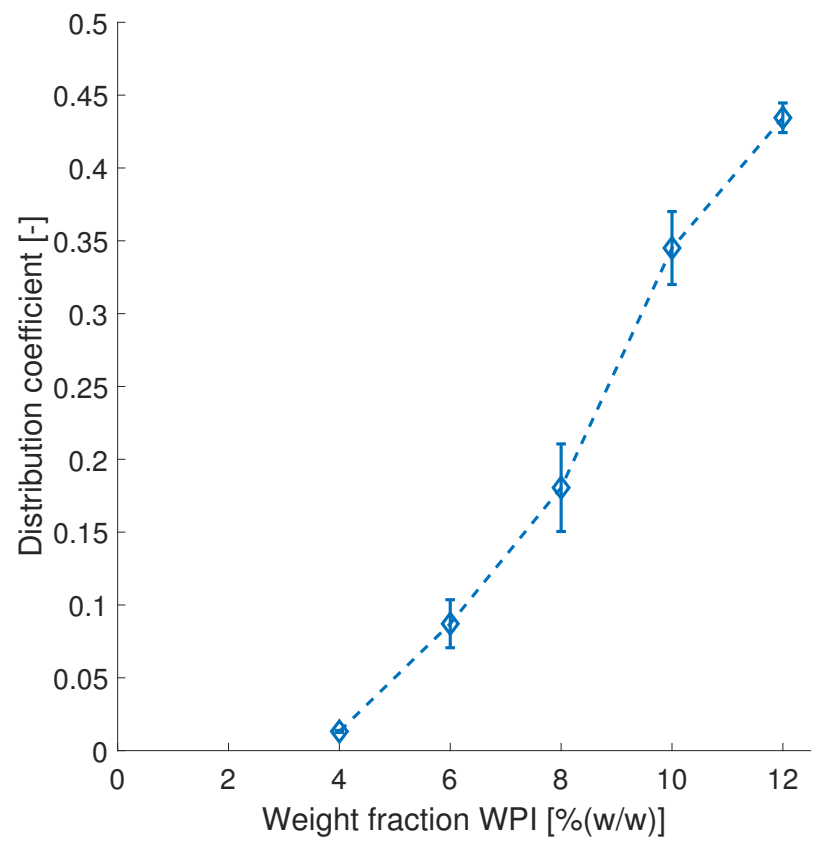

Figure 4.3: Solute inclusion in ice for whey protein solutions after 1 hour of freeze concentration. The stirrer speed was $500 \mathrm{rpm}$ and the cooling profile of $-0.1{ }^{\circ} \mathrm{C} / \mathrm{min}$ starting at $2.5{ }^{\circ} \mathrm{C}$ below the freezing point of the solution was used. The error bars indicate the standard deviation $(n=2)$. The dashed line is drawn to guide the eye.

(Burton et al. 1953). The inclusion of whey protein in the ice is expected to occur via small pockets of concentrated solution between the growing crystals (Vuist et al. 2020).

In fig. 4.3 these distribution coefficients are shown as a function of the WPI concentration in the original solution. The inclusion of whey protein increases at higher concentrations, which can be explained with the rapid increase of the viscosity, or even the formation of a gel layer with increasing concentration in the solution (Both et al. 2019). This reduces the diffusivity of the whey protein in the boundary layer and thus lowers the mass transfer. Since the freezing rate is mostly determined by the amount of cooling, the whey protein that cannot migrate to the solution should end up being included the ice. At high concentrations we expect that a thin gel layer can be formed. In ultrafiltration, gel layers are routinely found on top of the membrane, and typically have concentrations between $400-600 \mathrm{~g} / \mathrm{L}$ (Both et al. 2019). The increase in solute inclusion at higher concentrations under similar progressive freeze concentration conditions was also observed by Belen et al. (2018) for cheese whey and in an earlier review by Sánchez et al. (2011b) for dairy products. An approach to compensate for the increased loss of whey protein is to increase the stirrer speed at higher concentrations to reduce the boundary layer thickness and thereby to enhance the mass transfer (Vuist et al. 2020); or to reduce the freezing rate. 


\section{Effects of sucrose and sodium chloride addition on solute inclusion}

To examine the influence of carbohydrates on freeze concentration of whey protein solutions, sucrose was added to mixtures of 4 and $8 \%(w / w)$ whey protein, which were then freeze concentrated in the same manner as the whey protein solutions. The results of these experiments are shown in fig. $4.4 \mathrm{a}$. For both the 4 and $8 \%(\mathrm{w} / \mathrm{w})$ whey protein solutions we observe a linear increase in inclusions with increasing sucrose concentration. In contrast to the high molecular weight whey proteins, the addition of sucrose will create a significant reduction in freezing temperature (Moussaoui et al. 2018), which creates the possibility for constitutional super-cooling in the polarization layer (Myerson et al. 2019), and thus for more inclusions. This super-cooling causes the ice to form dendrites, which results in undesired large inclusions of concentrated solution in the ice (Ulrich et al. 2013). In addition, the solution in the polarization layer is concentrated in sucrose and low in temperature, and therefore is closer to its glass transition, resulting in a strong increase in viscosity. This again leads to a larger boundary layer thickness and reduced diffusion rate which will enhance solute inclusions in the ice.

The effect of sodium chloride on freeze concentration of whey protein was examined in a similar way. The results of these experiments are shown in fig. 4.4b. However we now see first an initial steep increase in solute inclusion upon increasing the concentration of sodium chloride, which levels off at higher concentrations. A similar observation is made by Sánchez et al. (2011a) and Belen et al. (2018) using fresh whey, which contains both salts and lactose. After desalination, less whey protein was included in the ice. Since sodium chloride $(58.4 \mathrm{~g} / \mathrm{mol})$ has a larger effect on the freezing point depression, compared to sucrose, this is expected. Due to the high freezing point depression the resulting freezing zone with constitutional super-cooling can induce significant dendritic ice formation (Myerson et al. 2019). Once an area of constitutional super-cooling exists, the amount of inclusions becomes dependent on the concentration of the solutes in this zone. The concentration of the solution between the dendrites is dependent on the liquid bulk concentration, the ice growth rate and the rates of diffusion of the solutes, which causes the build-up of solutes in the boundary layer by the exclusion of solutes from the ice layer. Viscosity plays a much smaller role for sodium chloride since its viscosity increase is much lower than that for sucrose (Chenlo et al. 2002), so the main effect will be due to its freezing point depression. 


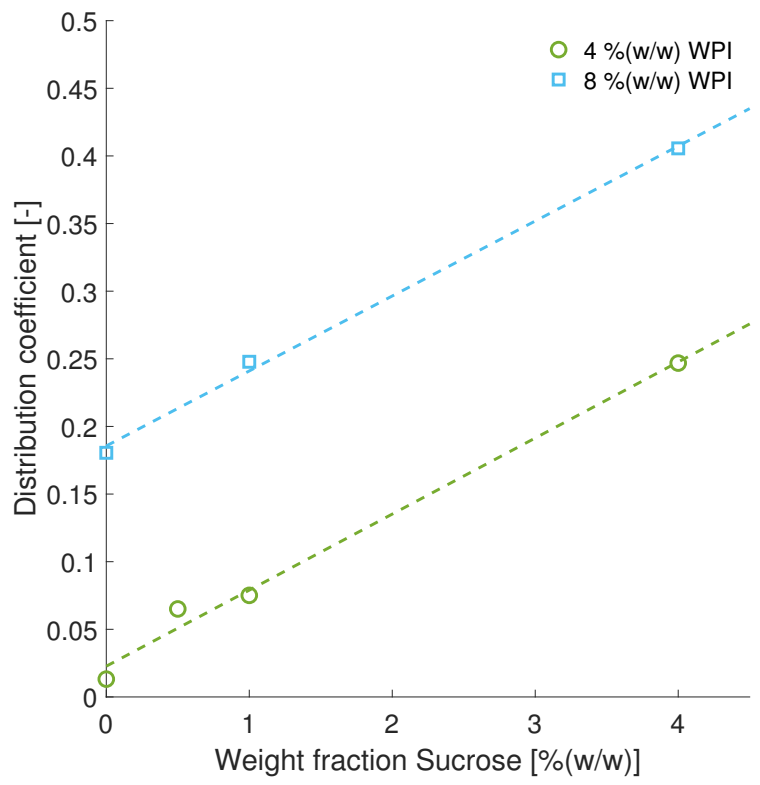

(a) Whey protein-sucrose

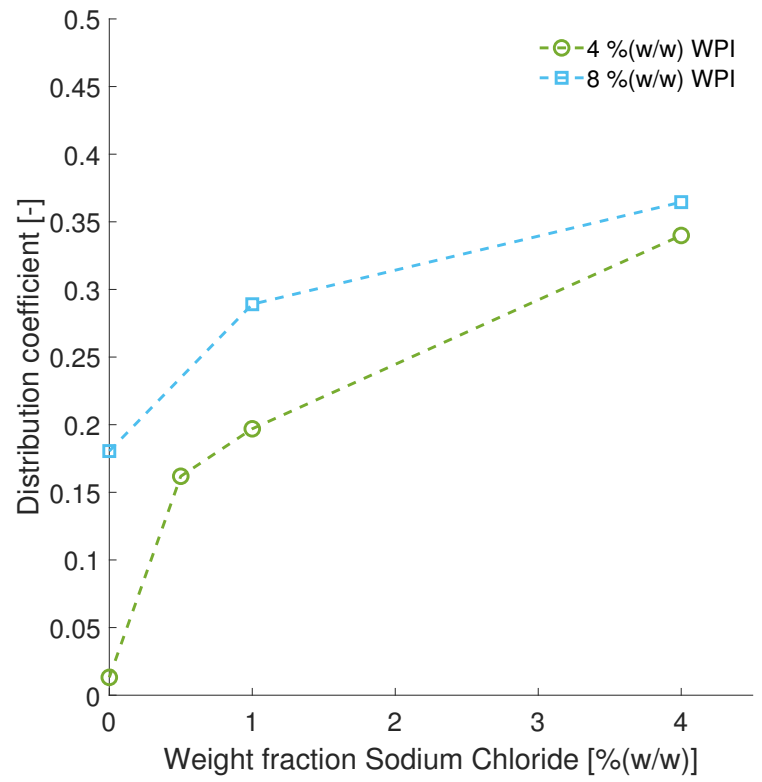

(b) Whey protein-sodium chloride

Figure 4.4: Distribution factor for whey protein-sucrose (a) and whey protein-sodium chloride (b) solutions. The stirrer speed was $500 \mathrm{rpm}$ and a cooling profile of $-0.1{ }^{\circ} \mathrm{C} / \mathrm{min}$ starting at $2.5{ }^{\circ} \mathrm{C}$ below the freezing point of the solution was used. The dashed line is drawn to guide the eye. 


\section{Combined effect on solute inclusion}

Since practically relevant streams are usually mixtures of protein, carbohydrates and/or salts, a set of experiments with model mixtures were carried out to investigate the effect combinations (fig. 4.5). For all conducted experiments the mass balances for individual and total sum of solutes were checked. It appeared that on average $97 \%$ of the solutes were found back in the concentrate and the ice compared to the feed, see also section 4.5. In all the mixtures with sodium chloride a steep increase in the distribution coefficient is observed. With more sucrose, this becomes less apparent (fig. 4.5a), just as with higher concentrations of WPI (fig. 4.5b). We expect that the increase in solute inclusion for mixtures high in sodium chloride is mainly caused by the increase in freezing point depression. For sucrose this occurs as well, albeit to a lesser degree due to its larger molecular weight, but the much larger increase in viscosity exacerbates its effect, since it influences the mass transfer in the boundary layer. In fig. $4.5 \mathrm{~b}$ the higher concentration of whey protein mainly has an influence at lower concentrations of the other solutes. We do not observe an additive effect when we combine both sucrose and sodium chloride, i.e. when the components are both present, we do not see any extra increase in inclusions. Since the inclusions are on the microscopic scale and not on the molecular scale the protein gets included as well. The increased inclusion at $8 \%(\mathrm{w} / \mathrm{w})$ is mainly due to the increased viscosity of the higher concentration solution (Kornet et al. 2021). When comparing to the $4 \%(\mathrm{w} / \mathrm{w})$ solutions the addition of sodium chloride and sucrose results in slightly higher inclusions. From this we can conclude that the freezing point depression is the dominant effect for promoting solute inclusion when low-molecular weight components are present.

Finally, we hypothesized that the individual components of the model system would distribute themselves unequally over the ice or the solution, because of the different diffusivities of sodium chloride, sucrose and protein. To determine the relative abundance of all components in the feed, ice and concentrate we used HPSEC for measuring protein and sucrose content and conductivity measurements for measuring sodium chloride concentration (fig. 4.6). For the mixtures with $1 \%(\mathrm{w} / \mathrm{w})$ sodium chloride the amount of sodium chloride is much lower than that in the feed fraction. This could be caused by the difference in diffusivity. However, because the absolute concentration in this fraction is quite low, the conductivity measurements are in this case less accurate. We can therefore conclude that there are overall no large differences in the inclusion for the different components in the ice compared to their presence in the concentrate. This may be related to the interactions between the multiple components in the system. The concentrations in the polarization layer are quite high, and the subsequent higher viscosities will not just reduce the diffusivity of the sucrose, but also that of the whey proteins and even $\mathrm{NaCl}$, or, in terms of frictions instead of diffusivities, the high concentrations will cause strong friction between the individual components, leading to strong coupling between the individual fluxes of the components. Therefore one should in fact not relate the inclusions to the diffusivities at infinite dilution, but the diffusivities (or intercomponent friction) at these high concentrations. 


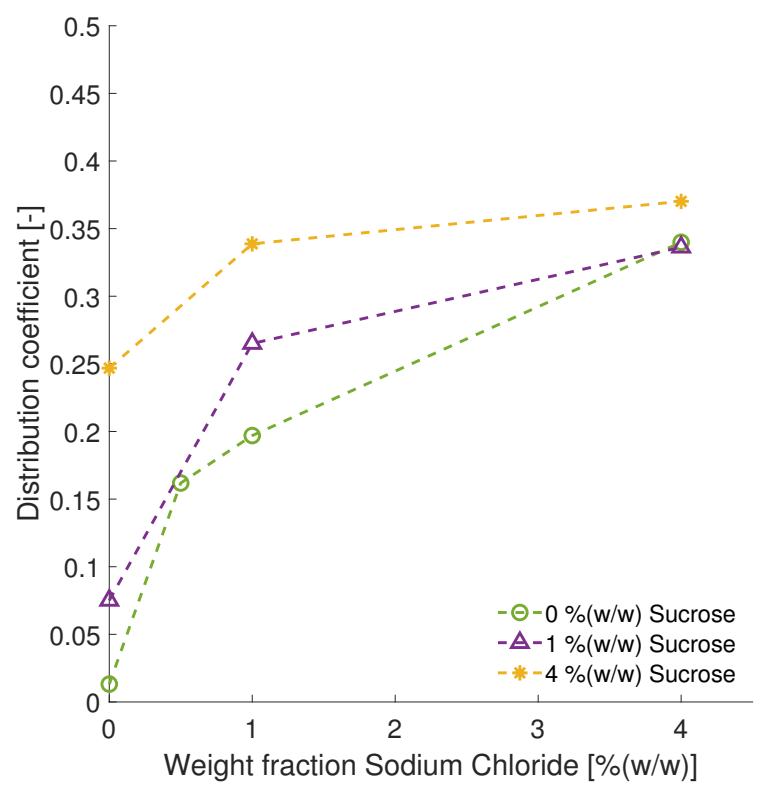

(a) $4 \%(w / w)$ WPI

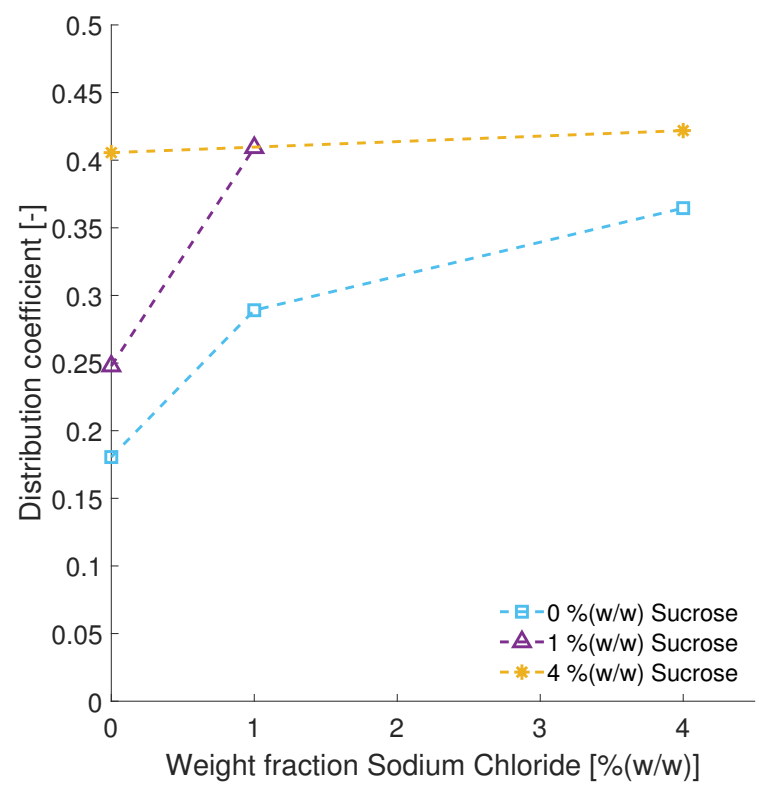

(b) $8 \%(w / w)$ WPI

Figure 4.5: Dry matter inclusion in ice for whey protein-sucrose-sodium chloride solutions. The stirrer speed was $500 \mathrm{rpm}$ and a cooling profile of $-0.1{ }^{\circ} \mathrm{C} / \mathrm{min}$ starting at $2.5{ }^{\circ} \mathrm{C}$ below the freezing point of the solution was used. The dashed line is drawn to guide the eye. 


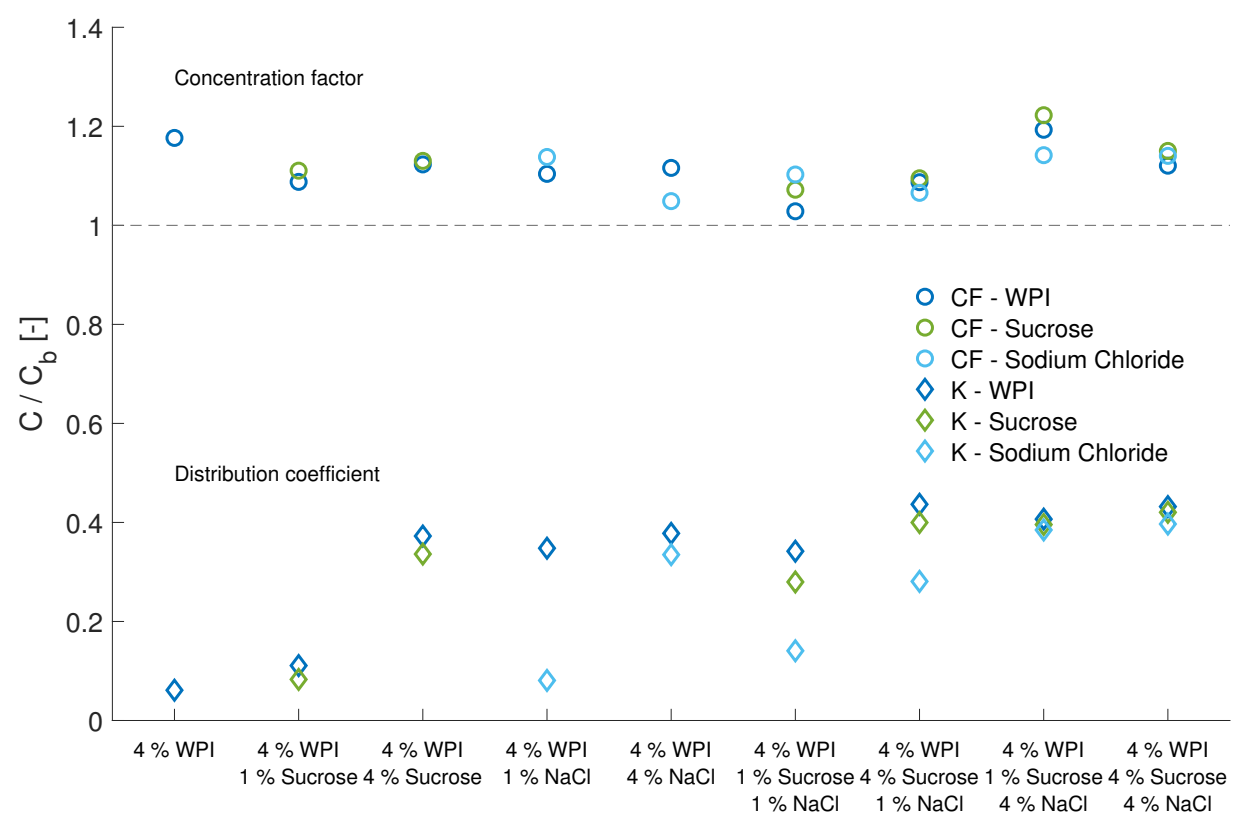

Figure 4.6: Distribution coefficient, $K=C_{i} / C_{l}$, and concentration factor, $C F=C_{l} / C_{b}$, for the individual components in the mixtures containing $4 \%(w / w)$ WPI

\subsection{Conclusion}

We showed that solutions of whey protein isolate can be successfully concentrated using progressive freeze concentration. Higher concentrations of whey protein lead to a higher concentration near the interface, which may create a gel layer that impedes the mass transfer from the boundary layer and hence promotes solute inclusion. Therefore, at higher concentrations of the whey proteins, the losses increase and the mass transfer in the bulk solution should be increased, or the freezing rate reduced, to prevent excessive inclusion.

With low-molecular weight components in the solution, the inclusions of all components, including the proteins, increase, due to freezing point depression, which then allows constitutional super-cooling and the formation of macroscopic inclusions. For sodium chloride this is the major mechanism, while for sucrose this also happens to a lower degree, but the effect is then exacerbated by the strongly increased viscosity in the boundary layer due to concentration polarisation in combination with the low temperatures. With both sucrose and sodium chloride in the solution, we do not see an additive effect, but we see that the largest effect of the two dominates the solute inclusion. Compositional analysis showed that there was no separation between the components in the ice and the concentrate and therefore progressive freeze concentration is not suitable for separation of individual components via ice formation. This is likely due to multicomponent effects at the high concentrations in the polarization layer.

The use of whey protein as a model system showed that progressive freeze concentration can be suitable as concentration method for streams which contain proteins, as long as these streams do not contain too many low-molecular weight components. If a stream does 
contain small components in high quantities a pre-treatment such as diafiltration would be recommended. Alternatively, depending on the product, the losses might be acceptable or the melted ice fraction might be recycled back into the process to avoid loss of the proteins or other solutes. 


\subsection{Mass balance of freeze concentrated whey protein mixtures}

Table 4.2: Mass balance of the individual components in the mixtures used in section 4.3

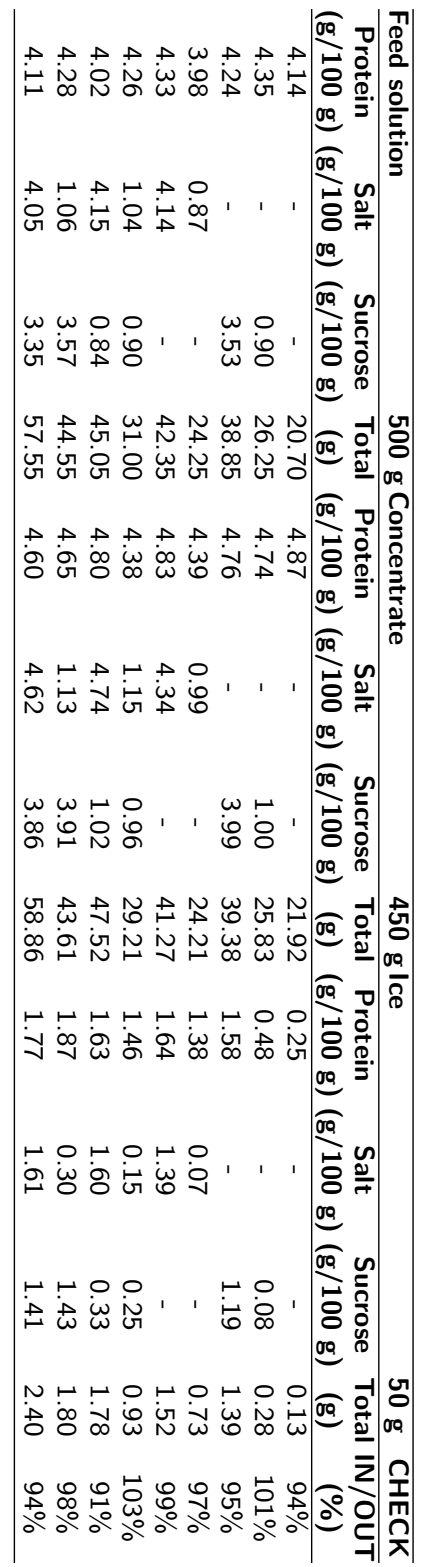




\section{References}

Barrow, G. M. (1961). “Colligative Properties of Solutions”. In: Physical chemistry. New York [etc.]: McGraw-Hill. Chap. 15, pp. 499-501 (cit. on p. 58).

Belen, Freddy, Merce Raventos, and Eduard Hernandez (2018). "Management of Cheese Whey by Film Freeze Concentration". In: Environmental Engineering and Management Journal 17.6, pp. 13731383. ISSN: 1582-9596. DOI: 10.30638/eemj . 2018. 136 (cit. on pp. 53, 59, 60).

Belén, F., S. Benedetti, J. Sánchez, E. Hernández, J. M. Auleda, E. S. Prudêncio, J. C. C. Petrus, and M. Raventós (June 2013). "Behavior of functional compounds during freeze concentration of tofu whey". In: Journal of Food Engineering 116.3, pp. 681-688. ISSN: 0260-8774. DOI: 10.1016/j . jfoodeng. 2013.01.019 (cit. on p. 53).

Belén, F., J. Sánchez, E. Hernández, J. M. Auleda, and M. Raventós (June 2012). "One option for the management of wastewater from tofu production: Freeze concentration in a falling-film system". In: Journal of Food Engineering 110.3, pp. 364-373. ISSN: 0260-8774. DOI: 10.1016/j . jfoodeng. 2011.12 .036 (cit. on p. 53).

Bona Muñoz, Isabella de, Ariadna Rubio, Mónica Blanco, Mercè Raventós, Eduard Hernández, and Elane Schwinden Prudêncio (Mar. 2019). "Progressive freeze concentration of skimmed milk in an agitated vessel: Effect of the coolant temperature and stirring rate on process performance". In: Food Science and Technology International 25 (2), pp. 150-159. ISSN: 1532-1738. DOI: 10.1177/ 1082013218803263 (cit. on p. 53).

Both, E. M., I. Siemons, R. M. Boom, and M. A. I. Schutyser (2019). "The role of viscosity in morphology development during single droplet drying”. In: Food Hydrocolloids 94, pp. 510-518. ISSN: 0268-005X. DOI: 10.1016/j . foodhyd . 2019.03.023 (cit. on p. 59).

Burton, J. A., R. C. Prim, and W. P. Slichter (1953). "The distribution of solute in crystals grown from the melt. Part I. Theoretical". In: The Journal of Chemical Physics 21.11, pp. 1987-1991. ISSN: 0021-9606. DOI: 10.1063/1.1698728 (cit. on p. 59).

Chenlo, F., R. Moreira, G. Pereira, and A. Ampudia (2002). "Viscosities of aqueous solutions of sucrose and sodium chloride of interest in osmotic dehydration processes". In: Journal of Food Engineering 54.4, pp. 347-352. ISSN: 0260-8774. DOI: 10.1016/S0260-8774 (01) 00221-7 (cit. on p. 60).

Deshpande, S. S., Munir Cheryan, Shridhar K. Sathe, and D. K. Salunkhe (Jan. 1984). "Freeze concentration of fruit juices". In: C R C Critical Reviews in Food Science and Nutrition 20.3 (3), pp. 173248. ISSN: 0099-0248. DOI: 10.1080/10408398409527389 (cit. on p. 53).

Dickey, Leland C., James C. Craig, E. Richard Radewonuk, Andrew J. McAloon, and Virginia H. Holsinger (June 1995). "Low Temperature Concentration of Skim Milk by Direct Freezing and Vacuum Evaporation”. In: Journal of Dairy Science 78.6, pp. 1369-1376. ISSN: 0022-0302. DOI: 10.3168/jds.S0022-0302 (95) 76759-5 (cit. on p. 53).

Ghanimah, Mohamed Abed and Eman Ibrahim (June 2018). "Effect of $\mathrm{pH}$, Carbohydrates, and $\mathrm{NaCl}$ on Functional Properties of Whey Proteins". In: Journal of Sustainable Agricultural Sciences 44 (2), pp. 93-99. ISSN: 2536-9571. DOI: 10.21608/JSAS . 2018.3617.1064 (cit. on p. 54).

Janson, Jan-Christer, Bo Ersson, and Jerker Porath (Jan. 1974). "The concentration of protein solutions by normal freezing”. In: Biotechnology and Bioengineering 16.1, pp. 21-39. ISSN: 0006-3592. DOI: 10.1002/bit. 260160104 (cit. on p. 53).

Kornet, Remco, Carol Shek, Paul Venema, Atze Jan van der Goot, Marcel Meinders, and Erik van der Linden (Aug. 2021). "Substitution of whey protein by pea protein is facilitated by specific fractionation routes". In: Food Hydrocolloids 117, p. 106691. ISSN: 0268-005X. DOI: 10 . 1016 / J . FOODHYD . 2021. 106691 (cit. on p. 62).

Moussaoui, Chaimae, Mónica Blanco, Isabella de Bona Muñoz, Mercè Raventós, and Eduard Hernández (Aug. 2018). "An approach to the optimization of the progressive freeze concentration of sucrose solutions in an agitated vessel". In: Separation Science and Technology 33.1 (1), pp. 1-11. ISSN: 0149-6395. DOI: 10.1080/01496395.2018.1508231 (cit. on p. 60).

Myerson, Allan S., Deniz Erdemir, and Alfred Y. Lee (June 2019). Handbook of industrial crystallization. English. Third edit. Cambridge ; Cambridge University Press, pp. 1-528. ISBN: 9781139026949. DOI: $10.1017 / 9781139026949$ (cit. on pp. 58, 60). 
Sánchez, J., E. Hernández, J. M. Auleda, and M. Raventós (Mar. 2011a). "Freeze concentration of whey in a falling-film based pilot plant: Process and characterization". In: Journal of Food Engineering 103.2, pp. 147-155. ISSN: 0260-8774. DOI: $10.1016 / \mathrm{j}$. jfoodeng. 2010.10.009 (cit. on pp. 53, $60)$.

- (Feb. 2011b). "Review: Freeze Concentration Technology Applied to Dairy Products". In: Food Science and Technology International 17.1, pp. 5-13. ISSN: 1082-0132. DOI: 10.1177/1082013210382479 (cit. on pp. 53, 59).

Singh, Kawal Jit and Yrjö H. Roos (May 2006). "Frozen State Transitions of Sucrose-Protein-Cornstarch Mixtures”. In: Journal of Food Science 70.3, E198-E204. ISSN: 0022-1147. DOI: 10.1111 / j . 1365-2621.2005.tb07136.x (cit. on p. 53).

Ulrich, Joachim and Torsten Stelzer (2013). "Melt Crystallization". In: Crystallization: Basic Concepts and Industrial Applications, pp. 289-304. DOI: 10.1002/9783527650323 . ch15 (cit. on p. 60).

Voudouris, Panagiotis, Angelica Tamayo Tenorio, Jan Peter Lesschen, Konstantina Kyriakopoulou, Johan P. M. Sanders, Atze Jan van der Goot, and Marieke E. Bruins (Dec. 2017). Sustainable protein technology : an evaluation on the STW Protein programme and an outlook for the future. Tech. rep. Wageningen: Wageningen Food and Biobased Research. DOI: 10.18174/429443 (cit. on p. 53).

Vuist, Jan Eise, Remko M. Boom, and Maarten A. I. Schutyser (Mar. 2020). "Solute inclusion and freezing rate during progressive freeze concentration of sucrose and maltodextrin solutions". In: Drying Technology, pp. 1-9. ISSN: 0737-3937. DOI: 10.1080/07373937.2020.1742151 (cit. on pp. 54-56, 59).

Waglay, Amanda, Salwa Karboune, and Inteaz Alli (2014). "Potato protein isolates: Recovery and characterization of their properties". In: Food Chemistry 142, pp. 373-382. ISSN: 0308-8146. DOI: 10. 1016/j.foodchem. 2013.07.060 (cit. on p. 53). 


\section{Solute inclusion modelling: A state diagram approach}

This chapter has been submitted for publication as:

Vuist, J. E., Schutyser, M. A. I., \& Boom, R. M. (2021).

Solute inclusion during progressive freeze concentration: A state diagram approach. 


\begin{abstract}
We propose a conceptual model for progressive freeze concentration, which predicts solute loss through inclusion in the ice based on the system's phase behaviour as illustrated in a state diagram. We compare the outcomes of the model for sodium chloride, sucrose, and bovine serum albumin (BSA). For ice growth rates in the order $10^{-2} \mu \mathrm{m} / \mathrm{s}$ there was no solute inclusion for sodium chloride or sucrose, but above this range, local super-cooling gives rise to a freezing zone. In this freezing zone ice and solution co-exist and the resulting uneven advancement of the ice causes inclusions. The model predicts that for macromolecular solutions such as BSA, no inclusion will take place through the proposed mechanism.
\end{abstract}


Nomenclature

\begin{tabular}{|c|c|c|}
\hline Subscript & Description & \\
\hline$b$ & Bulk & \\
\hline$c$ & Composition path & \\
\hline$f$ & Freezing point & \\
\hline$i$ & Interface & \\
\hline ice & & \\
\hline$m$ & Melting point & \\
\hline Symbol & Description & Unit \\
\hline$\Delta h_{f}$ & Heat of fusion & $\mathrm{J} / \mathrm{mol}$ \\
\hline$\delta$ & Thickness of boundary layer & $\mathrm{m}$ \\
\hline$\eta$ & Cooling duty used for ice formation & $\%$ \\
\hline$\lambda$ & Thermal conductivity & $\mathrm{W} /(\mathrm{m} \mathrm{K})$ \\
\hline$\rho$ & Density & $\mathrm{kg} / \mathrm{m}^{3}$ \\
\hline$b$ & Molality & $\mathrm{mol} / \mathrm{kg}$ \\
\hline$c$ & Concentration & M \\
\hline$c_{p}$ & Heat capacity & $\mathrm{J} / \mathrm{kg}$ \\
\hline$D$ & Diffusion coefficient & $\mathrm{m}^{2} / \mathrm{s}$ \\
\hline$h$ & Heat transfer coefficient & $\mathrm{W} /\left(\mathrm{m}^{2} \mathrm{~K}\right)$ \\
\hline$i$ & Van 't Hoff factor & - \\
\hline$K$ & Instantaneous distribution coefficient & - \\
\hline$K_{f}$ & Cryoscopic constant & $(\mathrm{K} \mathrm{kg}) / \mathrm{mol}$ \\
\hline$k$ & Mass transfer coefficient & $\mathrm{m} / \mathrm{s}$ \\
\hline $\mathrm{N}_{\mathrm{Nu}}$ & Nusselt number & - \\
\hline $\mathrm{N}_{\text {Sh }}$ & Sherwood number & - \\
\hline $\mathrm{N}_{\mathrm{Re}}$ & Reynold number & - \\
\hline $\mathrm{N}_{\mathrm{Sc}}$ & Schmidt number & - \\
\hline $\mathrm{N}_{\operatorname{Pr}}$ & Prandtl number & - \\
\hline$q$ & Cooling duty & $\mathrm{W} / \mathrm{m}^{2}$ \\
\hline$T$ & Temperature & K \\
\hline$v$ & Rate of water towards the interface / ice growth rate & $\mathrm{m} / \mathrm{s}$ \\
\hline$z$ & Coordinate & $\mathrm{m}$ \\
\hline
\end{tabular}





\subsection{Introduction}

Freeze concentration is a mild process that involves the concentration of solutions by selective freezing of water. The process is typically used for the concentration of fruit juices, coffee extract, dairy products, and ice bock; all these products are susceptible to thermal degradation and thus benefit from the low temperatures in the process. Freeze concentration is also considered for the treatment of waste water (Holt 1999), especially when these streams are corrosive, which can be reduced by the low temperature during the process.

Current freeze concentration process forms are suspension freeze concentration, block freeze concentration, and progressive freeze concentration (Sánchez et al. 2009; Sánchez et al. 2011). We here focus on progressive freeze concentration in which a layer of ice is created on the surface ofa heat exchanger. After the ice layer is grown, the concentrated solution is removed, the ice is melted and withdrawn from the system. This may be repeated multiple times to obtain enough concentration. Critical for the feasibility of this process is that the loss of solutes due to inclusion in the growing ice layer is minimised. These inclusions occur due to accumulation of solutes in the solution close to the ice growth front, which then induces uneven growth of the ice layer. Solute losses of up to $50 \%$ of the initial concentration can be found in the ice layer (Vuist et al. 2020; Vuist et al. 2021; Jusoh et al. 2009; Ojeda et al. 2017). Depending on the amount of the inclusions and use of the ice fraction this can pose a significant loss of dry matter.

The mechanism of solute inclusion during progressive freeze concentration in the growing ice layer is not yet completely unravelled. The phenomenon is generally understood to be caused by a temperature decrease in the boundary layer towards the ice interface. During ice growth, both water and heat are removed from the bulk solution, leading to an accumulation of solute on the ice surface, and a concurrent decrease in temperature in the boundary layer. Depending on the circumstances, the temperature in the boundary layer decreases below the freezing point of the local solution, which can then lead to ice growth from the surface, into the boundary layer (fig. 5.1b). If the undercooling in the boundary layer is small, this may be seen as a ripple on the surface of the ice; but with increasing undercooling, dendritic ice crystals will be formed, which are surrounded by concentrated solution. During further growth of the ice layer, part of this concentrated solution gets included as pockets in the frozen ice layer.

The extent to which this inclusion takes place determines the effectiveness of the concentration of the solution. Jusoh et al. (2009) found experimentally that the overall experimental partition coefficient for glucose was relatively constant over an entire concentration run. This led them to suggest a constant distribution coefficient for a particular solute or solution. However, a simple consideration shows that this cannot be fundamentally valid. Ice growth at an infinitesimally slow freezing rate at the freezing temperature of the solution will avoid any accumulation of solutes before the ice, and therefore should result in pure ice. Thus, in this limiting case, the distribution coefficient will be zero. On the other hand, infinitely fast or instantaneous - freezing will certainly lead to complete freezing of the solution, with just as much solute in the ice included, as was present in the original solution. In that case, the distribution coefficient will be one. Thus we conclude that the freezing rate influences the distribution coefficient: it varies at least with the rate of freezing, and it will therefore vary in time, as initially the freezing rate at the onset of the process will be large due to the absence of the ice film. Later in the process the freezing rate will drop, and thus the distribution co- 


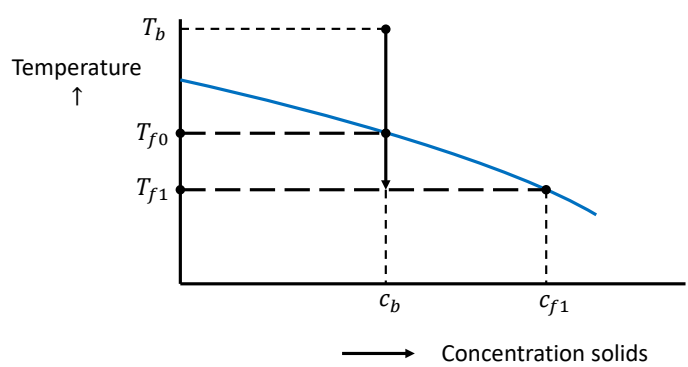

(a)

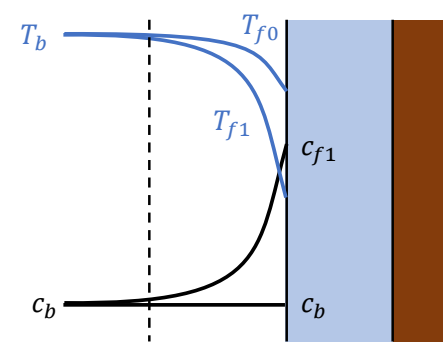

(b)

Figure 5.1: Partial state diagram (a) and depiction of the concentrations and temperatures near the ice layer (b). At infinitesimally slow growth rates, there is no concentration polarization, indicated by subscript 0 ; at higher rates, there is concentration polarization and subsequently stronger freezing point depression at the ice surface, indicated by subscript 1 (Myerson et al. 2019).

efficient will decrease. As indicated, previous research did not fully consider the impact of the dynamics on the inclusion behaviour of solutes, which is important for the effectiveness of this concentration method.

The aim of this study is therefore to offer an analysis to understand solute inclusion during progressive freeze concentration and how it is influenced by freezing point depression. For this we carry out a conceptual analysis of the freezing process, using state diagrams to visualize and analyse the process. We do this by constructing the trajectory of the solution through the state diagram while freezing, as function of the system parameters, and relative to the freezing curve in the state diagram. We consider the freeze concentration of three different types of solutes: $\mathrm{NaCl}$ as a representative of fast diffusing, low-molecular weight solutes; sucrose as a slower diffusing, intermediate molecular weight solute, and BSA as a representative of high molecular weight solutes. Finally, we extrapolate our findings towards even larger solutes, such as colloidal particles, which could for example be non-dissolved proteins.

\subsection{Theory}

\section{State diagram}

The freezing process takes place at the interface between the ice and the solution, assuming the presence of an initial ice layer that acts as a seed. The solute concentration on this surface is significant. Even if the solution itself has a limited solute concentration (say, a few percent), then the concentration polarization will result in much higher concentrations on the surface. We therefore need to take freezing point depression into account; which is represented in a state diagram as a freezing curve with a negative slope.

The freezing point depression can be described with the Clausius-Clapeyron equation; but it is generally used with a constant enthalpy of fusion (Fellows 2017). Since the enthalpy of fusion for water is quite dependent on the temperature, this leads to inaccurate description of the freezing curve in the state diagram; especially at higher solute concentration and 
hence lower freezing temperatures (Bertolini et al. 1985).Therefore, we choose Blagden's law instead, which states that the freezing point of a solution is a in direct proportion to its concentration (Barrow 1961):

$$
T_{m}=T_{m}^{0}-K_{f} \cdot b \cdot i
$$

With $K_{f}$ the cryoscopic constant (equal to $\left.1.86(\mathrm{Kkg}) / \mathrm{mol}\right), b$ the molality of the solution, and $i$ the Van 't Hoff factor.

Figure 5.2a shows for solutions of sucrose in water that while all descriptions are accurate for diluted solutions, Clausius-Clapeyron's equation deviates at lower temperatures and hence higher concentrations of sucrose. The established form of Blagden's law with $i=1$, is just as accurate for diluted solutions, but deviates somewhat at higher concentrations. We adjusted this by assuming a Van 't Hoff factor of 1.16. One should regard this correction as merely a fit to take into account some nonideality of the solutions at higher concentrations. For $\mathrm{NaCl}$ solutions (fig. 5.2b), we find that Clausius-Clapeyron and Blagden are identical, as long as $i=1.9$ is taken for both descriptions.

The molecular weight of BSA is so large, i.e. $66.5 \mathrm{kDa}$, that the precise value of $i$ is not very important. While a BSA molecule may have several counter-ions that would give rise of an i value that is clearly larger than one, for our considerations the freezing line for BSA is practically horizontal; therefore, we describe it with Blagden's law as well. 


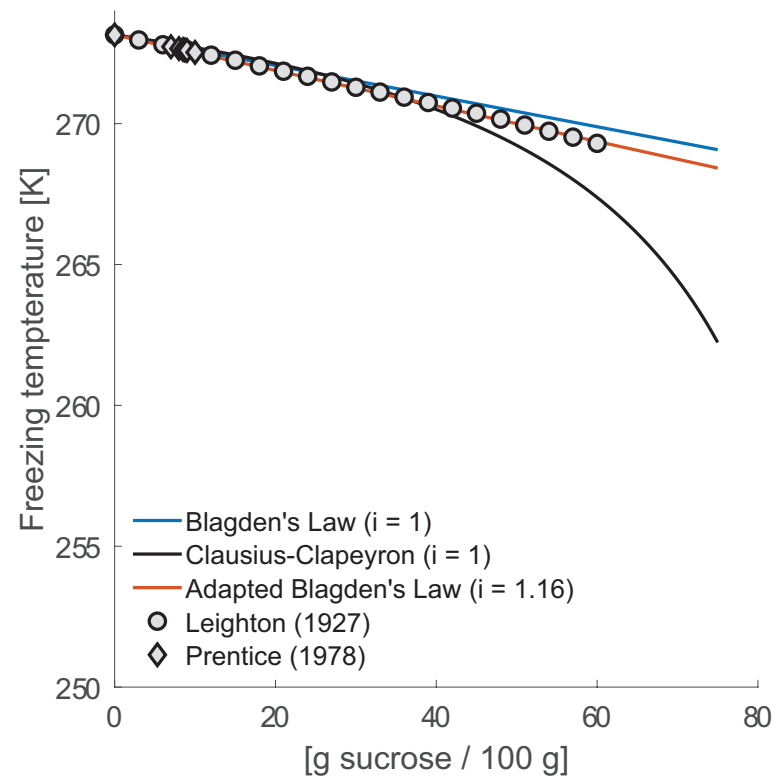

(a)

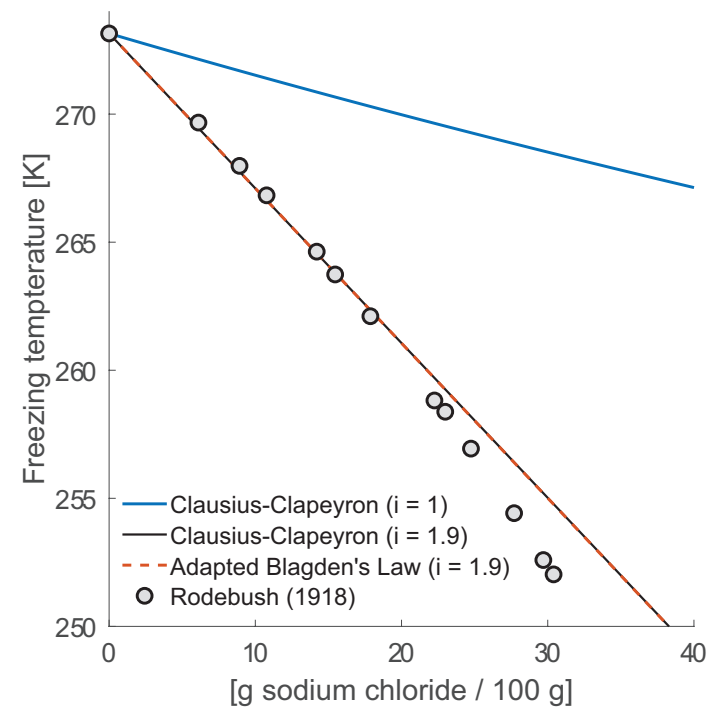

(b)

Figure 5.2: Description of the freezing curve of sucrose-water solutions (a) and $\mathrm{NaCl}-$ water solutions (b) by Clausius-Clapeyron's equation using $\Delta h_{f}=6001 \mathrm{~J} / \mathrm{mol}$; and using Blagden's law. For sucrose lines are shown with $i=1$ (blue line) and with $i=1.16$ (red line). For $\mathrm{NaCl}$ solutions, lines are shown with $i=1$, and with the generally assumed value of 1.9 (Leighton 1927; Prentice 1978; Rodebush 1918). 


\section{Concentration polarization and heat transfer}

We now turn to the dynamics of the freeze concentration process. We assume that we extract cold from the system with a cooling duty or heat flow of $q$ watts per $\mathrm{m}^{2}$, through the layer of ice that has already formed. This heat is extracted by freezing water on the interface between ice and solution, and through heat extraction from the bulk of the solution. We assume that the bulk of the solution is well-mixed, with a boundary layer determining the rate of both heat and mass transfer to the interface.

First, we consider heat transfer through the boundary layer. If we assume an interface fixed frame of reference, heat transfer is through two modes, advective (transfer of water towards the interface, $\left.v \rho c_{p}\left(T_{b}-T_{i}\right)\right)$; and conductive $\left(-\lambda \frac{\mathrm{d} T}{\mathrm{~d} z}\right)$. Further, heat is released by freezing, $\left(v \rho \Delta h_{f}\right)$, with $v$ the rate of water towards the interface $(\mathrm{m} / \mathrm{s})$ and $q$ is the cooling duty:

$$
v \rho c_{p}\left(T_{b}-T_{i}\right)-\lambda \frac{\mathrm{d} T}{\mathrm{~d} z}+v \rho \Delta h_{f}=q
$$

As the advective contribution is very small compared to the conductive and freezing contributions, we will neglect the first term. Using the heat transfer coefficient $h$, given by $h=\frac{\lambda}{\delta}$, with $\delta$ the thickness of the boundary layer, we get:

$$
h\left(T_{b}-T_{i}\right)+v \rho \Delta h_{f}=q
$$

The percentage of the cooling duty used for the formation of ice can be expressed as:

$$
\eta=\frac{v \rho \Delta h_{f}}{q} \times 100 \%
$$

The heat transfer is found through a Nusselt relation, which may be of the form for flat plates under turbulent conditions:

$$
\mathrm{N}_{\mathrm{Nu}}=0.0043 \mathrm{~N}_{\mathrm{Re}}^{0.8} \mathrm{~N}_{\mathrm{Pr}}^{0.33}
$$

We then turn towards mass transfer, by considering the local concentrations of solute in the boundary later. Mass transfer through the same boundary layer can be described by:

$$
v c-D \frac{\mathrm{d} c}{\mathrm{~d} z}=v c_{\mathrm{ice}} \quad \text { or } \quad \frac{\mathrm{d} c}{\mathrm{~d} z}=\frac{v\left(c-c_{\text {ice }}\right)}{D} \rightarrow \frac{c_{\mathrm{i}}-c_{\text {ice }}}{c_{\mathrm{b}}-c_{\text {ice }}}=\exp \left(\frac{v}{k}\right)
$$

With the mass transfer coefficient $k=D / \delta$, found through a Sherwood relation, analogous to the Nusselt relation as it takes place through the same boundary layer:

$$
\mathrm{N}_{\mathrm{Sh}}=0.0043 \mathrm{~N}_{\mathrm{Re}}^{0.8} \mathrm{~N}_{\mathrm{Sc}}^{0.33}
$$

Both mass and heat transfer occur in the same boundary layer. That means that the compositions and temperatures in the boundary layer will form a curve, that starts at the point $\left(c_{b}, T_{b}\right)$ and ends on the freezing curve at $\left(c_{i}, T_{i}\right)$. Schematically, the curve could look as in fig. 5.3. 


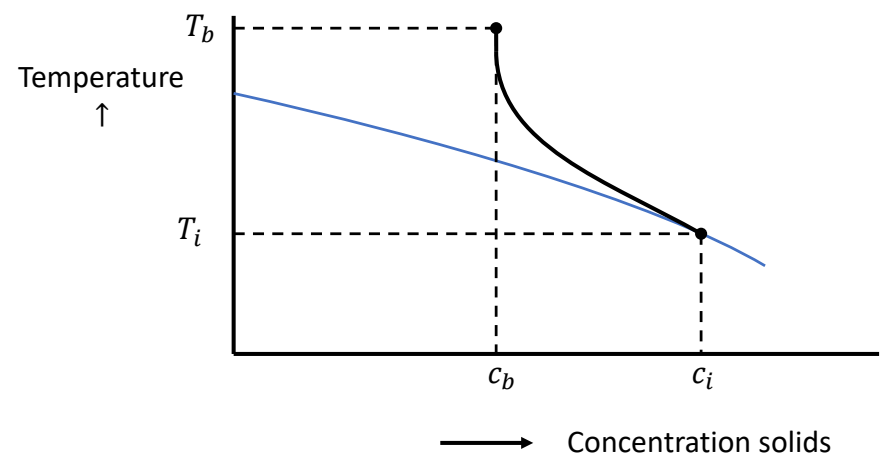

Figure 5.3: Concentration profile in the boundary layer, starting at the bulk temperature and concentration, and ending on the solution-ice interface with concentration and temperature $c_{i}, T_{i}$.

We can calculate this curve more precisely by using both the temperature and the concentration gradients in the boundary layer to find the dependence of the temperature as function of the concentration.

$$
\left.\begin{array}{l}
T_{z}=T_{i}+\left(T_{b}-T_{i}\right) \frac{z}{\delta} \\
\frac{c_{i}-c_{\text {ice }}}{c_{b}-c_{\text {ice }}}=\exp \left(\frac{v(\delta-z)}{D}\right)
\end{array}\right\} T_{c}=T_{b}-\left(T_{b}-T_{i}\right) \frac{k}{v} \ln \left(\frac{c_{i}-c_{\text {ice }}}{c_{b}-c_{\text {ice }}}\right)
$$

In this relation, we do not yet know the concentration and temperature on the interface, $c_{i}$ and $T_{i}$, and the concentration of solute in the ice, $c_{\text {ice }}$. We can find these by making use of the relations that we have. If we have solute inclusion, we can introduce the distribution coefficient $K=c_{\text {ice }} / c_{b}$, and thus eq. (5.8) can be rewritten in:

$$
T_{c}=T_{b}-\left(T_{b}-T_{i}\right) \frac{k}{v} \ln \left(\frac{c_{i}-K c_{b}}{c_{b}-K c_{b}}\right)
$$

We solve these eqs. (5.1), (5.3) and (5.9) for two distinct cases, in the first case we assume slow freezing and that there is no inclusion, i.e. $c_{\text {ice }}=0$ or $K=0$. In the second case we assume that the freezing is faster and that there will be inclusions. The system of equations was solved using MathCad Prime (PTC Inc., USA; version 4.0).

\section{Dynamics of slow freezing: no solute inclusion}

In the case of very slow freezing, the ice inclusions will be zero, and thus $c_{\text {ice }}=0$. In that case, it is straightforward to find the values of the parameters. We first set $v$ as independent parameter, which will give us $c_{i}$ through eq. (5.6) by taking $c_{\text {ice }}=0$; then using eq. (5.1) with $T_{m}=T_{i}$, to find $T_{i}$, which can then be used to find $h\left(T_{b}-T_{i}\right)$ and therefore $q$ using eq. (5.3) (figs. 5.5a and 5.5b). In figs. 5.4a and 5.4b the slow freezing is shown in the state diagram. The composition of the boundary layer does not cross the freezing line and therefore there won't be inclusions. If faster freezing is applied the composition in the boundary layer will cross the freezing line and a zone with super-cooling occurs in which solution and the tips of 


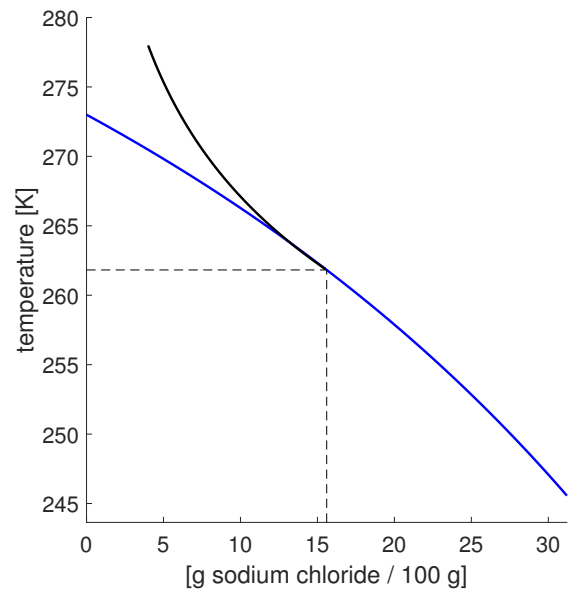

(a)

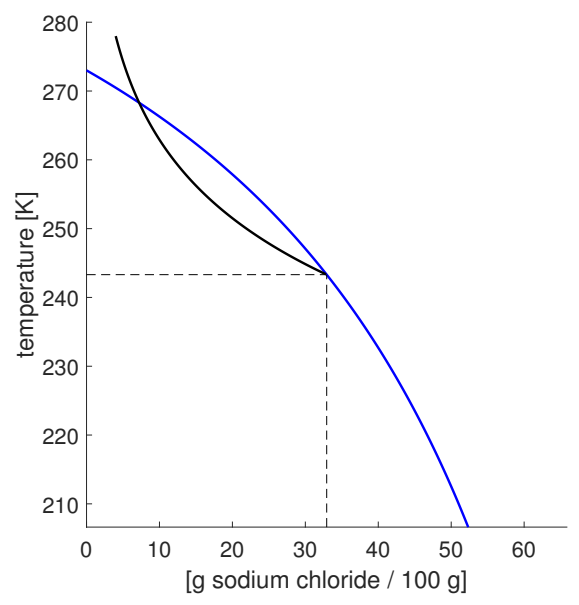

(c)

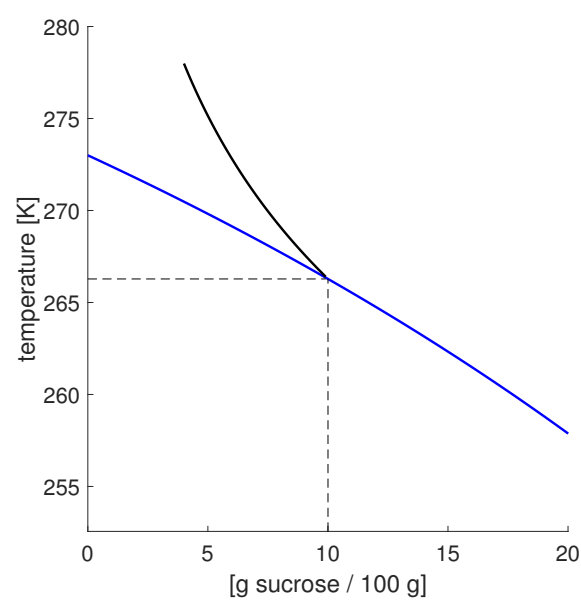

(b)

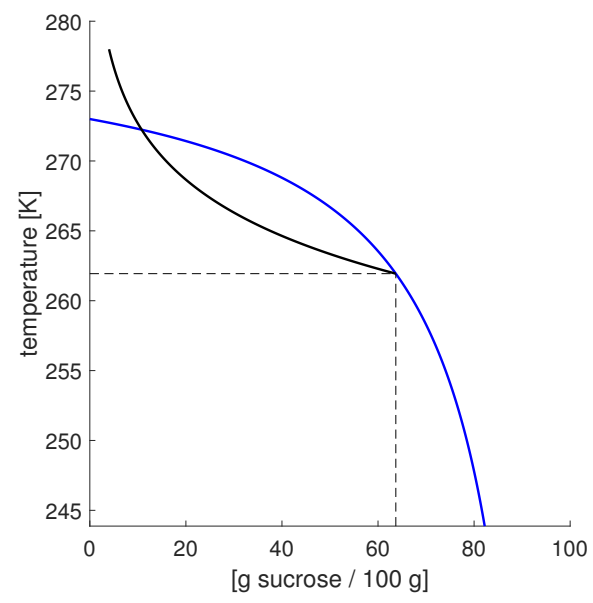

(d)

Figure 5.4: (a) and (c) are state diagrams for sodium chloride with $q=40 \mathrm{~W} / \mathrm{m}^{2}$ (a) and with $q=80 \mathrm{~W} / \mathrm{m}^{2}$ (c). (b) and (d) are state diagrams for sucrose with $q=20$ $\mathrm{W} / \mathrm{m}^{2}$ (b) and $q=40 \mathrm{~W} / \mathrm{m}^{2}$ (d). At (a) and (b), the freezing is stable. For the other situation, the composition in the boundary layer is unstable and will create a freezing zone in the boundary layer. The blue line represents the freezing line, the black line represents the temperature and composition in the boundary layer. The dashed lines indicate the temperature and composition at the interface. 


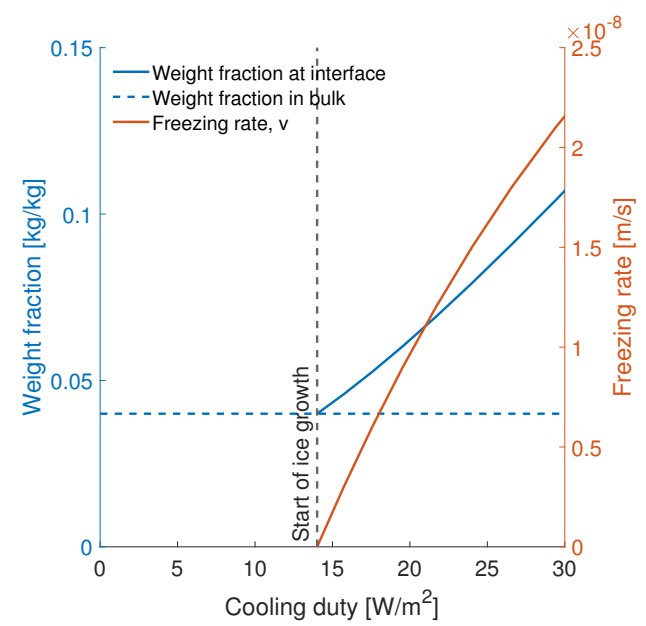

(a)

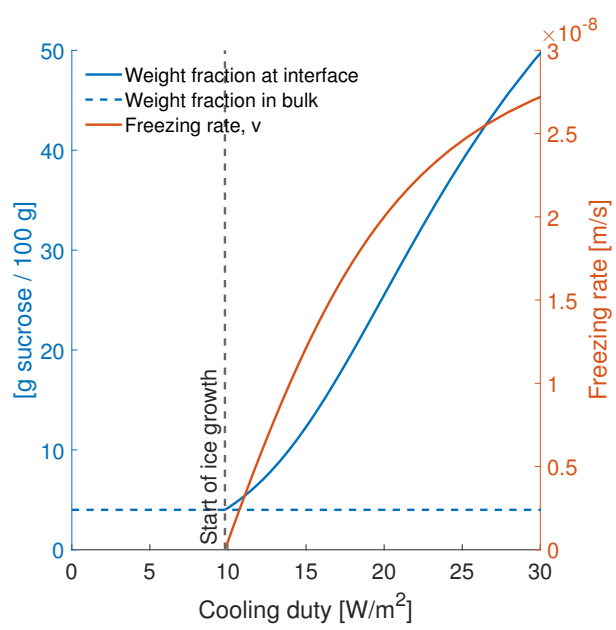

(b)

Figure 5.5: (a) sodium chloride and (b) sucrose, are plots of the freezing rate $v$ and concentration at the interface $c_{i}$, as function of the cooling duty $q$.

the ice crystals are present. In this case we need to invoke an extended model to account for the fast freezing (figs. 5.4c and 5.4d).

The model also allows us to determine the concentration at the interface, $c_{i}$, and the minimum required cooling duty for ice growth (figs. 5.5a and 5.5b). The concentration at the interface is useful information for to determine the maximum cooling duty to have no inclusions. This will be expanded upon in the next section. The minimum cooling duty arises from the heat flux for cooling down the bulk solution. This cooling down takes up part of the heat removed from the applied cooling duty (eq. (5.3)) and has to be overcome for the system to be able to form ice.

\section{Dynamics of fast freezing: solute inclusion}

If freezing is faster (induced by a larger temperature difference over the layer of ice), then the situation becomes different. The freezing front is stable, as long as the slope of the composition curve in the point $\left(c_{i}, T_{i}\right)$ is larger - in absolute sense - than the slope of the freezing curve. In fig. 5.6 we see an 'artist impression' of the situations.

At larger freezing rates (relative to the rate of diffusion of the solute), the concentration profile becomes steeper, and at some point it may cross the freezing curve (fig. 5.6C). At this point, the solution within the boundary layer is below the freezing curve and therefore can freeze itself. One also can observe that the driving force for the formation of ice, which is the temperature difference between the local composition and the freezing curve, is smallest on the ice surface, and gets larger with the distance from the surface. That means, that any irregularity on the ice surface will have a larger driving force for freezing and therefore will grow faster than the ice surface on average. This means that there is a driving force for the ice to form oscillations, ultimately leading to the formation of needle-shaped, or dendritic ice crystals, from the surface, into the boundary layer, creating a freezing zone. The solution 


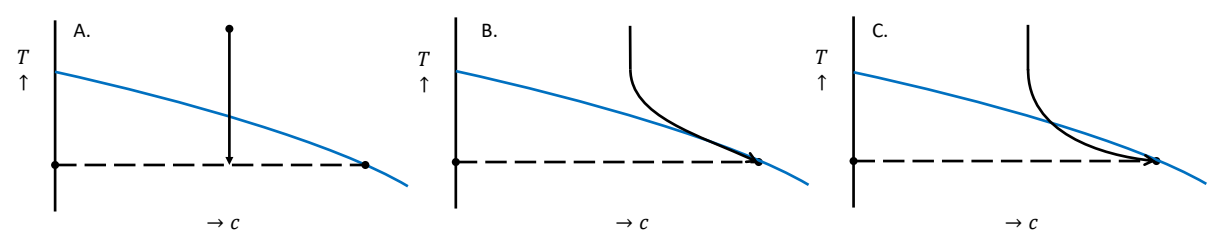

Figure 5.6: Paths through the state diagram. A: before nucleation has started, a temperature gradient is created, but compositions have not yet changed. B: Slow freezing. The composition path stays outside the freezing line, and therefore the freezing front is stable. C: Fast freezing, resulting in ice formation in front of the freeze front and solute inclusion.

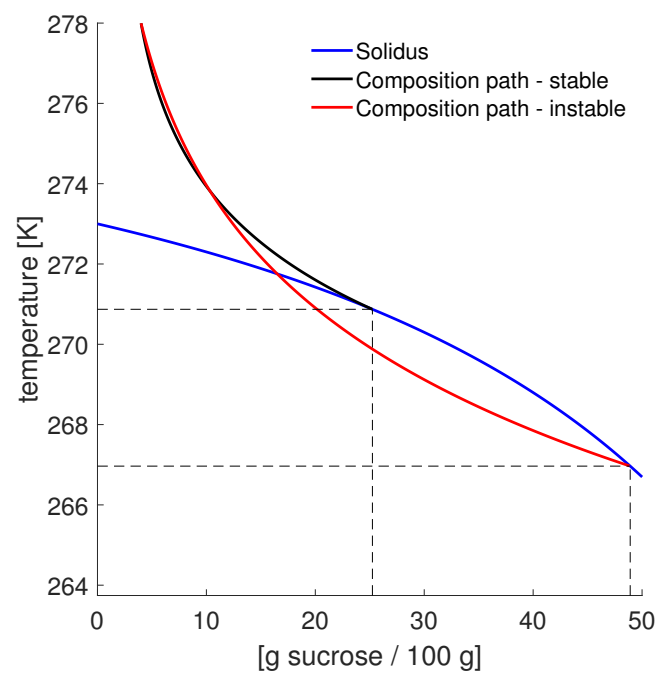

Figure 5.7: Situation for a $4 \mathrm{w} / \mathrm{w} \%$ solution of sucrose in water starting at $278 \mathrm{~K}$, with $29.6 \mathrm{~W} / \mathrm{m}^{2}$ total heat removal duty. The blue curve is the freezing line. The red, instable composition path gives rise to dendritic growth inside the boundary layer. The composition path for the boundary layer on top of the freezing zone, therefore relaxes to the verge of stability, indicated by the black curve. In this case we have a distribution coefficient of 0.49 , meaning that the solute concentration in the ice is $49 \%$ of that in the bulk solution (which was $4 \%(w / w)$ ) (eq. (5.9)).

surrounding these ice crystals will become more and more concentrated and will ultimately be trapped into the ice, while the ice front will continue to move towards the bulk solution.

From a macroscopic standpoint, we observe that the ice incorporates a part of the solution, while the concentration polarization itself will become less extreme since a part of the solutes is not accumulating anymore in the boundary layer (Vuist et al. 2020; Vuist et al. 2021). The situation as displayed in panel $\mathrm{C}$ of fig. 5.6 will therefore relax with the situation in the boundary layer on the verge of instability. 
The new situation, that results in zone freezing and solute inclusion, has one extra requirement, being that the slopes of the composition path and the freezing curve are the same:

$$
{\frac{\mathrm{d} T_{c}}{\mathrm{~d} c}}_{\left(c_{i}, T_{i}\right)}=\frac{\mathrm{d} T_{m}}{\mathrm{~d} c}{ }_{\left(c_{i}, T_{i}\right)}
$$

We can see in fig. 5.7 that in the new situation the surface temperature goes up, and therefore we extract less heat from the solution; therefore more of the cooling is used to actually freeze water, albeit at lower purities. By simultaneously solving eqs. (5.1), (5.3) and (5.9) and applying boundary condition (5.10), we can find now the composition path that represents the compositions in the boundary layer that is now on top of the zone that undergoes dendritic (or similar) freezing. So, in this zone pure ice crystals and concentrated solution co-exist. When the freezing continues the freezing boundary will move into the direction of the solute and the ice crystals will overtake this mixed zone causing the solute inclusion. The distribution coefficient, $K$, is derived from eq. (5.9), since this the only unknown not determined by the other equations. Note in fig. 5.7 that because the solution on top of the freezing zone has a higher temperature, this means that although we lose purification, we lose less heat through conduction from the bulk solution i.e. $T_{i}$ at the top of the freezing zone is higher (eq. (5.3)). We typically see a sudden, slight reduction in overall energy duty necessary at this transition.

\subsection{Results and discussion}

\section{Low-molecular weight solutions: $\mathrm{NaCl}-$ water and sucrose-water}

Low molecular weight components such as $\mathrm{NaCl}$ and sucrose are abundant in food and other industrial streams. To not complicate the analyses, we neglect the temperature dependence of the parameters. These would change the quantitative outcomes, but not the qualitative ones. For a $4 \%\left(\mathrm{w} / \mathrm{w}\right.$ ) solution, we assumed that the diffusivity of $\mathrm{NaCl}$ in water is $1.5 \times 10^{-9} \mathrm{~m}^{2} / \mathrm{s}$, and that of sucrose in water $5.2 \times 10^{-10} \mathrm{~m}^{2} / \mathrm{s}$; and that the bulk solution was at $298 \mathrm{~K}$. We also assumed that the thermal conductivity was constant at $0.5610 \mathrm{~W} /(\mathrm{m} \mathrm{K})$, and that the density of the solution remained at $1000 \mathrm{~kg} / \mathrm{m}^{3}$.

Both $\mathrm{NaCl}$ and sucrose give similar patterns as function of the freezing rate, with a stable freezing region below a certain cooling duty and freezing rates characterised by no inclusions, and instable growth with increasing levels of inclusion above this threshold (fig. 5.8). Due to the lower diffusion coefficients of sucrose in water, the transition occurs at a lower cooling duty with sucrose than with $\mathrm{NaCl}$. During unstable freezing (and thus solute inclusion, the solute concentration on the interface between the freezing zone and the solution has a lower concentration and thus a higher temperature (dictated by the freezing line), and the amount of heat extracted from the bulk solution decreases at a higher rate again before levelling off (eq. (5.4)). At higher bulk concentrations the threshold between stable and instable freezing will shift to lower freezing rates and therefore the process will be further limited, i.e. the maximally allowed cooling duty is lowered at higher concentrations. The threshold can be shifted to higher freezing rates if the Reynolds number goes up, i.e. if mixing in the bulk is improved.

It should be noted that the diffusivity of sucrose is in reality highly dependent on the temperature and concentration: since it is not too far off from the glass transition, it therefore follows Williams-Landel-Ferry kinetics, characterised by a much faster increase in viscosity 


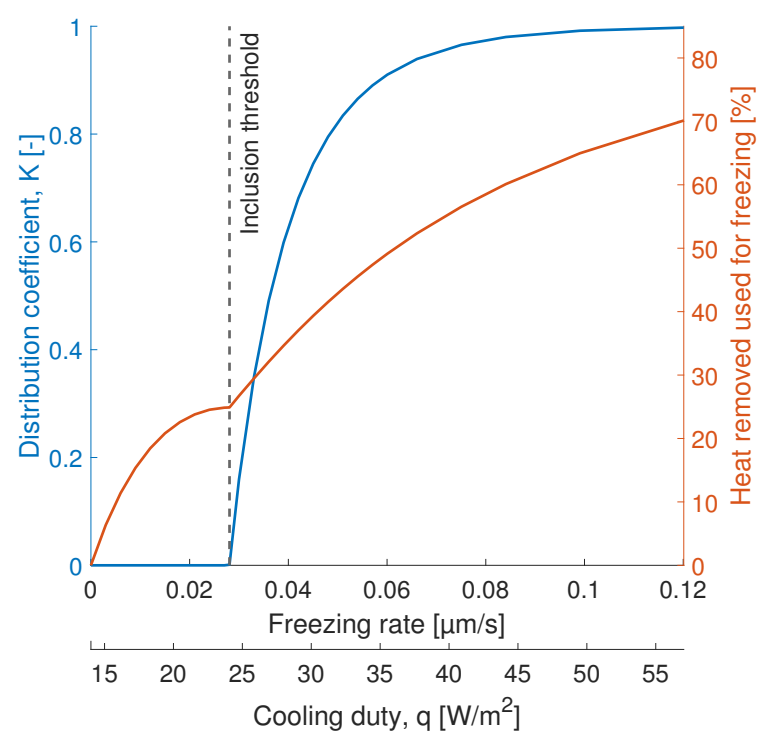

(a) $\mathrm{NaCl}$-water

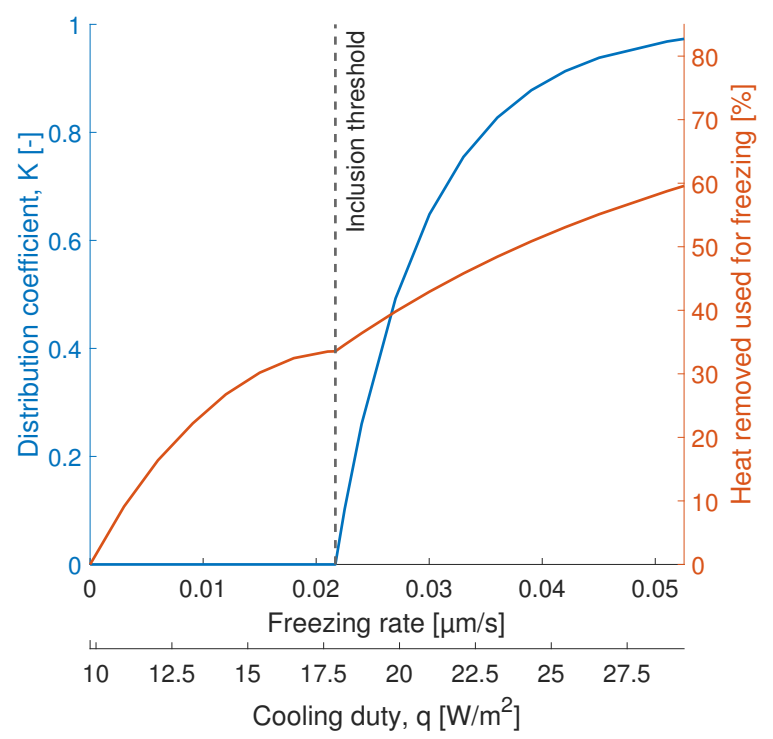

(b) sucrose-water

Figure 5.8: Distribution coefficient $K$ (blue line) and percentage of the cooling duty that is used for freezing of a $4 \%(\mathrm{w} / \mathrm{w})$ solution (eq. (5.4), the rest is used for cooling the bulk solution; red line). Below the threshold, the composition paths are above the freezing line and freezing is stable. Above the threshold, a part of the profile is below the freezing line and distribution occurs, with an increasing value of the distribution coefficient, towards a value of 1 (implying no concentration at all). 
and reduction in diffusivity than expected merely on basis of Arrhenius dependence (Kerr et al. 1994). The transition towards unstable freezing is therefore expected at even lower threshold values than indicated in fig. 5.8. Difference between the two will therefore be much stronger in reality.

\section{High-molecular weight solutions: proteins}

While the principles are the same with high-molecular weight solutes, the state diagram dictates a somewhat different process. We here take the protein bovine serum albumin (BSA) as an example and calculated the composition paths during freeze concentration of BSA for different cooling duties (fig. 5.9). The large molecular weight of the solute dictates a much more horizontal freezing line in the state diagram. Therefore, it is virtually impossible that the composition path in the boundary layer will get below the freezing line. Even at very high surface concentrations, the concentration polarization layer remains completely stable.

This means that for a high-molecular weight solute, no instable freezing inside the concentration polarization layer will occur, and that solute inclusion according to the mechanism proposed is not possible. Of course, this is only valid as long as the solute remains in solution and does not precipitate.

It is known from the field of crossflow ultrafiltration, that concentration polarization of proteins on a membrane, at some point leads to the formation of a gel layer, in which the concentration of the protein is a constant (at equal temperature and solvent quality); often at around $0.6 \mathrm{~kg} / \mathrm{m}^{3}$ (Hiddink et al. 1980). We expect that this will also occur on top of an ice layer that extracts water from the solution and hence creates the same type of concentration polarization.Thus, at higher rates of heat extraction, a gel layer will form on top of the ice layer. This gel layer will also be stable (i.e. will not induce dentritic ice growth) but will form an insulating layer, reducing the mass and heat transfer, and thus reducing the rate of freezing. Therefore, we expect that at higher freezing rates, the rate of freezing will increase less than proportionally with the driving force for freezing. We can therefore predict that the protein concentration will remain stable, even at higher freezing rates.

This is only valid, as long as the freezing line has a very small, absolute, slope. This is the case when the solution contains only a high-molecular weight solute, but as soon as lowermolecular weight solutes are also present, then the freezing curve will have a larger, absolute, slope. At some point, the concentration in the polarization layer can cross the freezing line again, and cause instable, dendritic ice growth in the boundary layer, and hence induce inclusion of both the low-molecular weight and the high-molecular weight solutes. We therefore predict that a solution containing both low-molecular and high-molecular weight solutes can result in solute inclusion again. So, unless the protein source is very pure, most realistic soluble protein solution will show solute inclusion in practice.

For proteins that are not dissolved at all but that are suspended as colloidal particles, we expect that the Brownian diffusivity of the particles is very small (Vuist et al. 2021). Even a very small amount of lower-molecular weight co-solutes will cause enough freezing point depression to allow these colloidal particles to be included. Therefore, we expect that for all practical conditions, undissolved components will be included in the ice. 


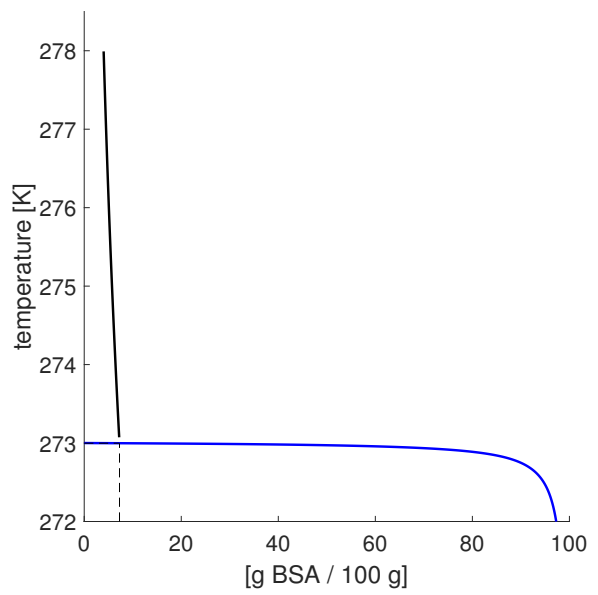

(a) $q=9.82 \mathrm{~W} / \mathrm{m}^{2}$

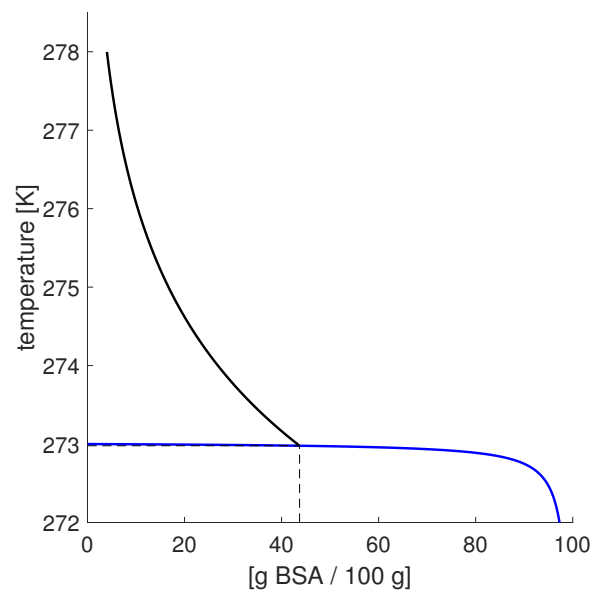

(b) $q=11.36 \mathrm{~W} / \mathrm{m}^{2}$

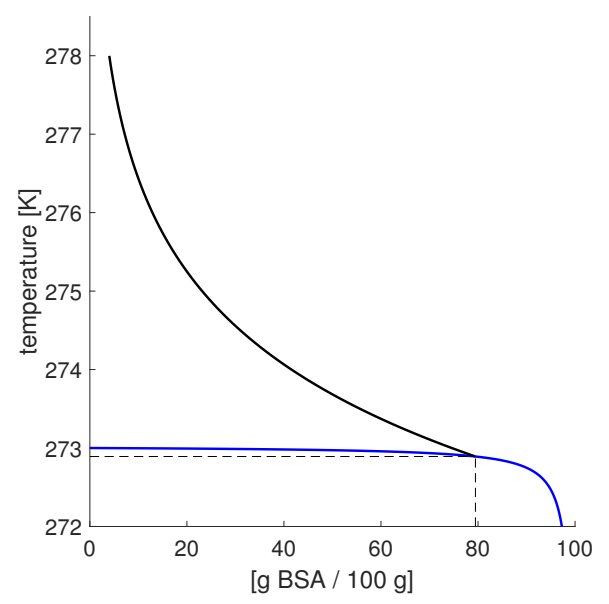

(c) $q=12.02 \mathrm{~W} / \mathrm{m}^{2}$

Figure 5.9: Composition paths for a starting solution of $4 \%(w / w)$ BSA, for three different rates of heat extraction. The freezing line is so flat, that it is virtually impossible for the concentrations in the boundary layer to come below the freezing line. Surface concentrations are 7,3 (a), 43.7 (b) and 79.5 (c) \%(w/w), respectively. The blue line represents the freezing line, the black line represents the temperature and composition in the boundary layer. 


\section{Discussion on application of the theory}

The results presented, are based on a highly simplified representation of the system. Diffusion and viscosity values were assumed to be constant and independent on the temperature. Of course, this is an oversimplification. A concentrated sucrose-water solution is anomalously viscous, since it is quite close to its glass transition. Such solutions exhibit WilliamsLandel-Ferry kinetics, characterised by very sharp increases in viscosity with a reduction in temperature or an increase in concentration. This implies that the local viscosity gradient for these solutions in the concentration polarization layer will be much steeper than assumed here. Similarly, the sucrose diffusion coefficient in water will be locally much lower in the concentration polarization layer, and hence the real concentration gradient will be much steeper. Therefore, the conclusions are only qualitative or at most semi-quantitative. The general behaviour that is found and described here, will however remain as is described. It is relatively straightforward to implement concentration and temperature dependence for the viscosity and diffusivities in the system, once these parameters are known with sufficient reliability in the relevant parameter space (temperature, composition).

Miyawaki et al. (1998) suggested that the inclusion factor be a constant. Later Gunathilake et al. (2013) observed that the inclusion factor is concentration dependent. One should bear in mind that experimental values for the inclusion factor are integrated over time, while the results shown here are only for momentary heat extraction rates. In a real process, the heat extraction at the beginning is very high, since there is no insulating ice layer formed yet on the heat exchanging surface, and will gradually decrease when the ice layer grows over time. At the beginning of the process, the inclusion rate will therefore be high, and will come down during the process. The experimentally measured inclusion factor is therefore a value that is integrated over time (Vuist et al. 2021). It is therefore expected that these integrated, experimental values are less variable than the momentary values, which are predicted in this work. Further elaboration of the model could certainly include the integration of the model over time.

\subsection{Conclusions}

It was shown that state diagrams can be useful to interpret the ice formation process during progressive freeze concentration. As long asthe composition path in the concentration polarization layer on top of the ice, does not cross the freezing line, freezing will be stable and unstable, dendritic ice formation inside the boundary layer is avoided. Instable ice formation inside the boundary layer will result in inclusion of solutes. This generally happens at larger ice formation rates, such that the concentration profile in the boundary layer becomes too steep, and in the state diagram, has a lower (absolute) slope than the freezing line. This prediction does not assume anything about the exact ice formation mechanism, and therefore, the phenomenon of solute inclusion therefore does not depend on whether the instable ice formation in the boundary layer is dendritic or through any other type of growth mechanism.

We showed that inclusion of low-molecular weight solutes happens fairly quickly, due to the strong freezing point depression. The transition to instable ice growth and solute inclusion happens at lower heat extraction rate with smaller molecules, larger absolute slope of the freezing line, and with slower-diffusing components, steeper concentration gradients. Solutions with only macromolecular solutes will not give any instable ice growth, since the 
freezing line is virtually horizontal in the state diagram, not allowing the concentration gradient to cross the freezing line. We do expect however, that at some point, a gel layer will be formed on top of the ice, which will slow the formation of the ice. Solutions that contain both low-molecular weight and high-molecular weight components, will most probably show solute inclusion: the low-molecular weight components will give significant freezing point depression and a freezing line that has a larger absolute slope, while the macromolecular components have low diffusivities and hence will quickly accumulate on top of the growing ice layer.

The system was here strongly simplified by assuming viscosities and diffusivities to be independent on concentration and temperature. Inclusion of these effects will improve the quantitative accuracy of the model. Integration of the model over time will yield overall inclusion factors that can be more easily compared to experimental values.

The main application of this model is that it can be used to consider streams for progressive freeze concentration and to calculate their expected performance. Since the data needed for the estimation are easily measurable, an estimation of the expected performance can be made. This will save time and resources, which is especially valuable for scaling up progressive freeze concentration to a scale interesting for industrial application. 


\section{References}

Barrow, G. M. (1961). "Colligative Properties of Solutions”. In: Physical chemistry. New York [etc.]: McGraw-Hill. Chap. 15, pp. 499-501 (cit. on p. 75).

Bertolini, D., M. Cassettari, and G. Salvetti (Sept. 1985). "Anomalies in the "latent heat" of solidification of supercooled water". In: Chemical Physics Letters 119.6, pp. 553-555. ISSN: 0009-2614. DOI: 10.1016/0009-2614(85)85387-2 (cit. on p. 75).

Fellows, P. J. (2017). “20 - Heat removal by refrigeration”. In: Food Processing Technology. Fourth. 2011, pp. 847-868. ISBN: 9780081019078. DOI: 10 . 1016/B978-0-08-100522-4 . 00020-1 (cit. on p. 74).

Gunathilake, Mihiri, Kiyomi Shimmura, and Osato Miyawaki (2013). "Analysis of solute distribution in ice formed in progressive freeze-concentration". In: Food Science and Technology Research 19.3 (3), pp. 369-374. ISSN: 1344-6606. DOI: 10.3136/fstr.19.369 (cit. on p. 86).

Hiddink, J., R. de Boer, and P. F. C. Nooy (Feb. 1980). "Reverse Osmosis of Dairy Liquids". In: Journal of Dairy Science 63.2, pp. 204-214. ISSN: 0022-0302. DOI: 10 . 3168/ jds . S0022-0302 (80) 82915-8 (cit. on p. 84).

Holt, S. (Dec. 1999). "The role of freeze concentration in waste water disposal". In: Filtration and Separation 36.10, pp. 34-35. ISSN: 0015-1882. DOI: 10.1016/S0015-1882 (00)80052-X (cit. on p. 73).

Jusoh, M., R. M. Yunus, and M. A. Abu Hassan (Dec. 2009). "Performance investigation on a new design for Progressive Freeze Concentration system". In: Journal of Applied Sciences 9.17 (17), pp. 3171-3175. ISSN: 1812-5654. DOI: 10.3923/jas.2009.3171.3175 (cit. on p. 73).

Kerr, William L. and David S. Reid (1994). Temperature dependence of the viscosity of sugar and maltodextrin solutions in coexistence with ice. DOI: 10.1006/fstl.1994.1046 (cit. on p. 84).

Leighton, Alan (1927). "Separation of Cane Sugar from Water Ice". In: Journal of Dairy Science 10.3, pp. 219-223. ISSN: 0022-0302. DOI: 10.3168/jds . S0022-0302 (27) 93835-1 (cit. on p. 76).

Miyawaki, Osato, Ling Liu, and Kozo Nakamura (Sept. 1998). "Effective partition constant of solute between ice and liquid phases in progressive freeze-concentration". In: Journal of Food Science 63.5 (5), pp. 756-758. ISSN: 0022-1147. DOI: 10.1111/j.1365-2621.1998.tb17893.x (cit. on p. 86).

Myerson, Allan S., Deniz Erdemir, and Alfred Y. Lee (June 2019). Handbook of industrial crystallization. English. Third edit. Cambridge ; Cambridge University Press, pp. 1-528. ISBN: 9781139026949 DOI: $10.1017 / 9781139026949$ (cit. on p. 74).

Ojeda, A., F. L. Moreno, R. Y. Ruiz, M. Blanco, M. Raventós, and E. Hernández (Aug. 2017). "Effect of Process Parameters on the Progressive Freeze Concentration of Sucrose Solutions". In: Chemical Engineering Communications 204.8, pp. 951-956. ISSN: 0098-6445. DOI: 10 . 1080/00986445. 2017.1328413 (cit. on p. 73).

Prentice, J. H. (1978). "Freezing-point data on a aqueous solutions of sucrose and sodium chloride and the Horvart test: a reappraisal". In: Analyst 103.1233, pp. 1269-1273. ISSN: 0003-2654. DOI: 10.1039/AN9780301269 (cit. on p. 76).

Rodebush, Worth H. (Aug. 1918). "The Freezing Points of Concentrated Solutions and the Free Energy of Solution of Salts.” In: Journal of the American Chemical Society 40.8, pp. 1204-1213. ISSN: 0002-7863. DOI: 10.1021/ja02241a008 (cit. on p. 76).

Sánchez, J., E. Hernández, J. M. Auleda, and M. Raventós (2011). "Review: Freeze Concentration Technology Applied to Dairy Products". In: Food Science and Technology International. ISSN: 10820132. DOI: $10.1177 / 1082013210382479$ (cit. on p. 73).

Sánchez, J., Y. Ruiz, J. M. Auleda, E. Hernández, and M. Raventós (Aug. 2009). "Review. Freeze concentration in the fruit juices industry". In: Food Science and Technology International 15.4 (4), pp. 303-315. ISSN: 1082-0132. DOI: 10.1177/1082013209344267 (cit. on p. 73).

Vuist, Jan Eise, Remko M. Boom, and Maarten A. I. Schutyser (Mar. 2020). "Solute inclusion and freezing rate during progressive freeze concentration of sucrose and maltodextrin solutions". In: Drying Technology, pp. 1-9. ISSN: 0737-3937. DOI: 10.1080/07373937.2020.1742151 (cit. on pp. 73,81$)$. 
Vuist, Jan Eise, Rikke Linssen, Remko M. Boom, and Maarten A. I. Schutyser (Aug. 2021). "Modelling ice growth and inclusion behaviour of sucrose and proteins during progressive freeze concentration”. In: Journal of Food Engineering 303, p. 110592. ISSN: 0260-8774. DOI: 10.1016/ j . jfoodeng. 2021.110592 (cit. on pp. 73, 81, 84, 86). 

General discussion 
Nomenclature

\begin{tabular}{lll}
\hline Symbol & Description & Unit \\
\hline$C_{\text {concentrate }}$ & Concentration of solids in the concentrate & $\mathrm{kg} / \mathrm{kg}$ \\
$C_{\text {feed }}$ & Concentration of solids in the feed & $\mathrm{kg} / \mathrm{kg}$ \\
$C_{\text {ice }}$ & Concentration of solids in the ice fraction & $\mathrm{kg} / \mathrm{kg}$ \\
$C F$ & Concentration factor & - \\
$C O P$ & Coefficient of performance & - \\
$E$ & Enthalpy & $\mathrm{kJ} / \mathrm{kg}$ \\
$K$ & Distribution coefficient & - \\
$\dot{M}_{\text {coolant }}$ & Mass flow of coolant & $\mathrm{kg} / \mathrm{s}$ \\
$M_{\text {ice }}$ & Mass of the ice fraction & $\mathrm{kg}$ \\
$P$ & Power & $\mathrm{kW}$ \\
$Q_{\text {cooling }}$ & Cooling power & $\mathrm{kW}$ \\
$S E C$ & Specific energy consumption & $\mathrm{kJ} / \mathrm{kg}$ ice \\
\hline
\end{tabular}




\subsection{Introduction}

The objective of the study reported in this thesis was to investigate the principles of progressive freeze concentration for concentration of solutions and finally its practical feasibility, using experiments with a pilot-scale freeze concentrator.

This chapter will first reflect on the main findings of this thesis, which concern small-scale experimental and theoretical analyses of the phenomena of solute inclusion and freezing point depression during progressive freeze concentration. Subsequently, the design and operation of a pilot scale progressive freeze concentrator is discussed. This part is not only important to verify our understanding of the freeze concentration process, but also to assess its feasibility in terms of separation and energy efficiencies. Finally, an outlook is provided of future research that can be done in the area of progressive freeze concentration.

\subsection{Main findings}

To investigate the principles of progressive freeze concentration, experiments with a smallscale freeze concentrator were combined with modelling of the responsible phenomena. In chapter 2, a lab-scale progressive freeze concentrator was designed and used for testing the freeze concentration behaviour of sucrose and maltodextrin solutions. Sucrose was selected as a model solute to allow comparison to other studies (Flesland 1995; Miyawaki et al. 1998; Auleda et al. 2011). Maltodextrin was used in this study as a solute with a larger molecular weight and smaller diffusion coefficient but otherwise like sucrose. From this initial study we concluded that, as expected, an increase in the ice growth rate increases the solute inclusion, while increasing the agitation leads to a decrease in the boundary layer thickness and less solute inclusion. A constant heat exchanger temperature causes the freezing rate at the beginning of the process to be high, and then gradually to decrease over time. This causes high levels of inclusion at the beginning which then gradually fall, leading to suboptimal overall separation. To counter this effect, the cooling strategy was changed to an initial temperature just below the freezing point of the solution which was then gradually lowered as the ice layer thickened. The rate of ice growth is then more or less constant in time. This gave a reduction in solute inclusion of up to a factor of 3 . During the process, the concentration of the solution increases, and this also increased the level of inclusions. This could be partially countered by increasing the stirrer rate over time. Theoretically, sufficiently increasing the stirrer rate could completely solve the problem of solute inclusion, however, there is a practical limit due to the heating of the fluid by the agitation, slowing or even stopping ice growth.

With the data gathered in chapter 2, a model was developed and applied to the data from the lab-scale system. Additionally, new experiments with whey protein isolate and soy protein concentrate solutions are reported in chapter 3. The model is based on existing theory from melt crystallization in which a constant distribution coefficient is used (Myerson et al. 2019). This empirical intrinsic distribution coefficient is the ratio between the momentary concentration in the ice and the momentary concentration at the interface at an infinitesimal small ice growth rate and near infinite mass transfer rate. From this coefficient the apparent distribution coefficient can be calculated which then gives the level of inclusions. After extending the model with the appropriate heat and mass balances and fitting this distribution coefficient in experimental data, the model was compared to the measurements. At low ice growth rates, we found good agreement between the model and our data; however, at higher 
ice growth rates the model underestimated the level of inclusions. One of the assumptions in the model, pertaining to the ice growth being slow and planar, does not hold during dendritic ice formation at faster ice growth.

The experiments with whey protein isolate and soy protein concentrate gave the insight that the properties of the solute are important for its inclusion behaviour. Soy protein, being a protein that is mostly not molecularly dissolved, showed high solute inclusion due to the slowly diffusing particles forming a layer on the ice. In contrast, whey protein, which is molecularly dissolved, showed almost no solute inclusion at lower ice growth rates. Whey protein was therefore chosen to serve as a model solute in chapter 4.

In chapter 4, whey protein solutions were therefore studied. Since industrial fluids seldomly contain just proteins, mixtures of protein with salt and sucrose were freeze concentrated. The addition of both sodium chloride and sucrose increased the inclusion of that solute, and of the protein. It was hypothesised that in the case of sodium chloride the solute inclusion is caused via localised super-cooling in the concentration polarization layer. In the area where the super-cooling occurs both ice crystals and solution can be present. Therefore, ice crystals form in the layer, and create an irregular extension of the ice front and when the front moves towards the solution, domains of concentrated solution are incorporated into the ice layer. The freezing point depression by sucrose is much less extreme (per unit of weight), so we here hypothesize that besides the effect of the localised super-cooling, the inclusions are caused by the strong increase of the viscosity and reduction of the diffusivity of the concentrated solution at low temperatures through William-Landel-Ferry kinetics (Kerr et al. 1994). This leads to a reduction of the mass transfer and subsequent solution inclusion in ice. When both sodium chloride and sucrose are added, the effect on inclusion is not additive but concurrent, i.e., the addition of both did not cause more inclusions than does adding either of the two.

With these observations a theoretical model for the prediction of solute inclusion was developed in chapter 5 . The model makes use of the state diagram. This model predicts the existence of two ice growth regimes. The first regime occurs at low ice growth rates for any solute, and at all growth rates for a solution with only macromolecular solutes. Here, the compositions within the boundary layer stay above the freezing line, and therefore the ice growth is stable. No inclusion is expected. The second regime is at larger ice growth rates, and with smaller solutes that do give appreciable freezing point depression. Here, the compositions in the boundary layer cross the freezing line, which then leads to freezing within the boundary layer, and therefore giving significant inclusion. The intrinsic distribution factor in this second regime follows from the balance between mass and heat transfer rates, and the position of the freezing line in the state diagram. To calculate the distribution factor, the system of equations for mass and heat transfer, and freezing point depression is solved with a constraint that the composition path should touch but not cross the freezing line. This represents the edge of where stable freezing would be possible for the applied freezing rate and that level of inclusions. This composition path gives the concentration and temperature on the edge of the freezing zone. This freezing zone is then the part of the solution that will eventually be included in the ice. The model predicts the inclusion of low-molecular weight components and the negligible inclusion of well-dissolved proteins, such as whey proteins. At very high freezing rates, even whey protein solutions do show inclusion. We expect that 
this is because the concentration of protein in the boundary becomes so high, that gelation (or jamming) takes place.

In the next part of the general discussion, the focus is on verification of our understanding of the principle of freeze concentration and assessment of the feasibility of progressive freeze concentration using a pilot-scale freeze concentrator.

\subsection{Pilot-scale progressive freeze concentration}

A pilot-scale progressive freeze concentrator was designed by ECN-TNO (fig. 6.1). General requirements for the design were that it should have a $100 \mathrm{l}$ capacity for the liquid product per batch and should enable an ice growth rate of up to approximately $2 \mathrm{~cm} /$ hour resulting in a desired water removal of 25 to $50 \%$ of the starting volume. This rendered the required compressor for the cooling system the determining factor for sizing of the unit. The final design of the unit is based on an indirect cooling system, which delivers a minimum temperature of $-20{ }^{\circ} \mathrm{C}$ and has a maximum cooling power of $15 \mathrm{~kW}$. This cooling system is coupled to a heat exchanger in the product vessel via an expansion vessel. Six heat exchanger plates were placed in the concentration vessel (220 1), which is split into two units connected in series, each containing three heat exchanger plates. The total cooling surface area is $10 \mathrm{~m} 2$. The liquid is recirculated by a pump. The liquid enters the vessel through distribution plates ensuring an even flow parallel to the heat exchangers. The preparation vessel and the required piping bring the total minimum liquid volume to 4751 (fig. 6.1b).

The design of the distribution plates was checked with the help of fluid dynamics simulations solved with Star-CCM+ (version 13.04.011, Siemens Digital Industries Software). In the model the Navier-Stokes equation was solved with $\kappa-\epsilon$ as the model description for turbulence. Geometry iterations were carried out to check whether the flow was evenly distributed and to determine the sizing of the pump to maintain sufficient flow over the plates for adequate mixing of the solution. In fig. 6.2a, the initial design without any distribution plates, is shown with an inlet of $23 \mathrm{~kg} / \mathrm{s}$ of water. The final design, that resulted from several iterations, is shown in fig. $6.2 \mathrm{~b}$ under the same inlet conditions.

The pilot-scale unit is designed to perform all the steps required for progressive freeze concentration. These steps are (1) pre-cooling of the solution to near its freezing point, (2) pre-cooling and pre-seeding of the heat exchanger, (3) cooling and freezing during concentration, (4) separation, melting of the ice layer and drainage of the melt water (fig. 6.3). During pre-cooling the fluid is introduced to the concentration vessel and the control system is set to the desired solution temperature (fig. 6.3a). The controller then operates the cooling compressor to reach this temperature. The recirculation pump is used to mix the fluid to prevent premature formation of ice crystals, since the heat exchanger temperature at this time is below the freezing point of the solution for cooling the solution to a temperature above but close to the freezing point. The pre-cooling of the solution is a step that in large-scale practice would be performed by a separate pre-cooler. After the solution is pre-cooled, it is transferred to the preparation vessel and when the concentration vessel is empty the pre-cooling and pre-seeding of the heat exchanger can be started.

The second step involves pre-seeding the heat exchanger surfaces with a thin and pure ice layer (fig. 6.3b). This is important to prevent super-cooling and spontaneous crystallization 


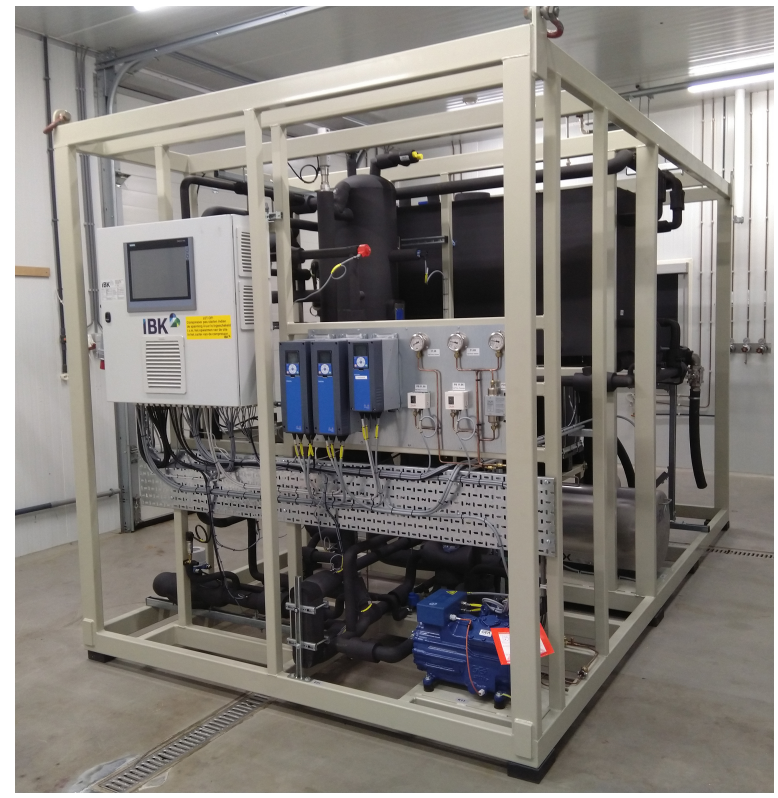

(a)

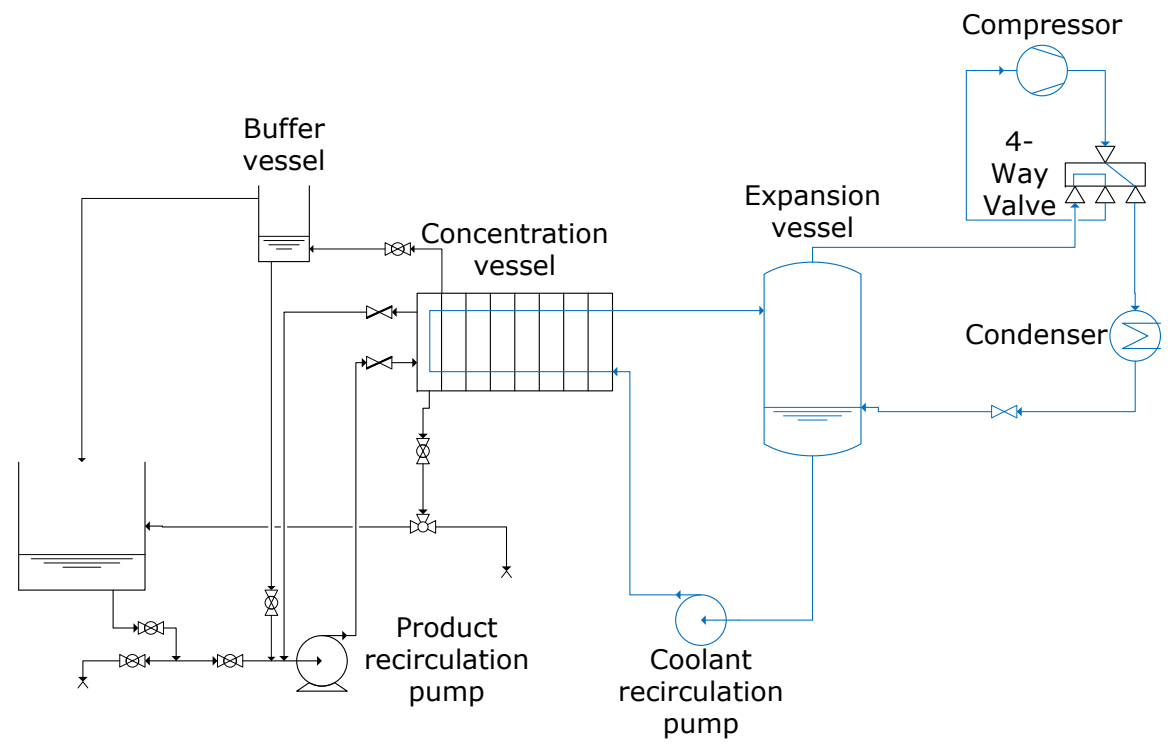

(b)

Figure 6.1: FreezeCon Pilot-scale unit (a) Pictured. (b) Schematic overview of the basic components of the pilot scale unit in cooling mode, the product side is in black and the heat pump side is in blue. For the melting cycle, the heat pump is reversed through the 4-way valve. 


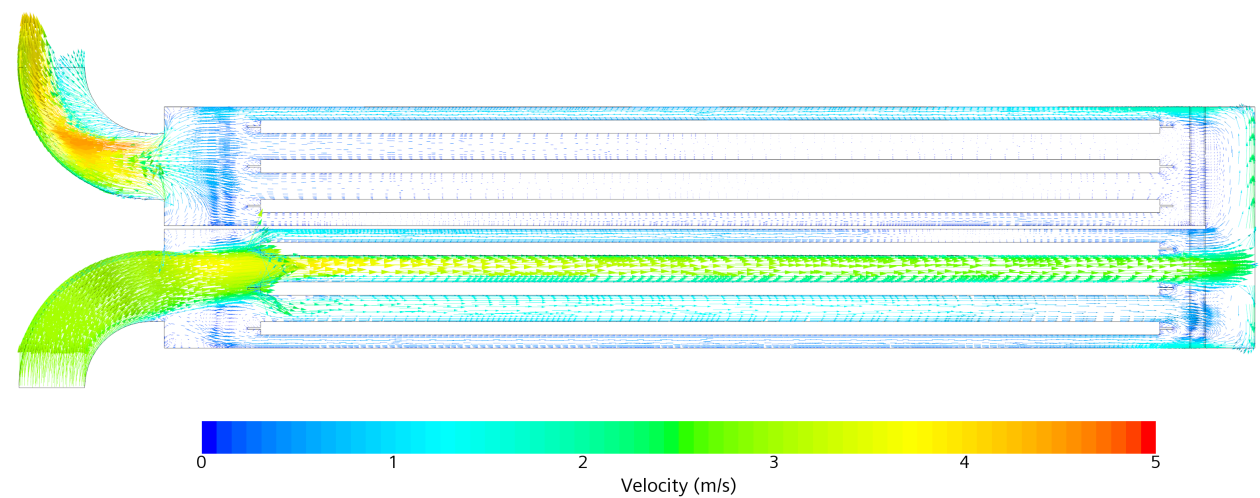

(a)
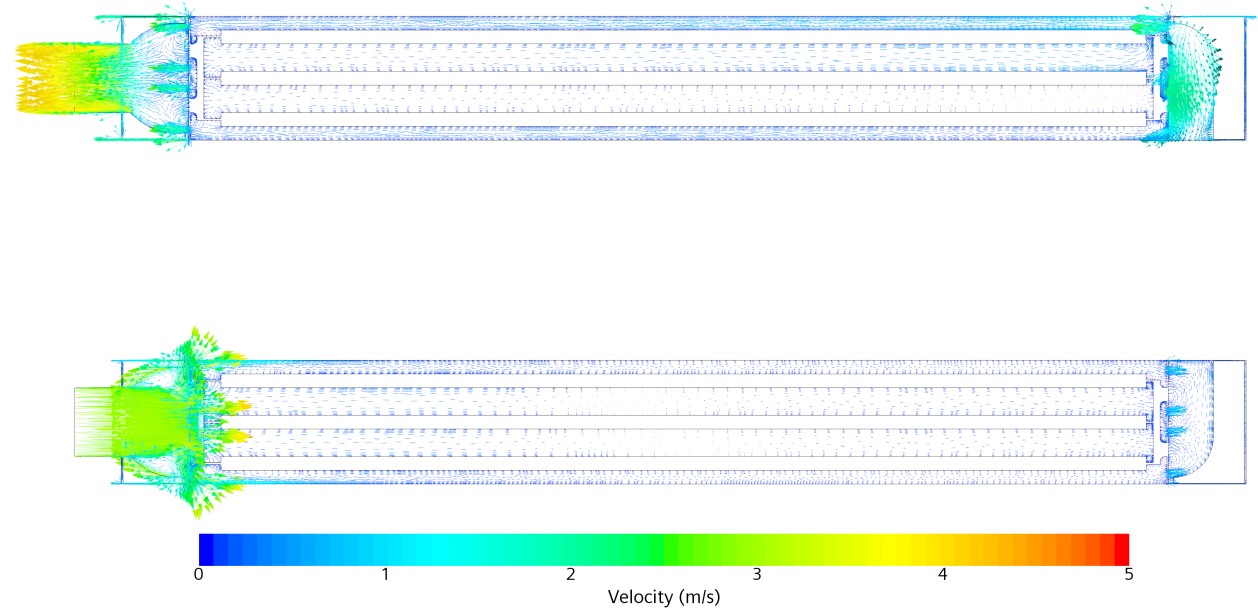

(b)

Figure 6.2: Slice of the flow pattern through the concentration vessel. From CFD analysis, the flow at the inlet is $23 \mathrm{~kg} / \mathrm{s}$ of water. (a) Without distribution plates and (b) with the final design of the distribution plates. To couple the two halves of the vessel pipes are used, which are not shown in this slice. 


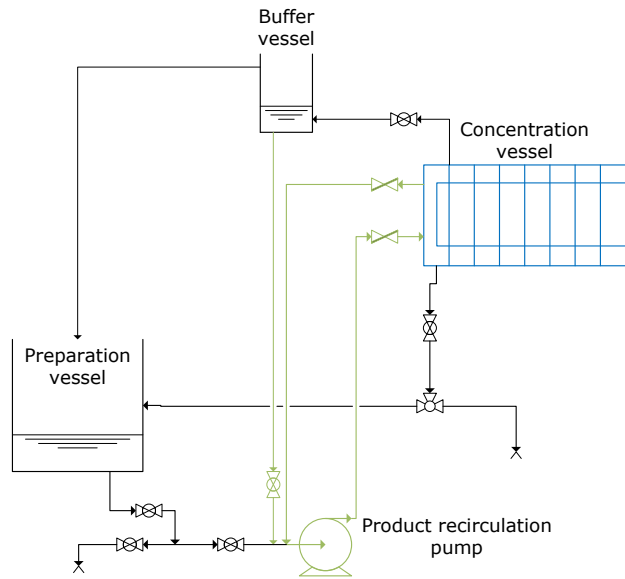

(a)

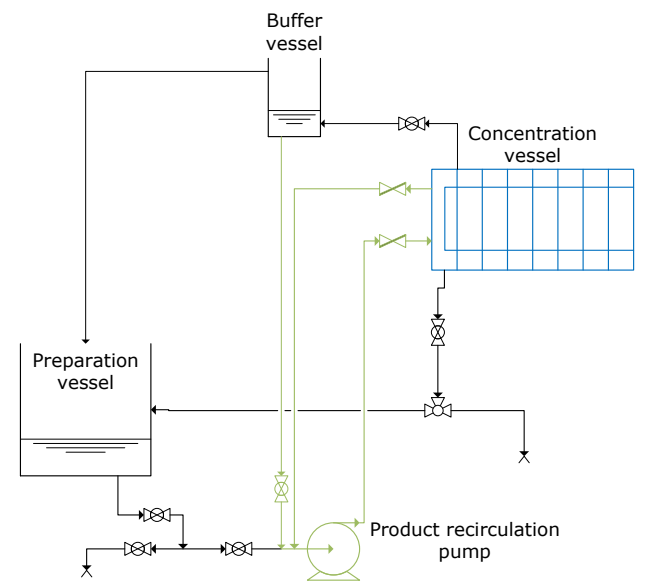

(c)

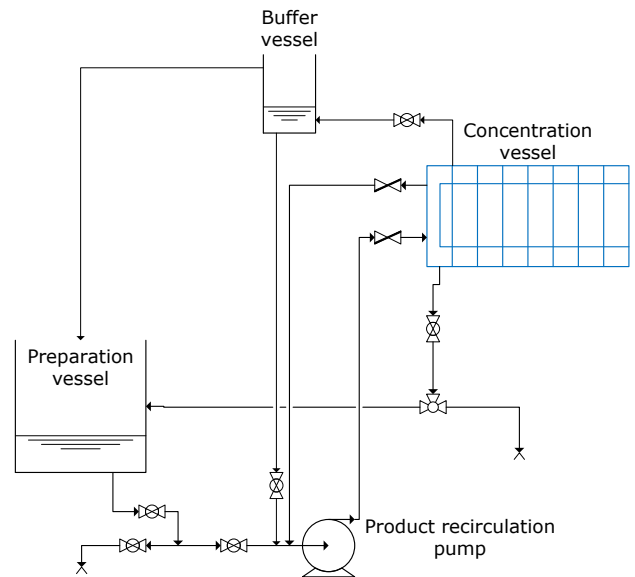

(b)

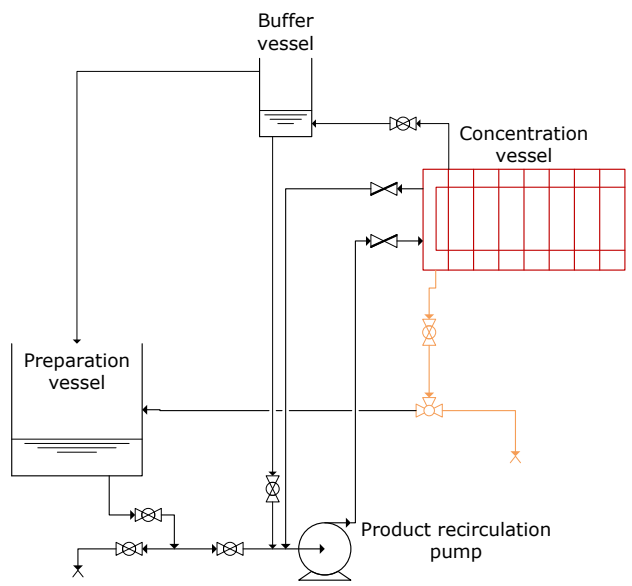

(d)

Figure 6.3: Operating modes of the pilot-scale freeze-concentrator. a) Pre-cooling, b) pre-seeding, c) concentration and, d) separation and melting. Green indicates the solution recirculating, blue, the heat exchanger is being cooled, and, red, the heat exchanger is being heated by the heat pump. Orange indicates the concentrate or ice being drained. 
in the bulk of the solution and to ensure that the ice is growing in an even layer on the heat exchanger surfaces. To create the pre-seed layer, some steam from a steam generator (Kärcher $\mathrm{SC} 4$, steam pressure 3.5 bar) is introduced through a valve into the concentration vessel. The steam is introduced when the heat exchanger has reached a temperature of $-5^{\circ} \mathrm{C}$ or lower and is applied until water vapour leaves the system through the expansion vessel. A second burst of steam is applied after a few minutes to ensure that the pre-seeding layer is thick enough everywhere (approximately $0.05 \mathrm{~mm}$ ).

In step three, the freeze concentration process itself can now be started (fig. 6.3c). During concentration, the cooling can be operated in two different modes. In the first mode the temperature of the evaporator is kept constant or follows a prescribed time-dependent polynomial. In effect this determines the temperature of the heat exchanger and therefore the rate of cooling and ice formation. If this temperature is kept constant this will result in a gradual slowing of the ice growth and the system eventually will reach a steady state. In the second mode, the cooling power is kept constant. The cooling power is calculated from the heat balance over the evaporator (eq. (6.3)). This cooling mode has the advantage that the ice growth rate will be near constant throughout the concentration step, after the solution has reached its steady state temperature. The cooling temperature is then automatically adapted to the momentary thickness of the ice layer and therefore, does not require knowledge about the expected ice growth rate, which is needed when using a prescribed cooling temperature profile. Based on our lab-scale experiments this approach leads to a better separation efficiency with less inclusions, compared to operation with a constant evaporator temperature.

In the fourth and final step the concentrate is separated from the ice by draining off the concentrate (fig. 6.3d). Subsequently, the ice layer is melted by reversing the cooling cycle of the cooling system, turning the heat exchanger into a condenser taking heat from the cooling water $\left(\approx 15^{\circ} \mathrm{C}\right)$. Finally, the melting water is drained off as well.

\section{Experimental set-up}

To evaluate the energy use of the pilot-scale unit, a set of experiments was conducted with sodium chloride $(5 \%(\mathrm{w} / \mathrm{w}))$ and sucrose $(5$ and $10 \%(\mathrm{w} / \mathrm{w}))$ solutions. The salt was supplied by Nouryon (Sanal-P, Nouryon, Deventer, The Netherlands). The sucrose was supplied by Royal Cosun (Standaardsuiker, Suikerunie, Dinteloord, The Netherlands). We prepared 500 1 solution per set of experiments in a week. The solution was cooled overnight at $4{ }^{\circ} \mathrm{C}$ before usage. During the week the solution was stored in the insulated part of the apparatus. To prevent excessive corrosion by the salt solution, sodium hydroxide was added to a $\mathrm{pH}>$ 8. Before and after each experiment samples were taken from the feed, concentrate and ice fractions. The concentration of sodium chloride was determined qualitatively by measuring the electrical conductivity at $20^{\circ} \mathrm{C}$. The concentration of sucrose was determined with a refractometer (Anton Paar, Abbemat 500, Germany). An internal reference was used to convert the refractive index into the sucrose concentration.

To test the performance of the equipment to concentrate protein solutions, a set of experiments with whey protein isolate solution (BiPRO® 9500, AgroPur, USA) was conducted. The starting point was a $5 \%(\mathrm{w} / \mathrm{w})$ solution that was concentrated using the optimal settings found for sucrose. The ice fraction was removed from the apparatus and the concentration of the concentrate was determined using an IR-heated weight balance at $105{ }^{\circ} \mathrm{C}$ until the mass 
had stabilized (Sartorius MA35, Germany). To counter foam formation in the concentration vessel, an anti-foaming agent (WITAFROL® 7420, IOI Oleo, Germany) was added to the solution at a concentration of $0.1 \%(\mathrm{w} / \mathrm{w})$. The concentration step was repeated four times. After the concentration experiments, the dry matter content of all the fractions was determined by drying 2-3 $\mathrm{ml}$ of each sample in an oven at $105^{\circ} \mathrm{C}$ overnight and weighing the samples before and after.

To evaluate the concentration performance the concentration factor $(C F)$ and overall distribution coefficient $(K)$ were calculated from the measured concentrations:

$$
\begin{gathered}
C F=\frac{C_{\text {concentrate }}}{C_{\text {feed }}} \\
K=\frac{C_{\text {ice }}}{C_{\text {concentrate }}}
\end{gathered}
$$

The data for the heat and mass balances and the electrical consumption was recorded by the control system. To calculate the cooling power of the system, an enthalpy balance was made over the evaporator:

$$
Q_{\text {cooling }}=\dot{M}_{\text {coolant }}\left(E_{\text {out }}\left(T_{\text {out }}, p_{\text {out }}\right)-E_{\text {out }}\left(T_{\text {in }}, p_{\text {in }}\right)\right)
$$

$\dot{M}_{\text {coolant }}$ is the mass flow of coolant in $\mathrm{kg} / \mathrm{s}, \mathrm{E}$ is the enthalpy of the coolant entering and leaving the evaporator in $\mathrm{kJ} / \mathrm{kg}$. The value is interpolated from a look-up table for saturated vapour of R134a. The cooling power is used as input for the PID-controller when the system is running in constant power mode. The cooling power is used to calculate the coefficient of performance (COP) for the cooling system:

$$
C O P_{\text {cooling }}=\frac{Q_{\text {cooling }}}{P_{\text {compressor }}}
$$

This equation gives us the raw COP of the cooling system and only considers the compressor of the cooling system. Since we are using an indirect cooling system, there is a coolant circulation pump running and to achieve efficient concentration the product is also recirculated with a pump, both these pumps need to be taken into account since they also influence the efficiency of the process. The total COP can then be calculated as:

$$
C O P_{\text {total }}=\frac{Q_{\text {cooling }}}{P_{\text {compressor }}+P_{\text {pump,coolant }}+P_{\text {pump,product }}}
$$

To calculate the energy required for the removal of $1 \mathrm{~kg}$ of water (specific energy consumption, SEC), the power of the compressor and pumps is numerically integrated using the trapezoidal method and divided by the mass of ice at the end of a batch:

$$
S E C=\frac{\int_{0}^{t_{\text {end }}} P_{\text {compressor }}+\int_{0}^{t_{\text {end }}} P_{\text {pump,coolant }}+\int_{0}^{t_{\text {end }}} P_{\text {pump,product }}}{M_{\text {ice }}\left(t_{\text {end }}\right)}
$$

We exclude the energy required to cool the solution down to near its freezing point, because this is handled in a separate step and the temperature of the incoming feed can vary from process to process. It is assumed that the whole ice fraction that is collected was frozen while in reality, part of this fraction can be some still-adhering, viscous non-frozen solution. 
The results from the previous lab-scale experiments were used to determine the operating conditions for the pilot-scale experiments. For $5 \%(\mathrm{w} / \mathrm{w})$ brine, the experiments were conducted using $1.5 \mathrm{~kW}$ cooling duty and the recirculation flow was set to 50 , and $70 \mathrm{~m}^{3} / \mathrm{h}$ in different experiments. The low cooling power was selected because it was predicted that high inclusion of salt would occur at higher cooling rates (chapter 5 ). For the $5 \%(\mathrm{w} / \mathrm{w})$ sucrose solutions a set of experiments with a constant cooling temperature $\left(-5^{\circ} \mathrm{C}\right.$ and $\left.-7.5^{\circ} \mathrm{C}\right)$ and recirculation flow rate of 30 and $50 \mathrm{~m}^{3} / \mathrm{h}$ was performed and compared with a set of experiments with constant power $(1.5,4.5$, and $7.5 \mathrm{~kW}$ evaporator power) and recirculation flow rates of 30,50 , and $70 \mathrm{~m}^{3} / \mathrm{h}$. For the experiments with $10 \%(\mathrm{w} / \mathrm{w})$ sucrose solutions the cooling power was set to $4.5 \mathrm{~kW}$ and the recirculation flow was set to 50 or $70 \mathrm{~m}^{3} / \mathrm{h}$. From the results obtained with sucrose the settings were selected for the experiments with whey protein solution. The cooling power was set to $4.5 \mathrm{~kW}$ and the recirculation flow was set to $50 \mathrm{~m}^{3} / \mathrm{h}$. The protein solution in these experiments was reused to perform a series of concentration experiments to show the potential of progressive freeze concentration for the concentration of protein solutions. To prevent the initial ice layer from detaching from the heat exchanger surface, the product circulation pump was always started at $30 \mathrm{~m}^{3} / \mathrm{h}$ and then increased, if required, to the desired final flow rate with a rate change of $2 \mathrm{~m}^{3} / \mathrm{h}$ per minute.

\subsection{Results and discussion of the pilot-scale experiments}

\section{Brine}

For initial pilot-scale unit experiments, a $5 \%(\mathrm{w} / \mathrm{w})$ brine was used as feed. During these runs the initial ice layer easily detached from the heat exchanger surface at recirculation rates above $50 \mathrm{~m}^{3} / \mathrm{h}$. Therefore, the protocol for the higher recirculation rates was adjusted as described in the previous section. The ice detaches because of the high shear induced by the pump controller overshooting at these rates. Besides, the ice can detach due to partial melting of the ice layer due to the incoming liquid that is one or two degrees above the melting point of the solution. After the adjustment to the protocol a stable ice layer could be formed, and concentration of the brine could be achieved. The observed ice layer has a rough and frost-like appearance, indicating that dendritic ice had formed (fig. 6.4). This indicates that the inclusion rate was high during the concentration step and constitutional super-cooling occurred (chapter 5). At a recirculation rate of $50 \mathrm{~m}^{3} / \mathrm{hr}$ and a cooling power of $4.5 \mathrm{~kW}$ the conductivity of the brine feed, concentrate, and ice was $80.1 \pm 0.6,87.0 \pm 0.9$, and $45.5 \pm 0.8 \mathrm{mS} / \mathrm{cm}$ respectively at approximately $80 \mathrm{~kg}$ of ice formed. If we assume that the conductivity is linear with the concentration this would result in a concentration factor of 1.09 and a distribution coefficient of 0.52. This confirms that there is indeed a high inclusion. Combined with our findings in chapters 4 and 5, brine is prone to super-cooling at reasonable freezing rates. On the scale of the pilot system the exact degree of super-cooling is hard to balance through the control of the heat pump and the product recirculation pump. 


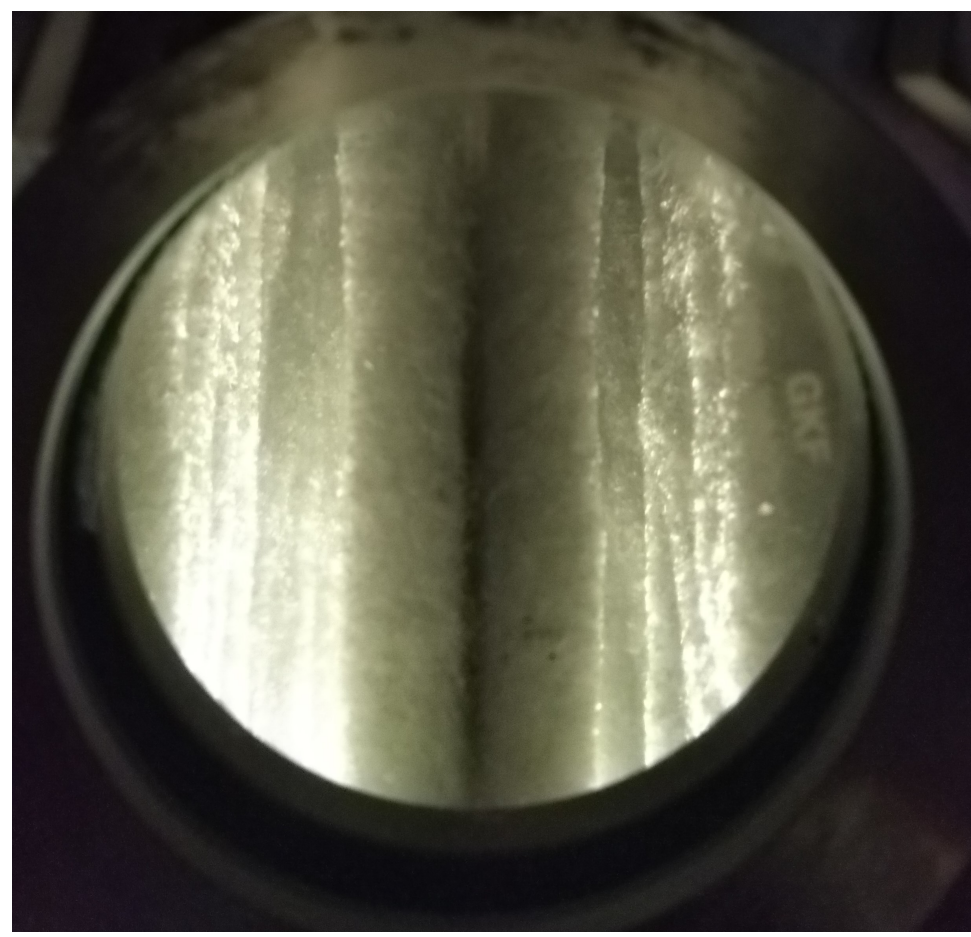

Figure 6.4: Ice formed during freeze concentration of brine in the plate heat exchanger as observed via a glass window.

\section{Sucrose solutions}

The goal of the experiments with sucrose solutions was to determine whether the constant power cooling operation yielded less inclusions than operating with constant evaporator temperature. Together with the variation in recirculation flow rate the performance of progressive freeze concentration was evaluated. The general trend found in fig. 6.5 is that the observed partition coefficients and thus the inclusions are high compared to the lab results (Vuist et al. 2020). This is partly caused by the ease of separation of the ice layer and the concentrate on lab scale, which on pilot-scale separation is obtained after draining the vessel by gravity, leaving more adhering residual liquid in the concentration vessel. The trends for the distribution coefficient are however similar to those found in the lab-scale experiments. With a lower evaporator temperature/high cooling power the number of inclusions increases as expected. Increasing the flow rate results in less inclusions in almost all the cases. Only with 7.5 $\mathrm{kW}$ cooling duty this effect is negligible; increasing the flow rate is here less effective due to the higher ice growth rate. This indicates that with $7.5 \mathrm{~kW}$ cooling duty there is insufficient mixing, and the cooling power is too high, leading to strong localized super-cooling. At a recirculation flow rate of $30 \mathrm{~m}^{3} / \mathrm{h}$ the distribution coefficient is independent of the cooling power applied (fig. 6.5b). This could indicate that the process is already diffusion limited at $1.5 \mathrm{~kW}$ of cooling and that the recirculation rate is inadequate to provide enough mixing to reduce the thickness of the stagnant layer. An optimal concentration process does not only depend on minimising solute inclusion, but also on achieving sufficiently large freezing (concentration) rates. The recirculation flow rate negatively influences the ice growth rate as the 


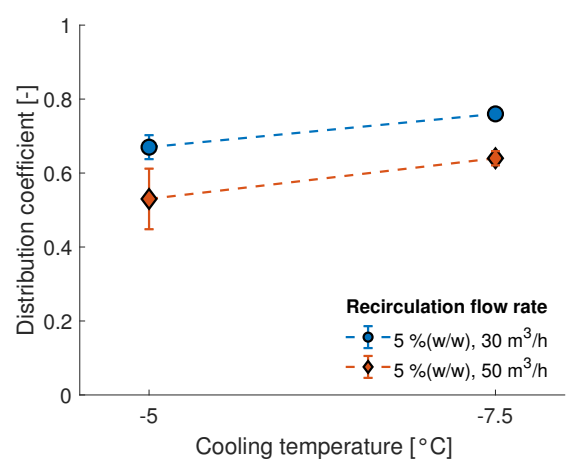

(a)

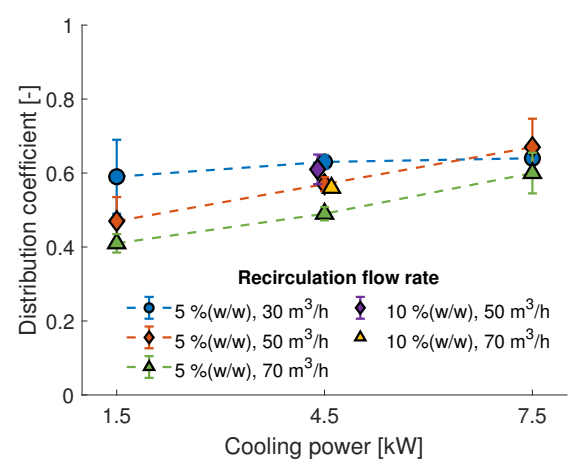

(b)

Figure 6.5: Distribution coefficients for sucrose at constant temperature (a) and constant power cooling (b) for different feed circulation rates. The error bars indicate standard deviation $(n=2)$.

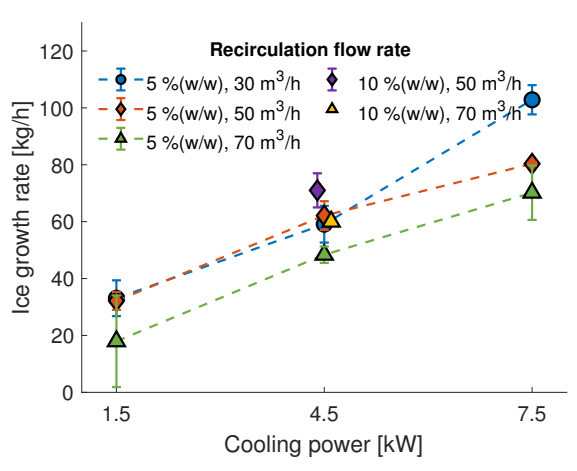

(a)

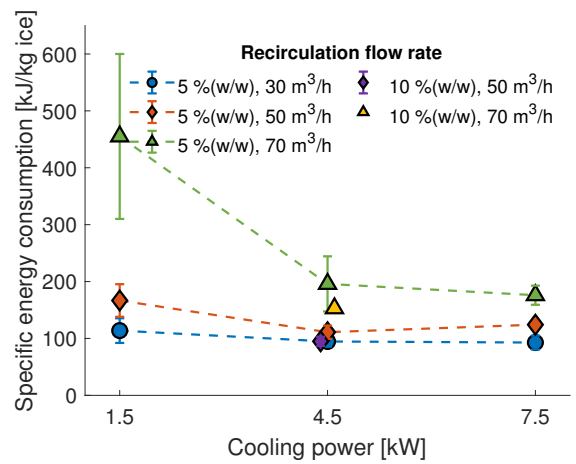

(b)

Figure 6.6: Ice growth rate (a) and specific energy consumption (b) for different feed circulation rates and cooling powers. The error bars indicate standard deviation $(n=2)$.

higher recirculation rate causes the pump to dissipate more heat into the solution, which must be removed by the cooling system and leads to a decrease in the energy efficiency (fig. 6.6a). This is reflected in the specific energy consumption (SEC; eq. (6.6)) in (fig. 6.6b). The SEC is 2-3 times higher with $1.5 \mathrm{~kW}$ cooling duty and $70 \mathrm{~m}^{3} / \mathrm{h}$ recirculation as compared to the other concentration experiments, mainly due to the low ice growth rate resulting in a much longer processing time to obtain $80 \mathrm{~kg}$ of ice. The difference in SEC between 30 and $50 \mathrm{~m}^{3} / \mathrm{h}$ is smaller than between 50 and $70 \mathrm{~m}^{3} / \mathrm{h}$, which is caused by the turbulent flow causing the energy demand of the pump to increase non-linearly, which then reduces the ice growth rate resulting in a longer processing time in these cases. A good balance between solute inclusion and energy usage was thus determined to be at $50 \mathrm{~m}^{3} / \mathrm{h}$ recirculation flow and $4.5 \mathrm{~kW}$ cooling power.

With a $10 \%(\mathrm{w} / \mathrm{w})$ sucrose solution an increase was observed in the distribution coefficient (fig. 6.5b), similar as found in the lab-scale experiments (Vuist et al. 2020). The distribution 
coefficient increases because the concentration in the boundary layer rises quickly, causing stronger localized supercooling leading to more inclusion. Remarkably, the specific energy consumption decreased with the higher concentration of sucrose (fig. 6.6b). This can partly be explained by the inclusion of more sucrose, which results in a larger part of the collected ice fraction being unfrozen sucrose solution. Additionally, Biswas et al. (1975) found that the heat of fusion $\left(\Delta H_{f u s}\right)$ decreases when sucrose is present in the solution, due to water bound to the sucrose molecules and this water does not participate in forming the ice crystals.

\section{Whey protein solutions}

On lab-scale, we observed that whey protein solutions show a low distribution coefficient during progressive freeze concentration (chapters 4 and 5). Inclusions with proteins are much less compared to sucrose and salt because there is no localized super-cooling thanks to the absence of any significant freezing point depression. However, in the pilot-scale experiments the distribution coefficients were higher and comparable to the ones found for brine and sucrose solutions (fig. 6.7). The concentration factor found in each subsequent experiment was similar and an approximate $10 \%$ increase in concentration is found. With no inclusion the expected concentration increase would be $25 \%$ in each step. A larger distribution coefficient was also observed in the lab-scale experiments at high concentrations (chapter 4 ). The stronger inclusion is caused by reaching the maximum packing concentration of the proteins in the boundary layer more quickly, forming a semisolid gel (Both et al. 2019). This causes the mass transfer to collapse and the proteins to get included. Another factor contributing to the higher inclusions found in pilot-scale experiments is that the - more concentrated boundary layer stays present on the ice layer, due to the lack of a washing treatment in our procedure (fig. 6.8). This confirms the creation of a gel layer on the ice. On lab-scale, we found that washing this layer would reduce the inclusions significantly.

The specific energy consumption for the whey protein concentration experiments was found to be around $135 \mathrm{~kJ} /(\mathrm{kg}$ ice $)$ over the subsequent runs and similar to an experiment under the same conditions with water and sucrose. The coefficient of performance (eq. (6.5))

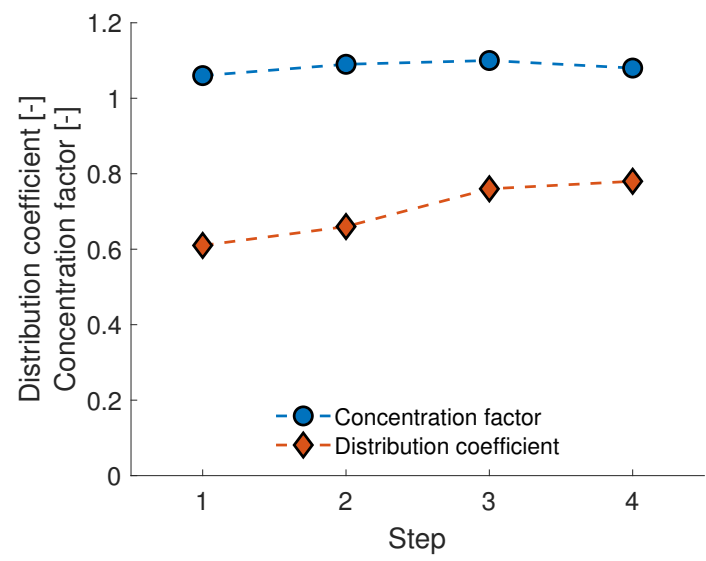

Figure 6.7: Measured distribution coefficient and concentration factor for the continued freeze concentration series of whey protein solution. 


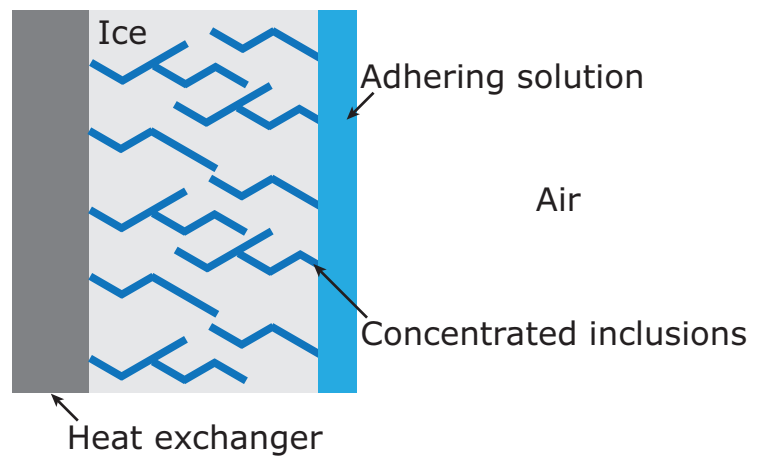

Figure 6.8: Schematic overview of the ice after drainage of the solutions. Beside the inclusions in the ice, on the surface of the ice the concentrated boundary layer is still present and contributes to high levels of solute loss.

was found to be approximately 2.4 for these operating conditions. This gives a slight mismatch with the latent heat of fusion of water $(333 \mathrm{~kJ} / \mathrm{kg})$, which could be caused by the unfrozen inclusions being part of the collected ice fraction.

\section{Compared to other methods of concentration}

Based on the data gathered for the sucrose experiments a business case was calculated (Pal et al. 2021). The business case was based on the energy consumption for $4.5 \mathrm{~kW}$ cooling power and a recirculation rate of $50 \mathrm{~m}^{3} / \mathrm{hr}$. These settings showed a balance in energy consumption and solute loss. The data were scaled to an installation of 10 tons of water removed per hour and compared to suspension freeze concentration, 6-stage evaporation, multi-stage evaporation with mechanical vapour recompression (MVR), and reverse osmosis (table 6.1).

Table 6.1: Costs of freeze concentration and alternative technologies for 10 ton $/ \mathrm{h}$ water removed (Pal et al. 2021)

\begin{tabular}{|c|c|c|c|c|c|}
\hline & $\begin{array}{l}\text { Progressive } \\
\text { freeze } \\
\text { concentration }\end{array}$ & $\begin{array}{c}\text { Suspension } \\
\text { freeze } \\
\text { concentration } \\
\text { (GEA IceCon) }\end{array}$ & $\begin{array}{c}\text { 6-stage } \\
\text { evaporator }\end{array}$ & $\begin{array}{l}\text { Multi-stage } \\
\text { evaporator } \\
\text { with MVR }\end{array}$ & $\begin{array}{l}\text { Reverse } \\
\text { osmosis }\end{array}$ \\
\hline $\begin{array}{r}\text { CAPEX [M€] } \\
\text { OPEX over }\end{array}$ & $4.3 \pm 1.3$ & 7 & 3.5 & 4.5 & 1.4 \\
\hline $\begin{array}{r}5 \text { years of } \\
\text { operation [M }[\mathrm{M}]\end{array}$ & $0.99 \pm 0.2$ & $1 \pm 0.3$ & 1.16 & $0.75 \pm 0.05$ & 1.7 \\
\hline $\begin{array}{l}\text { OPEX incl. } \\
\text { CO2 tax }[\mathrm{M} €]\end{array}$ & - & - & 1.69 & - & - \\
\hline
\end{tabular}

Progressive freeze concentration shows similar operational costs compared to suspension freeze concentration. The capital costs are estimated to be significantly lower than for suspension freeze concentration due to the increased mechanical simplicity of the progressive freeze concentration unit. Compared to evaporation the costs of freeze concentration are similar, however, when MVR is applied, the operational costs can be reduced significantly. When 
(Dutch) CO2 tax is applied to evaporation the operational costs of 6-stage evaporation will increase and freeze concentration becomes a feasible alternative although the capital costs are likely to be higher. The initial investment in reverse osmosis is quite low, due to the low costs of the modular components of the installation. However, this is offset by the higher operational costs due to the required periodical replacement of the membranes caused by wear during the concentration and cleaning process.

\subsection{Conclusion pilot-scale experiments and outlook to improvements}

The pilot-scale unit was built to study the scalability of progressive freeze concentration and to evaluate its energy usage. The experiments show that in terms of concentration the technology is well scalable, and most products could be concentrated. However, the losses of product into the ice fraction are still high and should be reduced. One of the biggest challenges in progressive freeze concentration on larger scale is to control the ice growth rate in the process. Especially in the beginning of the process, the ice layer is not stable and can be detached by the moving fluid. To prevent this, a thicker seeding layer can be created by applying a water film to the surface of the heat exchanger instead of the condensing water vapour that was used in the experiments. This thicker layer will however introduce a higher resistance to heat transfer, which requires a lower coolant temperature and a higher load on the cooling compressor to achieve this. Faster mixing can be allowed with a better seeding layer, which will lower the inclusion of the solutes. If the solutes have a lower molecular weight, they will depress the freezing point, which strongly affects solute inclusion and is thus critical for the separation efficiency. A high degree of super cooling near the growing ice front results in irregular crystal growth, which can enhance formation of included pockets of concentrated solution in the growing ice. In practice, progressive freeze concentration is therefore most promising for feed solutions that show limited freezing point depression but even there, the ice growth rate should remain limited.

Another challenge lies in the separation of the concentrate and ice fractions. In our system we only used gravity-assisted separation by free drainage. This leads to some of the viscous liquid product adhering to the ice. To apply the process to a production setting the separation can be improved by applying an after-treatment to the ice layer. On lab-scale we found that rinsing the ice layer would remove most of the solutes on top of the ice layer. In practice this will result in a dilute rinsing water stream which should be recycled into the process. This requires the unit to have somewhat larger capacity to attain the required throughput. Another approach to after-treatment is to apply a 'sweating' step (Myerson et al. 2019). Sweating is already used in practice for melt crystallization, where freeze concentration is based upon, to attain high purities. Sweating in progressive freeze concentration requires the ice to be heated somewhat from the product side either by hot air or just before the end of the concentration step, by heating the product stream to partially melt the ice layer. The ice temperature at the surface should then be below the melting point of pure water to prevent complete melting of the ice layer. Due to freezing point depression the concentrated inclusion domains will melt and leave the ice layer. In effect, the sweating step gives the same rinsing effect as adding external rinsing water, and therefore has the same disadvantages.

The energy required for the freezing of the solution was generally equal to the heat of fusion. There was only a significantly larger energy requirement with a high recirculation rate and low cooling power, due to a longer process time. The true energy savings in progressive 
freeze concentration come from using heat pumps, which have a coefficient of performance higher than 1. In our experiments the COP was somewhat higher than 2. Further reduction in energy requirements can result by coupling two units together (fig. 6.9). One unit would be in freezing mode and the other would be in melting mode. In this way the melting unit would provide the heat sink for the freezing unit. The temperature difference is small, and no extra energy will be spent on melting the ice layer to remove this from the concentration vessel. In the current pilot scale system, the concentration vessel is also used for the pre-cooling of the solution. In production version it would be advised to include a dedicated pre-cooler, which can be optimized for heat transfer, while the spacing of the heat exchanger plates in the concentration vessel are then optimized for maximum ice formation.

\section{Crystallizer}

Melter

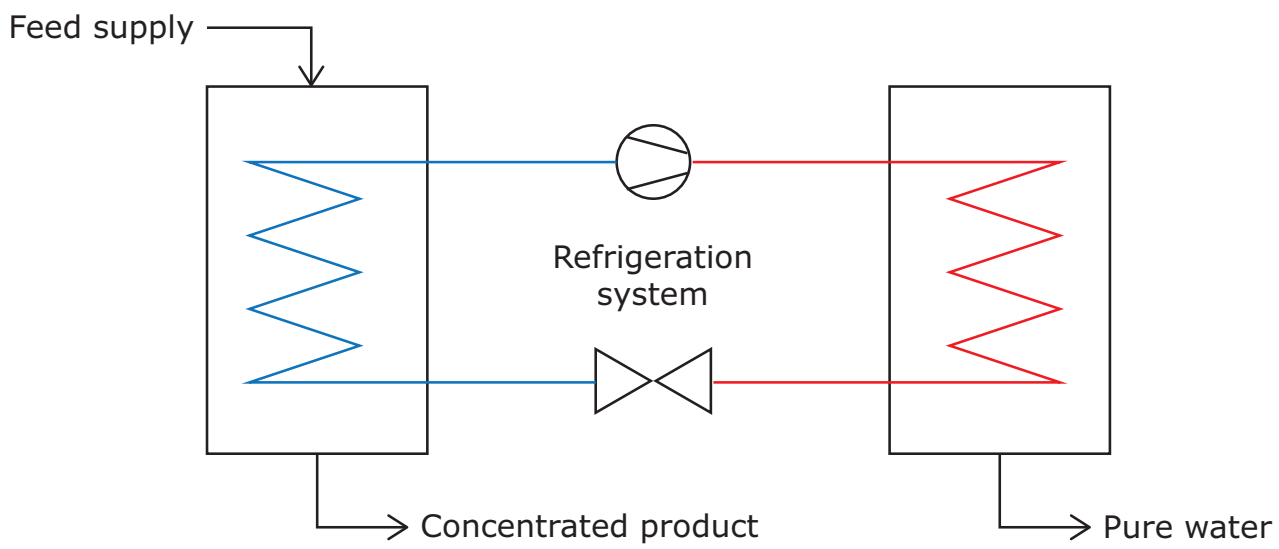

Figure 6.9: Coupling of a freezing and melting stage in a progressive freeze concentrator.

To achieve a doubling in concentration, half of the water must be removed. With progressive freeze concentration this would be hard to achieve in a single stage. Therefore, a multi-stage process must be designed. In a multi-stage process, one could combine different freeze concentration techniques. Since progressive freeze concentration was shown in this work to work well on lower concentrations it could be used as a precursor step before suspension freeze concentration to go towards full concentration. Suspension freeze concentration can concentrate with virtually no losses up to moderate concentrations (up to $30 \%(\mathrm{w} / \mathrm{w})$ ). This would combine the relatively simple equipment for progressive freeze concentration in the step and leaves further concentration for the more complicated system of suspension freeze concentration. Other approaches exist as well. One manufacturer proposed to combine suspension freeze concentration with static layer freeze concentration, shown in fig. 6.10 (Dette et al. 2020). Suspension freeze concentration is used for the initial step to concentrate the product to $30-40 \%(\mathrm{w} / \mathrm{w})$ solids. At higher concentrations the viscosity of the product becomes too high to efficiently operate the wash filter, used for the separation of the water from the product. The concentrated product is then transferred to a static layer freeze concentrator. In this unit, a "dirty" ice layer is grown to concentrate the product up to $50 \%(\mathrm{w} / \mathrm{w})$ solids. The ice layer contains up to $18 \%(\mathrm{w} / \mathrm{w})$ solids and is then melted and mixed with the feed of the suspension freeze concentrator. 


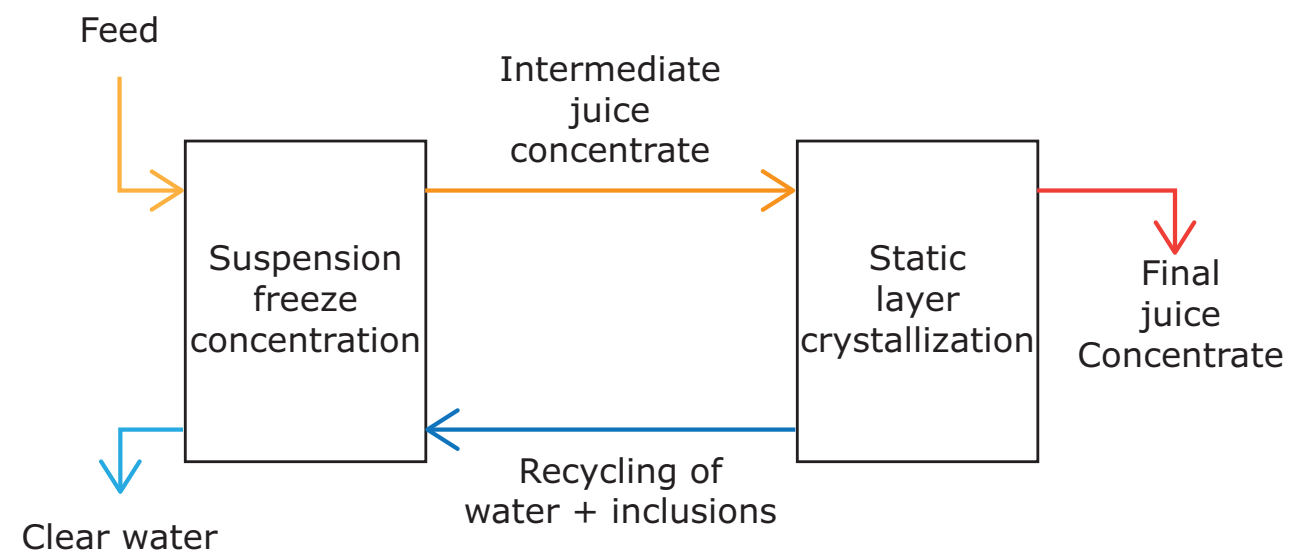

Figure 6.10: Process scheme for the combination of suspension freeze concentration and static layer crystallization. After Dette et al. (2020).

\subsection{Outlook to further research}

Next to further work required to improve the performance of progressive freeze concentration on pilot- and larger scales as described in section 6.5, also from a more fundamental point of view there is need for further research. We have identified the mechanism for inclusions during progressive freeze concentration, and our model as presented in (chapter 5) in principle can be applied to evaluate if a solution is suitable for progressive freeze concentration. However, to make the model quantitatively predictive, the concentration and temperature dependence of the diffusivities, viscosity and thermal conductivities should be incorporated. In addition, the model requires to be integrated over time to obtain the overall distribution coefficient. The underlying assumption of this model is that inclusion occurs in the freezing zone, which is due to freezing point depression of the components present in the solution. For solutions that contain proteins and have little to no freezing point depression another mechanism is responsible for inclusions. Solutions with carbohydrates often show an anomalously sharp increase in viscosity and reduction in diffusivity at the combination of low temperature and high concentrations, since the solution gets nearer the glass transition. This is known as William-Landel-Ferry kinetics (Kerr et al. 1994). In addition, very concentrated protein solutions will show 'jamming'; forming a gel like layer due to close stacking of the protein molecules. For this case a parallel may be drawn to membrane processes, where, due to the same phenomenon a gel layer is formed on top of an ultrafiltration membrane (Porter 1972). In progressive freeze concentration this gel layer impedes the mass transfer in the boundary layer, resulting in a shift from heat transfer limitation to mass transfer limitation. This will again cause instabilities in the ice layer causing inclusions. The quantification of these different mechanisms requires further research.

In this thesis we investigated different categories of components relevant for the food industry. Currently, there is a focus on the extraction of novel plant proteins, while maintaining their functionality. Low temperatures are preferred after extraction to reduce enzymatic degradation of the proteins of interest and avoid thermal degradation. These proteins are often extracted from materials or solutions that have high water content. Freeze concentration would be an excellent candidate for an initial concentration step after the extraction of these 
streams. It would be preferable to first remove the low-molecular weight components, for example by diafiltration, before applying progressive freeze concentration, to avoid instabilities caused by freezing point depression, see chapter 5 . In literature, it is shown that freeze concentration can maintain these native properties (Aider et al. 2009). However, research is required on the exact behaviour in freeze concentration.

\subsection{Closing remarks}

This thesis tries to improve the understanding of progressive freeze concentration and the underlying mechanism of solute inclusion. On the way, the requirements for progressive freeze concentration with low solute losses became clear. Generally, this requires well mixing and slow freezing, such that slowly diffusing solutes near the forming ice layer do not accumulate too much in a concentration polarization layer. With this knowledge, a model was formulated for solute inclusion based on heat and mass transfer in combination with the thermodynamic properties using state diagrams. Later, these insights and knowledge was applied to pilot-scale progressive freeze concentration experiments with different solutions. For these experiments and the business case evaluation it was found that progressive freeze concentration can be an energy-efficient alternative to other methods, which is mild to the solutes that are concentrated. 


\section{References}

Aider, Mohammed, Damien De Halleux, and Inna Melnikova (Mar. 2009). "Skim Milk Whey Cryoconcentration and Impact on the Composition of the Concentrated and Ice Fractions". In: Food and Bioprocess Technology 2 (1), pp. 80-88. ISSN: 1935-5130. DOI: 10.1007/s11947-007-0023-0 (cit. on p. 109).

Auleda, J. M., M. Raventós, and E. Hernández (Nov. 2011). "Calculation method for designing a multiplate freeze-concentrator for concentration of fruit juices". In: Journal of Food Engineering 107.1, pp. 27-35. ISSN: 0260-8774. DOI: 10.1016/J . JFOODENG. 2011.06.006 (cit. on p. 93).

Biswas, A. B., C. A. Kumsah, G. Pass, and G. O. Phillips (July 1975). "The effect of carbohydrates on the heat of fusion of water". In: Journal of Solution Chemistry 1975 4:7 4 (7), pp. 581-590. ISSN: 1572-8927. DOI: $10.1007 /$ BF00643380 (cit. on p. 104).

Both, E. M., I. Siemons, R. M. Boom, and M. A. I. Schutyser (2019). "The role of viscosity in morphology development during single droplet drying”. In: Food Hydrocolloids 94, pp. 510-518. ISSN: 0268-005X. DOI: 10.1016/j . foodhyd.2019.03.023 (cit. on p. 104).

Dette, Severine and Lucas Maetz (2020). TWICE ${ }^{\mathrm{TM}}$ - an ice-cold process for highest food concentration I Sulzer. URL: https : //www . sulzer . com/en/shared/stories/twice-an-ice-coldprocess-for-highest-food-concentration (cit. on pp. 107, 108).

Flesland, Ola (Jan. 1995). "Freeze concentration by layer crystallization". In: Drying Technology 13.8-9 (8-9), pp. 1713-1739. ISSN: 1532-2300. DOI: 10.1080/07373939508917048 (cit. on p. 93).

Kerr, William L. and David S. Reid (1994). Temperature dependence of the viscosity of sugar and maltodextrin solutions in coexistence with ice. DOI: 10.1006/fstl .1994.1046 (cit. on pp. 94, 108).

Miyawaki, Osato, Ling Liu, and Kozo Nakamura (Sept. 1998). "Effective partition constant of solute between ice and liquid phases in progressive freeze-concentration". In: Journal of Food Science 63.5 (5), pp. 756-758. ISSN: 0022-1147. DOI: 10.1111/j.1365-2621.1998.tb17893.x (cit. on p. 93).

Myerson, Allan S., Deniz Erdemir, and Alfred Y. Lee (June 2019). Handbook of industrial crystallization. English. Third edit. Cambridge; Cambridge University Press, pp. 1-528. ISBN: 9781139026949. DOI: $10.1017 / 9781139026949$ (cit. on pp. 93, 106).

Pal, M. van der and R. P. de Smidth (2021). Business Case Calculation Film Freeze Concentration. Research rep. P.O. Box 15, 1755 ZG Petten, The Netherlands: TNO Energy Transition (cit. on p. 105).

Porter, Mark C. (Sept. 1972). "Concentration Polarization with Membrane Ultrafiltration”. In: Industrial and Engineering Chemistry Product Research and Development 11 (3), pp. 234-248. ISSN: 01964321. DOI: $10.1021 /$ i360043a002 (cit. on p. 108).

Vuist, Jan Eise, Remko M. Boom, and Maarten A. I. Schutyser (Mar. 2020). "Solute inclusion and freezing rate during progressive freeze concentration of sucrose and maltodextrin solutions". In: Drying Technology 39.10, pp. 1285-1293. ISSN: 1532-2300. DOI: 10 . 1080/07373937 . 2020 . 1742151 (cit. on pp. 102, 103). 
Summary 
Dewatering and drying are common process operations in the food and biobased industry. To minimise the energy required for drying, products are often concentrated before drying. This usually increases the solid concentration from below $10 \%$ to around 40-70 \% solids, depending on among others the viscosity of the specific formulation. The most widely applied concentration method is evaporation, which is a fast process but is energy intensive and operates at elevated temperatures. This makes evaporation not suitable for food products that suffer from thermal degradation. For these products, alternative mild concentration methods can provide a better product quality.

One of these methods is freeze concentration. When a solution is frozen, the ice crystals exclude the solute from their crystal matrix. If the ice is removed, a concentrated solution is obtained. Since freeze concentration makes use of cooling instead of heating, it is suitable for products containing volatile or thermally sensitive components. In theory, the energy required to remove water should be equal to the latent heat of fusion of water, which is 7 times lower than the latent heat of vaporization at atmospheric pressure. The process can be configurated in multiple ways. The focus of this thesis is on progressive freeze concentration, during which ice crystals are grown on the wall of a heat exchanger. The advantages of the technique are that the ice crystals can be separated easily from the concentrated solution and that it is well suited for extensive heat integration. While freeze concentration in theory should create pure ice, this requires unproductive and slow ice growth rates. At faster ice growth, part of the solute will be included in the ice fraction and be lost after separation. The present work therefore aimed to understand why solute inclusion occurs in freeze concentration and to apply this to a pilotscale progressive freeze concentrator. For this, we used lab-scale experiments to investigate the influence of cooling, mixing, and solutes on solute inclusion. The data generated in these experiments were combined with a modelling approach to understand the mechanism of solute inclusion during progressive freeze concentration.

In chapter 2 freeze concentration of model solutions of sucrose and maltodextrin is evaluated in a laboratory-scale freeze concentration system. The influence of the cooling strategy and the mixing of the product on the amount of inclusion in the ice or solute loss to the ice fraction is evaluated. From this initial study we concluded that, as expected, an increase in the ice growth rate would lead to higher inclusions at a constant heat exchanger temperature. However, when the initial temperature of the heat exchanger was higher and only gradually lowered, the inclusion was less without reducing the total amount of ice formed. A constant heat exchanger temperature in the beginning imposes a high degree of super-cooling, which leads to an irregular ice front creating pockets of concentrated solution that become encapsulated in the ice. When the temperature difference between the heat exchanger and the freezing point is reduced, the degree is much lower and a smooth ice front is formed that excludes the solutes more effectively. The solute inclusion can be further reduced with stronger agitation, which aids in minimising concentration polarization.

Chapter 3 reports on experiments and modelling with different products, including proteins. Specifically, solutions of soy protein and whey protein were evaluated using the cooling and mixing conditions established in the previous chapter. The solute inclusion was modelled using an existing theory using empirical parameters, which was linked to the heat and mass balances describing the ice growth rate. At low ice growth rates, we found good agreement between the model and our data, but at high ice growth rates the model underestimated the level of inclusions. The conclusion is that one of the assumptions in the model, pertaining to 
the ice growth being slow and planar, does not hold during dendritic ice formation at higher ice growth rates.

Whey protein was selected as a model protein in chapter 4 . Since most products in the food industry do not consist of only protein, we investigated the concentration of mixtures of whey protein, salt, and/or sucrose. The addition of both sodium chloride and sucrose increased the inclusion of that solute, but also that of the protein. It was hypothesised that in the case of sodium chloride the solute inclusion is caused via localised super-cooling in the concentration polarization layer. In the zone where the super-cooling occurs, ice crystals form within the layer, which then incorporate domains of concentrated solution into the ice layer. The freezing point depression by sucrose is much less extreme (per unit of weight), so we here expect that besides the effect of the localised super-cooling, the inclusions are caused by the very strong increase of the viscosity and reduction of the diffusivity of the concentrated solution at low temperatures. When both sodium chloride and sucrose are added, the effect on inclusion is not additive but concurrent, i.e., the addition of both did not cause more inclusions than does adding either of the two.

With these observations a theoretical model for the prediction of solute inclusion was developed in chapter $\mathbf{5}$, using the state diagram. This model predicts the existence of two ice growth regimes. The first regime is at low ice growth rates, and with high-molecular weight solutes that gives negligible freezing point depression. Here, the compositions within the boundary layer stay above the freezing line, and therefore the ice growth is stable, and no inclusion is expected in this regime. The second regime is at larger ice growth rates, and with smaller solutes that does give appreciable freezing point depression. Here, the compositions in the boundary layer cross the freezing line, which then leads to freezing within the boundary layer, converting this into a freezing zone, and leading to inclusion. The model predicts the inclusion of low-molecular weight components and the negligible inclusion of macromolecules, such as whey proteins.

Finally, in chapter 6 progressive freeze concentration is evaluated in a pilot-scale progressive freeze concentrator and compared into alternative concentration methods. In the pilot-scale unit brine, sucrose, and whey protein solutions were concentrated. Overall, for all the solutions it was observed that the product losses were higher than on lab scale, mainly due to scaling issues in the separation of the concentrate and ice fractions. To reduce the losses the ice fraction should be treated to recover the product. The energy requirements were found to be approximately $150 \mathrm{~kJ} / \mathrm{kg}$ ice removed from the solution. This would make progressive freeze concentration competitive with alternative concentration methods. Comparing to other methods of concentration, it was found that the CAPEX of a progressive freeze concentrator was lower than for a suspension freeze concentrator and comparable to that of a multistage evaporator with mechanical vapour recompression. Reverse osmosis has a much lower CAPEX but its OPEX are much higher than for progressive freeze concentration. Concluding progressive freeze concentration would be an energy-efficient alternative concentration method, which is mild to the solutes that are concentrated. 



\section{Samenvatting}


Concentreren en drogen zijn veel voorkomende processen in de levensmiddelen- en biobased industrie. Om de energie die nodig is voor het drogen tot een minimum te beperken, worden producten vaak geconcentreerd voordat ze worden gedroogd. Over het algemeen neemt het aandeel droge stof dan toe van minder dan $10 \%$ tot 40 tot $70 \%$. De behaalde concentratie is onder meer afhankelijk van de viscositeit van het product. De meest toegepaste concentratiemethode is verdamping, een snel maar energie-intensief proces. Doordat hier wordt gewerkt met hogere temperaturen is verdamping niet geschikt voor levensmiddelen die hierdoor worden afgebroken. Voor deze producten kunnen alternatieve milde concentratiemethoden een beter resultaat bieden waarbij de productkwaliteit gewaarborgd blijft.

Als alternatief proces kan vriesconcentratie worden gebruikt. Als een waterige oplossing wordt ingevroren, dan worden alle andere moleculen dan water uitgesloten bij de vorming van de ijskristallen. Als het ijs vervolgens wordt verwijderd, blijft een concentraat over. Omdat vriesconcentratie gebruik maakt van koeling in plaats van verwarming, is het zeer geschikt voor producten die vluchtige en/of thermisch onstabiele componenten bevatten. In theorie zou de energie die nodig is om water te verwijderen gelijk zijn aan de latente warmte nodig voor het bevriezen van water. Deze is 7 keer lager dan de latente warmte voor verdamping bij atmosferische druk. Bij vriesconcentratie is het mogelijke om de ijskristallen op verschillende manieren te vormen. Bij deze thesis ligt de nadruk op progressieve-vriesconcentratie waarbij er een ijslaag wordt gevormd op de wand van een warmtewisselaar. Het voordeel van deze techniek is dat het ijs gemakkelijk van de geconcentreerde oplossing kunnen worden gescheiden. Daarnaast is het vrij eenvoudig om de warmte die vrijkomt bij het vriezen elders in het proces te hergebruiken. Alhoewel vriesconcentratie in theorie puur ijs zou moeten opleveren, vereist dit lage ijsgroeisnelheden waardoor het proces te lang zou duren. Bij snellere ijsgroei zal een deel van de opgeloste stoffen ook in de ijslaag worden ingesloten en dat zal dan bij de scheiding verloren gaan. In dit werk ligt dan ook de focus op het begrijpen hoe deze insluiting plaatsvindt en hoe dit toe te passen op grotere schaal in een progressieve-vriesconcentrator. De experimenten op labschaal leverden inzicht over de invloed van koeling en menging op de insluiting van de verschillende onderzochte stoffen. Met deze gegevens is er een model opgesteld om het mechanisme van insluiting tijdens progressief vriesconcentreren beter te begrijpen.

In hoofdstuk 2 werden er modeloplossingen van suiker en maltodextrine gevriesconcentreerd op labschaal. Hierbij werd gekeken naar de invloed van de koelstrategie en het mengen van de oplossing op de insluitingen in het ijs. Hieruit kon worden geconcludeerd dat als er, zoals verwacht, sneller kan worden ingevroren bij een constante koeltemperatuur. Als de start-koeltemperatuur werd verhoogd en vervolgens deze langzaam wordt verlaagd werden er echter veel minder insluitingen waargenomen, terwijl de hoeveelheid ijs gelijk bleef. Een constante koeltemperatuur leidt tot een hoge mate van onderkoeling van de vloeistof. Dit leidt tot de vorming van een onregelmatig ijsfront waarin gebieden ontstaan waarin geconcentreerde oplossing in de ijsmassa terecht komt. Wanneer het temperatuurverschil wordt teruggebracht, wordt een glad ijsfront gevormd wat leidt tot minder inclusies. Als er vervolgens dan intensiever wordt gemengd kan het verlies nog verder worden teruggedrongen.

In hoofdstuk 3 worden er experimenten uitgevoerd met verschillende eiwitbronnen. Hierbij werd vergeleken hoe soja- en wei-eiwit worden ingesloten in het ijs. De instellingen voor het koelen en mengen werden overgenomen uit het vorige hoofdstuk. De insluiting van de eiwitten werd gemodelleerd op basis van een bestaande theorie. Het empirisch model van de 
insluitingen werd gekoppeld aan een model voor de ijsgroeisnelheid, gebaseerd op de warmteen massabalansen van het systeem. Bij lage ijsgroeisnelheden kon de insluiting goed voorspeld worden, maar bij hogere ijsgroeisnelheden werd de insluiting onderschat. Een van de aannames in het model is dat het ijs langzaam aangroeit en geen dendrieten vormt. Deze dendrieten geven extra ruimte voor insluitingen en leiden tot een meer insluiting van de opgeloste moleculen.

Uit de experimenten in hoofdstuk 3 bleek dat het gebruikte soja-eiwit niet goed oplosbaar was en daardoor geen goede kandidaat was voor ons modelsysteem. In hoofdstuk 4 werd er gekozen om verder te gaan met wei-eiwit. Omdat de meeste producten niet alleen uit eiwit bestaan, zijn er mengsels met eiwit, zout en suiker onderzocht. Als er natriumchloride of sucrose werd toegevoegd stegen de inclusies. Er wordt aangenomen dat het zout gelokaliseerde onderkoeling veroorzaakt. Dit leidt ertoe dat er zich ijskristallen in de oplossing kunnen vormen (dendrieten) in de concentratiepolarisatielaag. De ijskristallen sluiten dan delen van de laag in het ijs in. Omdat sucrose veel minder vriespuntverlaging per gewichtseenheid veroorzaakt maar wel de viscositeit van de oplossing verhoogt bij lage temperaturen, zal dit ervoor zorgen dat diffusiviteit in de concentratiepolarisatielaag afneemt wat ook tot meer insluitingen leidt. Wanneer zout en suiker beide aanwezig zijn, nemen de insluitingen niet verder toe dan als een van beide aanwezig is.

Met de uitkomsten van de experimenten van hoofdstuk $\mathbf{4}$ is een theoretisch model ontwikkeld om de insluitingen in het ijs te beschrijven met behulp van het toestandsdiagram in hoofdstuk 5. Vanuit het toestandsdiagram kunnen twee regimes worden onderscheiden. Het eerste regime geldt bij lage ijsgroeisnelheden en voor componenten met een hoog molecuulgewicht. Als dit het geval is, blijft de oplossing in de concentratiepolarisatielaag boven de solidus, wat resulteert in stabiele aangroei van de ijslaag zonder insluitingen. In het tweede regime is er een hogere ijsgroeisnelheid en is er sprake van significante vriespuntverlaging. Hierdoor komt de samenstelling in de concentratiepolarisatielaag onder de vrieslijn. Dit leidt tot het onstaan van een bevriezingszone waarin dat deel van de oplossing wordt ingesloten in de ijslaag. Het model voorspelt de opname van componenten met een laag molecuulgewicht en een verwaarloosbare opname van macromoleculen, zoals wei-eiwitten.

In de algemene discussie (hoofdstuk 6) wordt tot slot progressieve-vriesconcentratie op grote schaal bestudeerd en vergeleken met alternatieve concentratiemethoden. In een speciaal daarvoor gebouwde progressieve-vriesconcentrator werden pekel, sucrose- en wei-eiwitoplossingen geconcentreerd. In alle experimenten waren de productverliezen groter dan op labschaal. Dit werd helaas veroorzaakt door een minder goede scheiding tussen de ijsfractie en het concentraat in dit apparaat. Om deze verliezen terug te dringen is er in de toekomst een nabehandeling van het ijs nodig om nog aanwezig achtergebleven concentraat eerst te verwijderen. Om $1 \mathrm{~kg}$ water te verwijderen met behulp van vriesconcentratie is ongeveer $150 \mathrm{~kJ}$ nodig. Dit lage energieverbruik zorgt ervoor dat de technologie evenveel of minder energie gebruikt in vergelijking met alternatieve processen zoals omgekeerde osmose en indampen met behulp van mechanische dampcompressie. De kosten om een progressieve-vriesconcentrator te bouwen zijn lager dan die van een suspensie-vriesconcentrator en vergelijkbaar met een meertrapsindamper met mechanische dampcompressie. Omgekeerde osmose heeft veel lagere investeringskosten, maar hiervoor zijn de uitgaven voor onderhoud weer hoger dan die voor progressieve-vriesconcentratie. Kortom, progressieve-vriesconcentratie is een energieefficiënte concentratiemethode die ook nog eens mild is. 

Acknowledgements 
Although the cover states otherwise, the completion of this thesis is not the work of a single person. I was very lucky in meeting many wonderful people during the 4 years of being a $\mathrm{PhD}$ candidate. These wonderful people made the whole endeavour so much more enjoyable and without them completing a $\mathrm{PhD}$ would not have been possible. I would like to thank you all!

First and foremost, I would like to thank my supervisors. Maarten, bedankt voor je geduldige begeleiding en dat de deur altijd openstond voor de belangrijke en minder belangrijke vragen. Bedankt, dat je me er af en toe aan de planning herinnerde. En natuurlijk bedankt voor al je pizza-diners, deze waren altijd erg gezellig. Remko, bedankt voor al je advies en je wonderlijke ideeën, die mijn onderzoek een stuk verder hebben geholpen. Ik waardeer je enthousiasme en je positieve benadering van alle problemen, groot en klein. Maarten en Remko, van jullie beide heb ik veel geleerd. Bedankt dat jullie mijn begeleiders waren van het begin tot het einde van mijn promotieonderzoek.

The FreezeCon project would not have been possible without the input of the project partners. I would like to thank TNO (Andrew, Michel and Robert), Royal Cosun (Aleksandra, André, Emma, Johan and Marco), Nouryon (Henk, you will be dearly missed, Allert and Bart) and the ISPT office.

Het vele werk in deze thesis heb ik natuurlijk niet alleen gedaan. Gelukkig kreeg ik veel hulp van alle thesis-studenten. Bedankt Daniel, Martijn, Tine, Rikke, Caspar, Stefan, Merit, David, Arjen en Jort. Bedankt voor al jullie labwerk, vragen en ideeën. Een promotieonderzoek is zoveel leuker met jullie input! Ik heb er erg van genoten om met jullie samen te werken.

Al het werk bij FPE wordt natuurlijk gefaciliteerd door de stille kracht achter de schermen, de technici en het secretariaat. Jos, bedankt voor al je hulp bij het uitdenken van FreezeCon proefopstelling en al je praktische adviezen. Maurice, bedankt voor al je hulp bij de analyses en voor alle gesprekken tijdens de lunchwandelingen en daar buiten. Martin, bedankt voor alle ondersteuning in het lab en alle gesprekken tijdens de pauzes. Wouter, bedankt voor al je hulp en de gezellige pauzes en borrels. Jarno, bedankt voor je andere kijk op de wereld. Marjan en Ilona, bedankt voor jullie hulp bij alle administratieve dingen. Bedankt dat de deur bij jullie altijd open staat.

A special thanks goes out to all my office mates, Evelien, Anja, Lu and Bijoy. Thank you for all the conversations in between, tips and tricks. Lu, thank you for creating the cover of this thesis. Also thanks to my labuitje-buddies, Bijoy and Anouk, I've had much fun organising the labuitje together with you. Both of you, thank you for being my paranymphs. To all other colleagues at FPE, thank you for making the PhD-trip, the borrels, the breaks, the sport activities, the lunch walks and all other activities so much more fun. You are with too many to name you all here, but I hope you all feel appreciated! 
Thank you to all the people I've met through sports and sport centre De Bongerd. Ingi, bedankt voor al je enthousiasme en motivatie. Ellen, bedankt voor de uitnodiging om de Stelvio te bedwingen op de fiets. Dat was ontzettend gaaf. Anki and Patrick, thank you for never letting me down, unless I asked for it near the top of the climbing wall. Dank aan alle fietsvrienden bij TCW'79, bedankt voor alle mooie tochten die geweest zijn en die nog gaan komen.

Zo tegen het eind, van het schrijven, wil ik ook graag mijn familie en vrienden bedanken. Pap, mam, oma, Marjo, Johan, Peter, Lucie, Jolanda, Bennie, Gerard, Truus, Margriet, Janet, Peter, Helma, Martine, Jacoline, Johan, Andrienne en Sietse. Bedankt dat jullie er altijd voor me zijn, door dik en dun. Pap en oma, jammer dat jullie er niet meer bij kunnen zijn. Ik mis jullie.

Bart, Bjorn, Christel, Marcel, Marjolein, Matthijn, Pauline, Randy, Robertjan, Simone en Stefan. Bedankt voor alle gezelligheid, tijdens alle etentjes, uitjes en verjaardagen. Ik ben blij dat we mekaar onderweg zijn tegengekomen.

\section{Jan-Eise}





\section{About the Author}

Jan-Eise Vuist was born on 27 February 1988 in Heerenveen, the Netherlands. He attended secondary school at 'Linde College' in Wolvega, where he obtained his diploma in 2006.

In the same year, Jan-Eise started the bachelor Biotechnology at Wageningen University. For his BSc thesis he studied the application of extended Kalman filtering in fermentation at the department of Systems and Control. In 2011, he continued with the master Bioprocess Engineering at Wageningen University. His MSc thesis was on the optimization of the scheduling of filter cleaning in beer filtration at the department of Systems and Control. After completing his thesis, Jan-Eise did an internship at Nestlé in Nunspeet, the Netherlands, where he worked on cation and anion exchange of whey.

After obtaining his MSc-degree, he started working as a research-assistant in the department of Biomass Refinery and Process Dynamics at Wageningen University. Here he assisted in making models for downstream processing of algae broth and milk powder production more accessible for the end-users. Besides this he assisted in the courses on mathematics and modelling. Thereafter, Jan-Eise started as a researcher at the Laboratory of Food Process Engineering at Wageningen University, where he assisted in the modelling activities in the department. In 2017, he started as a PhD-candidate in the FreezeCon-project. This project was a collaboration with ECN-TNO, the Institute for Sustainable Process Technology, Royal Cosun and Nouryon. 



\section{Publications}

\section{This dissertation}

Vuist, J. E., Boom, R. M., \& Schutyser, M. A. I. (2021) Solute inclusion and freezing rate during progressive freeze concentration of sucrose and maltodextrin solutions. Drying Technology, 39(10), 1285-1293.

Vuist, J. E., Linssen, R., Boom, R. M., \& Schutyser, M. A. I. (2021). Modelling ice growth and inclusion behaviour of sucrose and proteins during progressive freeze concentration. Journal of Food Engineering, 303, [110592].

Vuist, J. E., Boom, R. M., \& Schutyser, M. A. I. (2021) Progressive freeze concentration of protein-sucrose-salt mixtures. Innovative Food Science and Emerging Technologies, ahead of print, 1-15.

Vuist, J. E., Schutyser, M. A. I., \& Boom, R. M. (Under review) Solute inclusion during progressive freeze concentration: A state diagram approach.

\section{Other scientific publications}

Vuist, J. E., Schutyser, M., \& Boom, R. (2019). A systematic parameter study on film freeze concentration. In A. A. Kiss, E. Zondervan, R. Lakerveld, \& L. Özkan (Eds.), 29th European Symposium on Computer Aided Process Engineering (pp. 1501-1506). (Computer Aided Chemical Engineering; Vol. 46). Elsevier B.V..

Muijlwijk, K., Huang, W., Vuist, J. E., Berton-Carabin, C., \& Schroën, K. (2016). Convective mass transport dominates surfactant adsorption in a microfluidic Y-junction. Soft Matter, 12(44), 9025-9029.

Qiu, J., Vuist, J. E., Boom, R. M., \& Schutyser, M. A. I. (2018). Formation and degradation kinetics of organic acids during heating and drying of concentrated tomato juice. Food Science and Technology = Lebensmittel-Wissenschaft und Technologie, 87, 112-121. 



\section{Overview of completed training activities}

\section{Discipline specific activities}

\section{Courses}

Numerical Methods for Chemical Engineers

$\begin{array}{rr}\text { OSPT } & 2017 \\ \text { Eindhoven, } N L & \\ \text { Siemens Industry Software } & 2019 \\ \text { Den Bosch, } N L & \\ \text { VLAG } & 2019 \\ \text { Wageningen, } N L & \end{array}$

\section{Conferences}

NWGD Symposium $^{\mathrm{o} p}$

NWGD 2017

Wageningen, NL 2018

Rheden, NL 2019

$21^{\text {st }}$ International Drying Symposium ${ }^{p}$

UPV 2018

Valencia, ES

ESCAPE-29p

EFCE/CAPE-WP

2019

Eindhoven, $N L$

$33^{\text {rd }}$ EFFoST International Conference ${ }^{o}$

EFFoST 2019

Rotterdam, NL

${ }^{\mathrm{o}}$ Oral presentation, ${ }^{\mathrm{p}}$ Poster presentation 


\section{General courses}

VLAG PhD Week

Competence Assesment

The Essentials of

Scientific Writing and Presenting

Supervising Thesis Students

Scientific Writing

Scientific Artwork

Assertiviteitstraining Intensief (HBO)

Introduction to $\mathrm{R}$

Career Perspectives
VLAG
Baarlo, $N L$

Wageningen Graduate Schools

Wageningen, $N L$

Wageningen Graduate Schools

Wageningen, $N L$

Educational Staff Development

Wageningen, $N L$

In'to Languages

Wageningen, $N L$

WUR Library

Wageningen, $N L$

Schouten en Nelissen

Wolfheze, $N L$

Wageningen Graduate Schools

Wageningen, $N L$

Wageningen Graduate Schools

Wageningen, $N L$
2017

2017

2018

2018

2018

2018

2019

2019

2020

2017

2017-2021

2017-2019

2018

FPE PhD Study Tour Canada ${ }^{o, p}$

${ }^{\circ}$ Oral presentation, ${ }^{\mathrm{P}}$ Poster presentation 

The work presented in this thesis has been carried out in the framework of the Institute for Sustainable Process Technology, ISPT, under the project

"DR-20-08: Freeze Concentration."

This project is co-funded with subsidy from the Topsector Energy by the Ministry of Economic Affairs and Climate Policy.

Cover design by Lu Zhang

Printed by Gildeprint 